\title{
Una edad del bronce en los Andes Centrales Contribución a la elaboración de una historia ambiental
}

L'âge du bronze dans les Andes centrales

Contribution à l'élaboration d'une histoire environnementale

The bronze Age in the central andes

A contribution for the elaboration of an environmental history

\section{Anne Marie Hocquenghem}

\section{(2) OpenEdition}

\section{Journals}

Edición electrónica

URL: http://journals.openedition.org/bifea/5728

DOI: $10.4000 /$ bifea. 5728

ISSN: 2076-5827

Editor

Institut Français d'Études Andines

Edición impresa

Fecha de publicación: 1 agosto 2004

Paginación: 271-329

ISSN: 0303-7495

Referencia electrónica

Anne Marie Hocquenghem, « Una edad del bronce en los Andes Centrales

Contribución a la elaboración de una historia ambiental », Bulletin de l'Institut français d'études andines

[En línea], 33 (2) | 2004, Publicado el 08 abril 2004, consultado el 01 diciembre 2020. URL : http:// journals.openedition.org/bifea/5728; DOI : https://doi.org/10.4000/bifea.5728

\section{cc)}

Les contenus du Bulletin de l'Institut français d'études andines sont mis à disposition selon les termes de la licence Creative Commons Attribution - Pas d'Utilisation Commerciale - Pas de Modification 4.0 International. 


\title{
UNA EDAD DEL BRONCE EN LOS ANDES CENTRALES
}

\author{
CONTRIbUCión A LA ELABORACIÓN DE UNA HISTORIA AMBIENTAL
}

Anne Marie HOCQUENGHEM*

\section{Resumen}

Se trata de presentar algunas evidencias de un desarrollo territorial espectacular logrado a inicios del Período Intermedio Tardío en los valles de los ríos Piura, Chira y Tumbes: ampliación de la frontera agrícola en el bosque seco ecuatorial, reubicación de los sitios administrativos y ceremoniales, crecimiento de las zonas urbanas, extensión de la red de caminos, aumento del caudal de los intercambios a larga distancia. Son transformaciones que implican, inducen y requieren reestructuraciones y ampliaciones de las esferas administrativas y ceremoniales, así como atestiguan de un incremento de poder de la elite de la teocracia Sicán Medio de 900 a 1100 d.C. Relacionamos estos importantes cambios con una innovación tecnológica, la producción de cobre arsenical y, para contribuir a la elaboración de una historia ambiental, proponemos considerar las modalidades y consecuencias, en los Andes Centrales, de una Edad del Bronce que se iniciaría a fines del primer milenio de nuestra era en los valles de Lambayeque.

Palabras claves: Andes Centrales, Perú, valles de Lambayeque, Piura y Tumbes, Período Intermedio Tardio, Edad del Bronce, herramientas de cobre arsenical, desarrollo territorial, historia ambiental.

\section{L'ÂGE DU BRONZE DANS LES ANDES CENTRALES CONTRIBUTION À L'ÉLABORATION D'UNE HISTOIRE ENVIRONNEMENTALE}

\section{Résumé}

Il s'agit de présenter quelques évidences d'un développement territorial spectaculaire qui a lieu au début de la Période Intermédiaire Tardive dans les vallées du Piura, Chira et Tumbes: expansion de la frontière agricole dans la forêt sèche équatoriale, déplacement des sites administratifs et cérémoniels, croissance des zones urbaines, extension du réseau routier, augmentation du flux des échanges à longue distance. Ce sont des transformations qui impliquent, induisent et requièrent des restructurations et des ampliations des sphères administratives et cérémonielles et témoignent du pouvoir croissant de l'élite de la théocratie Sicán Moyen entre 900 et 1100 d.C. Nous établissons une relation entre ces importants changements et une

* Directora de Investigación, CNRS (Centro Nacional de Investigación Científica), París; IRD (Instituto de Investigación para el Desarrollo UR-021), UMR 021, Lima; IFEA (Instituto Francés de Estudios Andinos), Lima, casilla 18-1217, Lima 18; CONCYTEC (Consejo Nacional de Ciencia y Tecnología), Lima. E-mail: amhocque@ec-red.com 
innovation technique, la production de cuivre arsenical et, pour contribuer à l'élaboration d'une histoire environnementale, nous proposons de considérer les modalités et les conséquences, dans les Andes Centrales, d'un Âge du Bronze qui commencerait à la fin du premier millénaire de notre ère dans les vallées de Lambayeque.

Mots clés :Andes Centrales, Pérou, Lambayeque, Piura et Tumbes, Période Intermédiaire Tardive, Âge du Bronze, outils de cuivre arsenical, développement territorial, histoire environnementale.

\title{
THE BRONZE AGE IN THE CENTRAL ANDES \\ A CONTRIBUTION FOR THE ELABORATION OF AN ENVIRONMENTAL HISTORY
}

\begin{abstract}
Evidence exists of a spectacular territorial development at the beginning of the Late Intermediate Period in the valleys of Piura, Chira and Tumbes: expansion of the agricultural frontier in the equatorial dry forest, changes in the administrative and ceremonial sites, growth of the urban centers, extension of the road system, and increase of long distance exchanges. These transformations required the reorganization and extension of the administrative and ceremonial sphere and testify to the increasing power of the Middle Sicán elite between 900 and $1100 \mathrm{~d}$. C. We establish a relation between these important changes and a technical innovation, the production of a particular form of bronze . In keeping with our elaboration of an environmental history of the North Coast, we propose here that these changes are the consequence of a Bronze Age that expanded throughout the Central Andes at the end of the first millenium from its beginning in the valley of Lambayeque.
\end{abstract}

Keys Words: Central Andes, Peru, Lambayeque, Piura and Tumbes valleys, Late Intermediate Period, Bronze Age, arsenical copper implements, territorial development, environmental history.

\section{1. ¿UNA EDAD DEL BRONCE EN LOS ANDES CENTRALES?}

Se entiende hoy en día por bronce una aleación de por lo menos $60 \%$ de cobre y de uno o más metales adicionales en los cuales no debe predominar el zinc. El bronce estañífero es el bronce propiamente dicho, con cobre y estaño, mientras que la aleación de cobre y arsénico es llamada por algunos investigadores "cobre arsenical” y por otros “bronce arsenical” (Lueger, 1961: 93, 790; Oehm, 1984: 58, 63).

Arthur Baessler (1906), Eric Boman (1908), Erland Nordenskiöld (1921) reconocieron la presencia de arsénico en artefactos andinos de cobre y Alfred Kroeber (1944), Gustavo Fester (1962), Earle Caley \& Dudley Easby Jr. (1959), Earle Caley \& Lowell Shank (1971), Caley (1973) subrayaron el significado de estas aleaciones como verdaderos bronces. A partir del inicio de la década de 1970, y desde entonces, Heather Lechtman contribuye al estudio de la metalurgia prehispánica andina y en particular de los bronces estañíferos del sur del Perú y los bronces arsenicales del norte de este país (Lechtmann, 1973 a 1998). En la conclusión de su artículo, "El bronce y el Horizonte Medio" (600-900 d.C.), esta investigadora sostiene en 1998 que:

"No se debe confundir lo que ocurrió en la zona andina con lo que sucedió en el Viejo Mundo. Allá los arqueólogos hablan de una 'Edad de Bronce' cuando 
cambios importantes en el desarrollo de ciudades, el intercambio a larga distancia de bienes exóticos, el crecimiento de grandes estados políticos coincidieron con el desarrollo del bronce y hasta cierto punto fueron facilitados por la producción de ese material.

No se puede sostener que hubo una 'Edad de Bronce' en los Andes. Lo que se observa es la explotación y utilización de una gama mucho más extensa de recursos minerales y una prolija experimentación con nuevos materiales cuyas propiedades fueron muy diferentes de aquellas de los metales y aleaciones más viejos: propiedades de dureza, resistencia, ductilidad, y color. Los conocimientos sobre cómo fundir las nuevas menas y cómo controlar las aleaciones se difundieron por toda la región." (Lechtman, 1998: 24).

Sin embargo Izumi Shimada quien, con sus colaboradores en el Proyecto Arqueológico Sicán, logró reconstituir el proceso de elaboración del cobre arsenical, escribía en 1995:

"En resumen, hacia fines de 1983, demostramos que a mediados del siglo X d.C. los antiguos Sicán desarrollaron exitosamente una tecnología y una industria de fundición de cobre arsenical. Como es de esperarse, con el inicio de la fundición de bronce a gran escala, el cobre, soporte anterior de la metalurgia norperuana, fue permanentemente reemplazado (p.e., Lechtman, 1979; Shimada \& Merkel, 1991). Inclusive las herramientas de piedra y hueso fueron gradualmente sustituidas por los implementos de cobre arsenical. Así la cultura Sicán Medio (900-1100 d.C.) fue verdaderamente la precursora de la 'Edad de Bronce' para el norte del Perú." (Shimada, 1995: 25-26).

Recopilando las informaciones del Proyecto Arqueológico Sicán sobre el proceso de producción del cobre arsenical, reconsiderando la función de herramientas como las puntas y rejas que facilitan la remoción de grandes volúmenes de tierra y nuestros datos relativos al desarrollo del extremo norte peruano, los actuales departamentos de Piura y Tumbes (figs. 1 y 2), trataremos de:

- Enfocar las evidencias de importantes transformaciones, ampliación de la frontera agrícola y crecimiento demográfico, extensión de las rutas de intercambio y acumulación de los beneficios, crecimiento del sector administrativo y ceremonial e incremento del poder de la teocracia Sicán Medio, que implican entre 900 y 1100 d.C. un desarrollo territorial, económico y sociopolítico de los valles de los ríos Piura, Chira y Tumbes (figs. 1, 2).

- Relacionar este desarrollo con un cambio tecnológico, la producción en masa de cobre arsenical, que habría permitido el florecimiento y apogeo de la teocracia Sicán Medio.

- Abogar a favor de la consideración de una "Edad de Bronce", que se iniciaría en los valles de la costa norte peruana a fines del primer milenio de nuestra era y tendría importantes y rápidas consecuencias en los Andes Centrales.

- Proponer algunos temas de estudio en cuanto a la evolución de la tecnología metalúrgica en América con la finalidad, en particular, de contribuir a la 

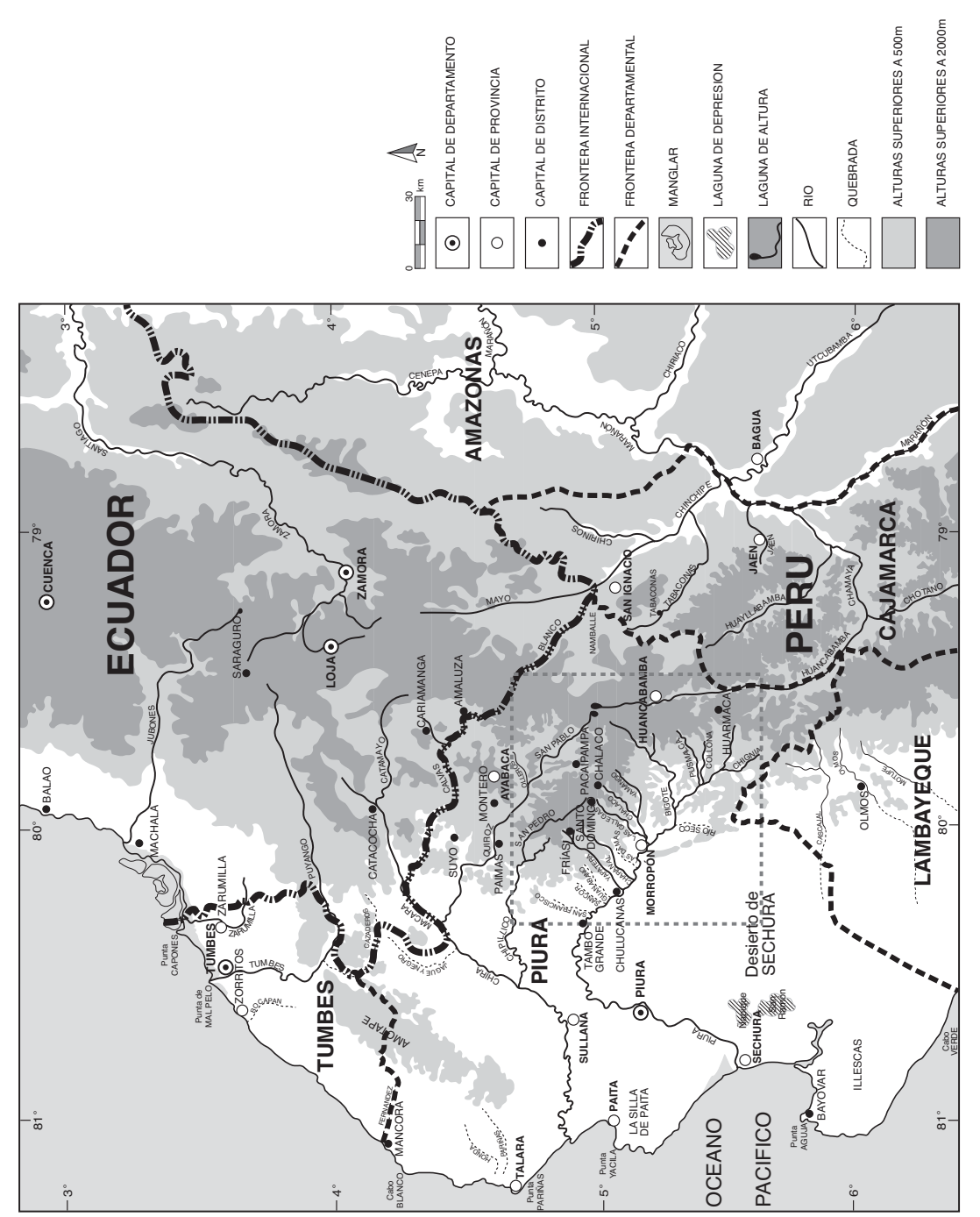

 

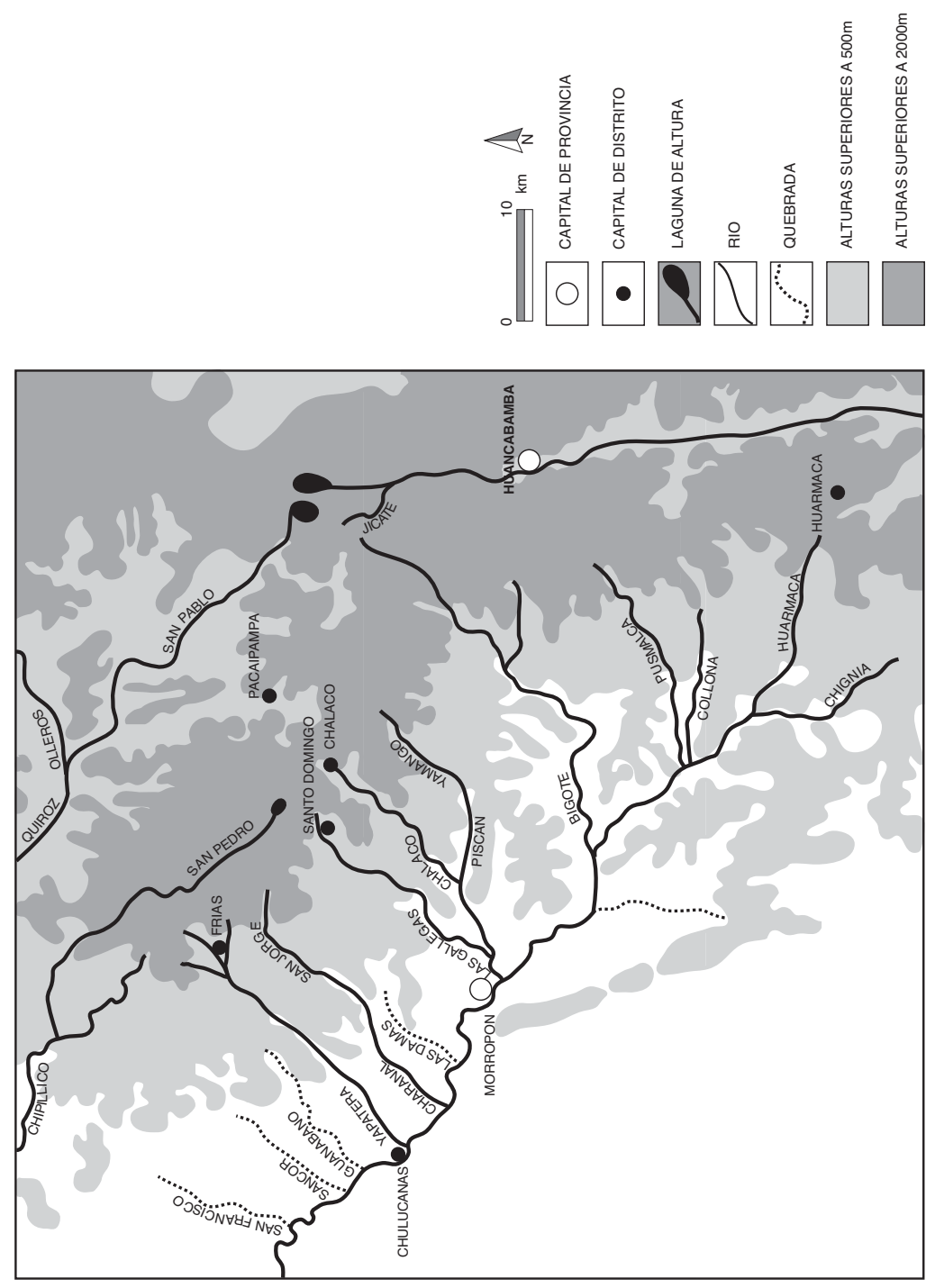

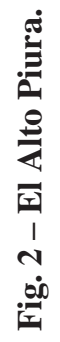


elaboración de una historia de la relación que los hombres, por medio de sus organizaciones sociales y sus tecnologías, establecen con sus entornos naturales, de hecho una historia ambiental a nivel continental.

Agradecemos los comentarios de Izumi Shimada y Luisa Vetter, las páginas que siguen no hubieran sido escritas sin los resultados de sus investigaciones, y los de John Topic y Ulana Klymyshyn que nos permitieron mejorarlas.

\section{EL COBRE ARSENICAL SICÁN Y LAS HERRAMIENTAS DE LABRANZA}

\section{1. El proceso de producción del cobre arsenical}

En Lambayeque, en el valle de La Leche, en la Reserva Nacional Arqueológica y Ecológica de Poma, cerca de Batán Grande, se desarrolló, bajo la dirección de Shimada, el Proyecto Arqueológico Sicán. Uno de los objetivos de este proyecto fue estudiar la tradición metalúrgica de esta área. Las excavaciones realizadas a partir de 1979 dieron amplias evidencias de que la zona de Batán Grande fue un centro metalúrgico donde, a partir de 900 d.C., a inicios del Período Intermedio Tardío durante la fase Sicán Medio, se produce a gran escala cobre arsenical (Shimada, 1981; 1985a; 1985b; 1987; 1988; 1990; 1992; 1994; 1995; Shimada et al., 1982; 1983; Shimada \& Merker, 1991; 1993; Shimada \& Montenegro, 1993; Epstein \& Shimada, 1984; Merkel et al., 1994). De hecho Shimada y sus colaboradores, en el sitio administrativo y ceremonial de Sicán y sus alrededores, evidenciaron el proceso de producción de bronce arsenical, ubicaron las minas, analizaron los minerales, identificaron las instalaciones de molienda, excavaron los hornos de fundición y de orfebrería, estudiaron y restauraron los objetos de metal depositados en las tumbas Sicán Medio.

\section{1. 1. Las minas y los minerales}

Las prospecciones en el piedemonte andino entre los valles de La Leche, Lambayeque y Zaña, revelaron cuatro áreas mineras, fácilmente accesibles a pocas horas al sur de Batán Grande (Shimada, 1987). En Cerro Mellizo quedan evidencias de un camino de acceso, de construcciones de mampostería estandarizadas sobre tres grandes terrazas, así como entierros de conchas Spondylus. En Cerro Barranco Colorado el pozo principal alcanzó una profundidad estimada de 40 m por debajo de la superficie; se piensa que proporcionó unos 14000 metros cúbicos de mineral de óxido de cobre. En Cerro Blanco Shimada et al. (1982) encontraron enseres mineros, piedras de martillo triangulares, de aproximadamente $20 \mathrm{~cm}$ de largo y de 10 a $12 \mathrm{~cm}$ en la parte más ancha, que iban probablemente insertos en cuñas de madera (Oehm, 1984: 29).

Los análisis preliminares muestran que el mineral es rico en óxido de cobre y/o arsenopirita. Se estima que a unos $5 \mathrm{~kg}$ de escoria derretida debieron estar asociados unos $2 \mathrm{~kg}$ de mineral de cobre, con algo de $30 \% \mathrm{Cu}$ y de 4 a $6 \mathrm{~kg}$ de fundente, óxido de fierro, de lo cual se podía recoger entre 300 y 600 gr de cobre metálico, dependiendo de la calidad de las cargas y la eficiencia del fundido (Merkel, 1984; Shimada, 1987: 19; 1995: 159). 


\section{1. 2. Las instalaciones de molienda}

El mismo nombre del principal asiento moderno del valle, Batán Grande, viene del hecho que se encontraron en la zona numerosos batanes de piedra llamados yunques, de un metro de diámetro aproximadamente que fueron utilizados para moler minerales y escorias con pesadas piedras denominadas chungos.

\section{1. 3. Los hornos de fundición}

El cobre arsenical se logró mezclando deliberadamente y directamente malaquita, que se obtenía cerca de la superficie en los depósitos locales de cobre. Formas oxidadas de arsenopirita como la scorodita, contenía de 1,35 a $6 \%$ de arsénico. La fundición se realizaba en una serie de talleres ubicados en la Huaca del Pueblo Batán Grande, Cerro Huaringa, también llamado Cerro de los Cementerios, Cerro Sajino, Cerro Jotoro, Huaca Julupe entre otros.

Los hornos, orientados hacia donde sopla el viento, son pequeños, en forma de pera, con dimensiones similares al interior: de 30 a $35 \mathrm{~cm}$ de largo, por 20 a 25 de profundidad y 25 a 30 de ancho, con una capacidad de 1,25 a 2,5 litros. Están asociados con sedimentos de escorias, numerosas toberas, puntas de tubos para soplar, tiestos con escorias adheridas, fragmentos de mineral. En las excavaciones de la Huaca del Pueblo se expusieron:

"[...] cuatro juegos completos de hornos de fundición y parte de un quinto, en cinco capas superpuestas ubicadas entre 4 y 5,5 m debajo de la superficie. Estos hornos estuvieron asociados con cerámica diagnóstica Sicán Medio y carbón datado por radiocarbón 14 (SMU) en circa 850-1050 +/- 50 d.C. Estos juegos de hornos consisten de 3 a 5 hornos ubicados próximamente y alineados a lo largo de ejes norte sur o este-oeste. Con excepción del juego más temprano (que tiene tres hornos con sus propias bases circulares inmediatas debajo de la boca de los hornos), los hornos Sicán Medio están alineados a lo largo de zanjas angostas. Se cree que las zanjas fueron usadas para mantener de manera temporal las cargas para los hornos y los residuos removidos de ellos." (Shimada, 1987: 16).

"La fuerza necesaria para fundir la carga en el horno a temperaturas de cerca de 1000-1100 centígrados era provista por la capacidad pulmonar de varios hombres que probablemente invertían de dos a tres horas soplando, al mismo tiempo, a través de tubos. Aparentemente el fuelle no fue conocido en el Nuevo Mundo. Con este limitado potencial para alimentar la temperatura del horno, no fueron capaces de fundir suficiente carga como para producir un lingote. En vez de eso se formaban prills o pequeñas gotitas esféricas de metal - generalmente de 1 a $5 \mathrm{~mm}$ de diámetro-, las cuales permanecían atrapadas en la viscosa escoria. Moliendo esta escoria se liberaban los prills, para luego ser recogidos y vueltos a fundir para formar lingotes planos convexos. Aunque cada horno de fundición tenía una capacidad solamente de 1,5 a 3,0 litros aproximadamente, la alta productividad fue alcanzada a través del uso de numerosos hornos, en talleres contiguos construidos especialmente para tal modalidad de trabajo." (Shimada, 1995: 23-24). 
Es decir que la fundición se lograba en dos etapas, la fundición propiamente dicha del metal y la fundición de las gotas para obtener los lingotes

La situación es similar en Cerro Huaringa, a $2 \mathrm{~km}$ al sur y Cerro Sajino a unos $4 \mathrm{~km}$ hacia el sur este. En Cerro Huaringa se excavó la totalidad de un taller para fundir y moler escorias y parcialmente otros tres. Pertenecen a la fase Sicán Tardío 1150 \pm 50 d.C. y siguen en uso durante el Período Chimú e Inca (Shimada \& Merkel, 1991: 83). En Cerro Huaringa hubieran funcionado unos 12 talleres al mismo tiempo y al menos otros tantos en Cerro Sajino (Shimada, 1987: 16-17).

Shimada y sus colaboradores no solamente excavaron los talleres de fundición, realizaron además réplicas del proceso de fundición de cobre arsenical, a una de las cuales asistimos en 1986. Asumiendo que los artesanos sicán fueron mucho más aptos para la tarea de soplar aire dentro de los hornos que los experimentadores se demostró que:

"Dado el espaciamiento y la presencia de cuatro hornos en la mayoría de los talleres, bien podría haberse usado dos hornos simultáneamente para lograr hasta cuatro fundiciones por taller por día, asumiendo un conservador día de trabajo de 8 horas. Aunque estos cálculos son simples estimaciones, ahora podemos apreciar mejor el poder de mando del personaje de la élite Sicán Medio enterrado con cientos de kilogramos de objetos de cobre arsenical." (Shimada, 1995: 159-160).

Es necesario recalcar que se puede establecer una continuidad entre la fundición de cobre desde las fases Mochica Tardío y Sicán Temprano, durante el Horizonte Medio, en la Huaca del Pueblo de Batán Grande, y la de cobre arsenical cuya producción en masa se atestigua solamente durante la fase Sicán Medio, a inicios del Período Intermedio Tardío. Hasta la llegada de los españoles no se notan cambios en los procesos de fundición de cobre arsenical, y esta tecnología es descrita por algunos cronistas, entre otros Pedro Cieza de León (Oehm, 1984: 30-31). La tecnología de fundición del cobre arsenical del norte peruano muestra una gran estabilidad a lo largo del tiempo (Shimada, 1987: 17; Stothert, 1997).

\section{1. 4. Los combustibles}

Los algarrobales del valle de la Leche y, más al norte del despoblado piurano, ofrecen madera para la elaboración de un carbón de larga duración que proporciona altas temperaturas. Las actividades de fundición de los minerales y de recalentamiento del metal eran sumamente demandantes en combustibles. Se estima que una docena de talleres pudieron haber consumido diariamente unos $150 \mathrm{~kg}$ de carbón y además se necesitaba combustible adicional para precalentar los hornos y luego derretir las gotas de metal (Shimada, 1987: 17, 19).

\section{1. 5. La mano de obra}

En una sola tumba Sicán Medio de la Huaca Loro, se hallaron aproximadamente 1,2 toneladas de objetos, entre los cuales se encontraron cerca de $200 \mathrm{~kg}$ de implementos de cobre arsenical. Para elaborar tal cantidad fue necesario contar con una mano de obra 
muy grande, para la extracción, la trituración, la fundición, la forja de los metales, así como la tala de los algarrobos, el corte de la madera y la elaboración del carbón requerido para obtener las altas temperaturas de los hornos y la manufactura de los diversos ornamentos e instrumentos de cobre arsenical.

\section{1. 6. Los costos de producción}

La producción de cobre arsenical era altamente costosa en minerales, combustibles y mano de obra y estos tres ingredientes se encontraban reunidos en las cercanías de Batán Grande. Requería además una compleja organización de las diversas tareas que implicaban la extracción del mineral y su transporte entre las minas y los talleres de fundición, la fundición del mineral, la elaboración de los objetos e instrumentos así como la distribución de estos. Finalmente tenían un carácter profano y sagrado, como lo atestiguan las huellas de rituales, ofrendas de conchas Spondylus encontradas en las áreas mineras, las ofrendas de fetos de llamas enterradas en el momento de la construcción de los hornos de fundición y de vasijas de cerámica con comidas y/o bebidas depositadas en el momento en que dejaron de ser utilizados. Todo indica que debía ser al nivel de la elite de la teocracia Sicán Medio que se planificaba esta producción (Shimada, 1987: 21; 1995: 24).

\section{1. 7. Los artefactos}

Si la producción de cobre arsenical representaba una gran inversión en trabajo, los objetos elaborados con este material debían alcanzar un alto valor de intercambio, mucho más elevado que los de cobre. En la opinión de Lechtman las ventajas de esta aleación, como de todos los bronces, frente al cobre eran la facilidad de su fundición, su dureza que adquiría al ser martillado, su resistencia bajo compresión y tensión, su ductibilidad que permitía lograr láminas finas y resistentes así como sus colores y sonidos (Lechtman, 1998: 4-7, 24).

Los objetos de cobre arsenical se depositaban en las tumbas de personajes importantes, en Sicán, pero también en los valles de los ríos Piura, Chira y Tumbes. En muchos sitios de los Andes Centrales, las pinzas, los cinceles y los tumis, los tajadores, debían ser valorados por ser resistentes y cortantes. Asimismo se reconocía la calidad de las agujas, torteros de huso, dardos, anzuelos, ganchos de estólicas, puntas, hachas, cuñas, clavos. Además los "naipes” elaborados a partir de finas y resistentes láminas de cobre arsenical podían tener un valor de intercambio, haber servido de monedas primitivas (Shimada, 1985a: 358, 376, 384, 386, 390-391, 392; 1987: foto 19). Estamos persuadidos de que el cobre arsenical circulaba hacia el oriente, por Olmos y los valles del Chamaya, Marañón, Chinchipe y Utcubamba. Ruth Shady observó en la región de Jaén y San Ignacio, evidencias de cerámica Sicán Medio (Shimada, 1995: 167). Hacia el sur los objetos de cobre arsenical aparecen en Pikillacta cerca de Cusco, y según Lechtman el Lago Titicaca constituye el límite austral de la difusión de este metal (Lechtman, 1998: 11-12).

En el sur de Ecuador se conocen muchas piezas de cobre arsenical conservadas en los museos, pero se desconocen tanto sus orígenes exactos como sus fechados 
(Mayer, 1992). Entre otros son notables las "hachas monedas" que, al igual que los "naipes" hubieran podido tener un valor de intercambio (Holm, 1966-1967; 1975; 1978; 1980; Easby et al., 1967). Se conocen también objetos de cobre arsenical que provienen de la costa norte del Perú (Hosler et al., 1990: 70, 71). Algunos figuran en el inventario de la famosa tumba del cacique de Guayas, en la Compañía Tola B, excavada por Betty Meggers, Clifford Evans y Emilio Estrada (Estrada, 1961), que es muy rica en objetos de cobre arsenical. Lastimosamente esta tumba no ha sido datada, y es más, su contenido podría haber sido mezclado con el de una tumba posterior.

Por vía marítima la tecnología del bronce arsenical se difundió hacia el norte a lo largo de la costa pacífica. Los objetos en esta aleación formaban parte de los ajuares funerarios de dignatarios o de las ofrendas enterradas en las estructuras de los centros administrativos y ceremoniales en el occidente mexicano. Se encuentran sonajas y cascabeles, que debían ser apreciados porel sonido de este metal, placas, hachas ceremoniales y ornamentos diversos, que debían ser atractivos por los variados y relucientes tonos de las aleaciones. Hay fuertes razones para pensar que el desarrollo de la metalurgia en el Occidente de México ha sido inducido, vía contactos con los balseros, a partir de la costa norte peruana, si bien desde México y Ecuador se tiende a no tomar en cuenta el hecho de que el cobre arsenical se producía en la costa norte. Sobre el tema de los intercambios a larga distancia existe una abundante literatura y diversas opiniones, pero lo que queda claro por ahora es que tecnologías relacionadas con la metalurgia y objetos de cobre arsenical pasaban de sur a norte. Veremos más adelante que a cambio llegaban de norte a sur las conchas Spondylus (Alcina Franch et al., 1987; Beltrán Medina, 1991; 1994; 1997; Cooke \& Sanchez Herrera, 1997; Hosler, 1986-1998; Hosler et al., 1990, Hosler \& Stresser-Pean, 1992; Hosler \& MacFerlane, 1996; Marcos, 1977-1981; 1985; 1986a; 1986b; 1995; Marcos \& Norton, 1981; Norton, 1985; 1986; 1992; Pendergast, 1962; Rieff Anawalt, 1997; Samano \& Jimenez, 1968[1527]; Shimada, 1985a).

Volviendo al Perú y al bronce arsenical, Lechtman escribe:

"Todos los bronces arsenicales que he examinado hasta ahora y la mayoría de los citados por Caley (1973: cuadro VII) son objetos modelados por martillado: torteros de uso, hojas para herramientas agrícolas, cinceles, agujas para coser o tejer, etc. Para esta región se carece de estudios sobre vaciado. He visto - y lo he comentado en otra oportunidad- (Lechtman, 1976) gran número de "puntas de cobre' macizas y a veces parcialmente trabajadas (Figs. 1, 2, 3, 4), comunes por lo menos al área comprendida entre los valles de Moche y Lambayeque, cuando no a una región más extensa, en el Período Intermedio Tardío. Estos implementos comprenden hojas de herramientas agrícolas, puntas de lanza (?), cinceles y otros tipos similares de objetos que a menudo se usaban asegurándolos a un cabo de madera. Es frecuente encontrarlos acumulados y enterrados en gran número, a veces por centenares, y tanto el Museo de Arqueología de la Universidad de Trujillo como el Museo Brüning de Lambayeque conservan infinidad de ejemplares. Bennett describe varios de estos tipos, especialmente los implementos agrícolas que excavó en el valle de Lambayeque, en tumbas 'Chimú Medio' (Bennett, 1939: 104-15)." (Lechtman, 1978: 504-505). 
En el Alto Piura hemos podido recuperar en 1993 un lote de instrumentos de cobre arsenical que un huaquero llevaba a vender por kilos en Chulucanas, donde se compraba el metal para fundirlo y luego forjar puntas de barretones. Eran cinceles, puntas, ganchos de estólicas, cascabeles, naipes, tumis, pero también pesadas herramientas, un gran clavo, puntas y rejas de diferentes formas y tamaños (figs. 3, 4, 5, 6). En 2004 vimos las colecciones de instrumentos de metal, entre los cuales se encuentran cantidades de piezas que parecen ser de cobre arsenical, conservadas en el colegio Santo Domingo el Savio de Tumbes, en el Museo Municipal Vicús de Piura y en los museos Brüning y Sicán de Lambayeque. En el marco de este artículo nos centraremos en las puntas y rejas que son partes de instrumentos de labranza.

\section{2. Las herramientas de labranza}

\section{2. 1. Las puntas}

En la tumba de Huaca Loro se encontraron 489 puntas de cobre arsenical, que fueron estudiadas por Luisa Vetter (Vetter, 1993; 1994; 1996; Vetter et al., 1997). Los resultados de los análisis químicos indican que tienen un contenido promedio de $2,67 \pm 0,81 \%$, con una variabilidad $1,35 \%$ a 4,45 \% de arsénico, y:

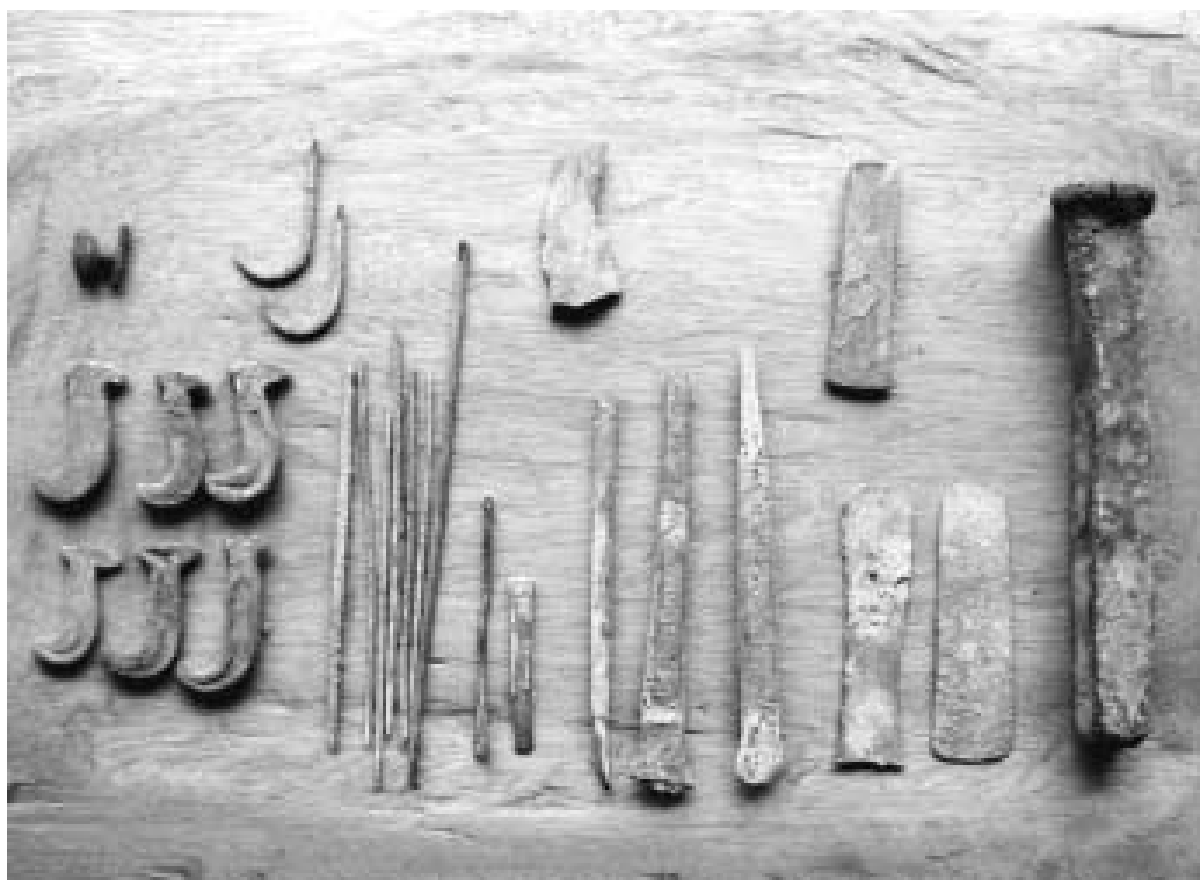

Fig. 3 - Instrumentos diversos del Alto Piura (1).

(1) Todas las fotos de este texto son de la autora. 


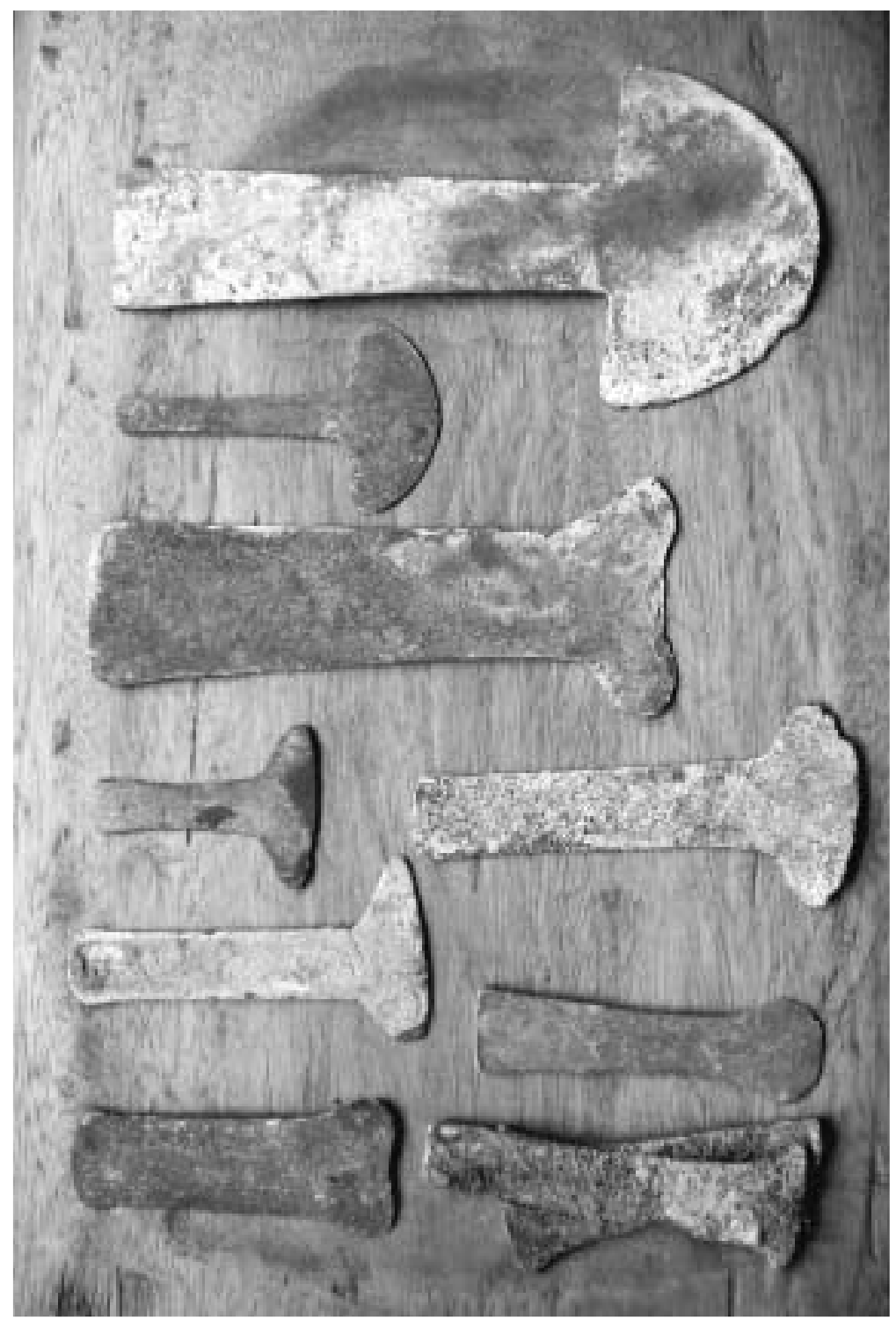

包 

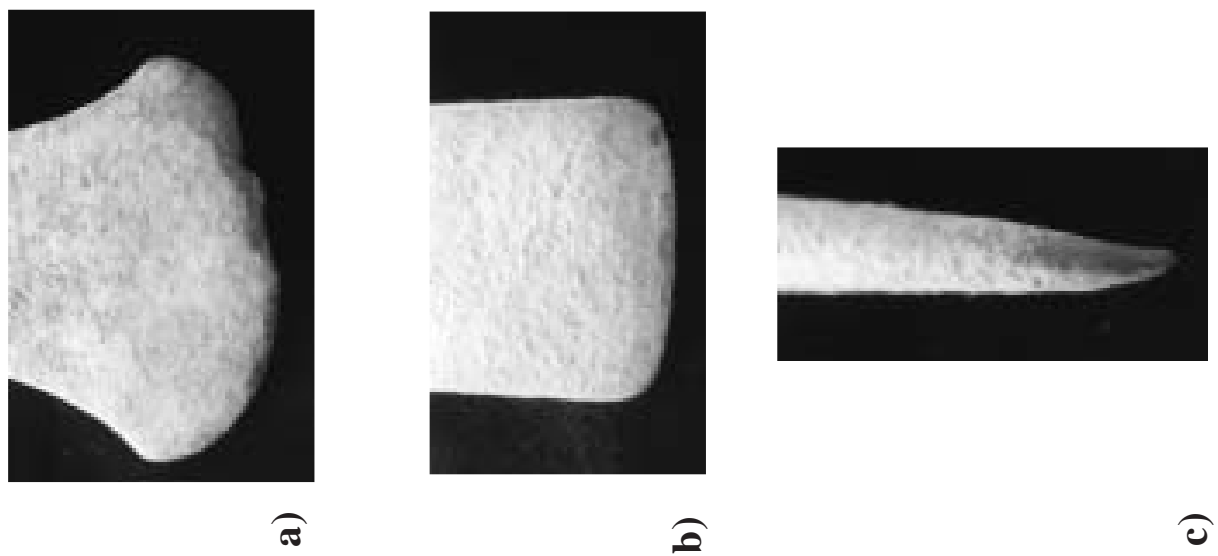

o

ช
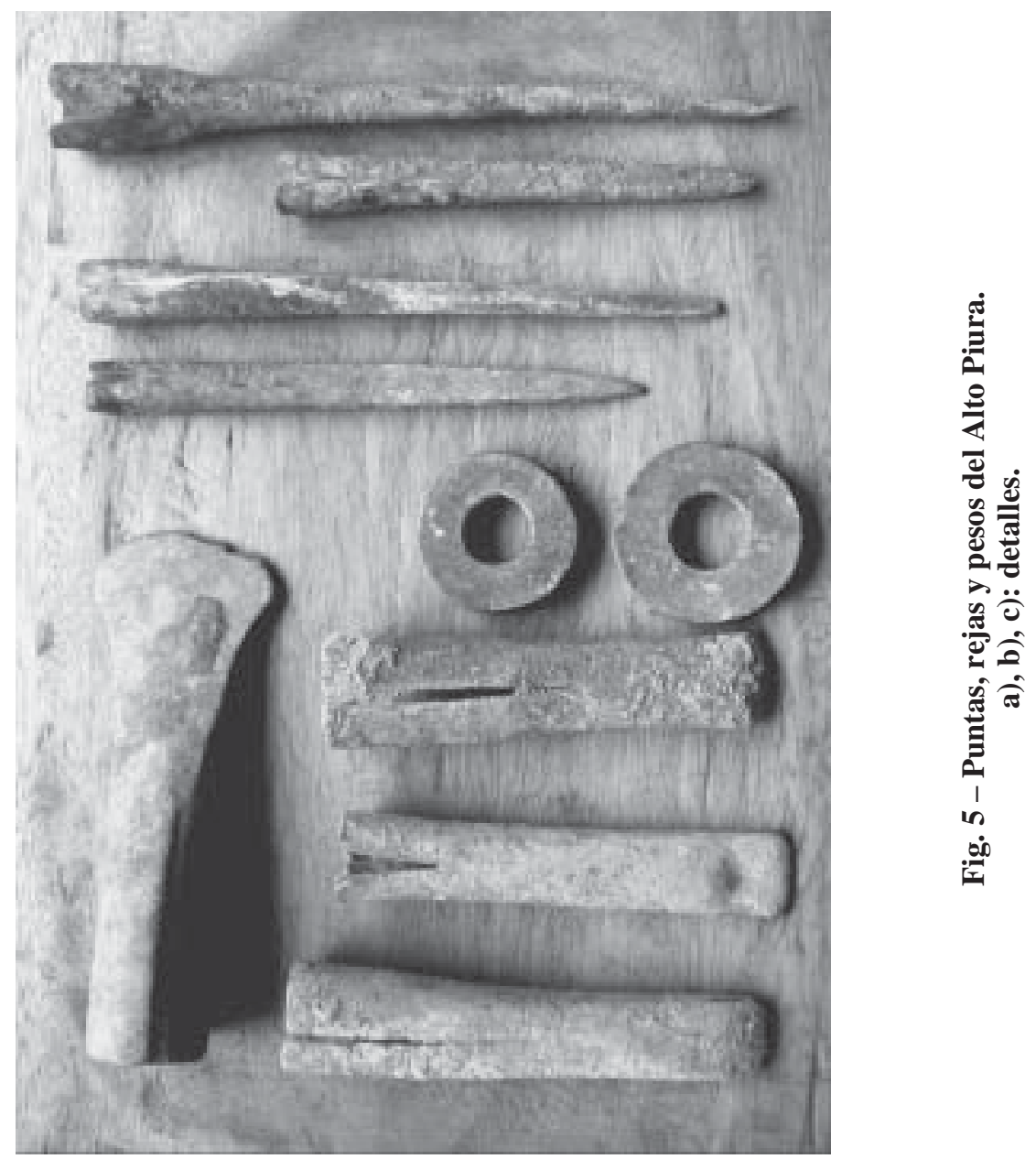


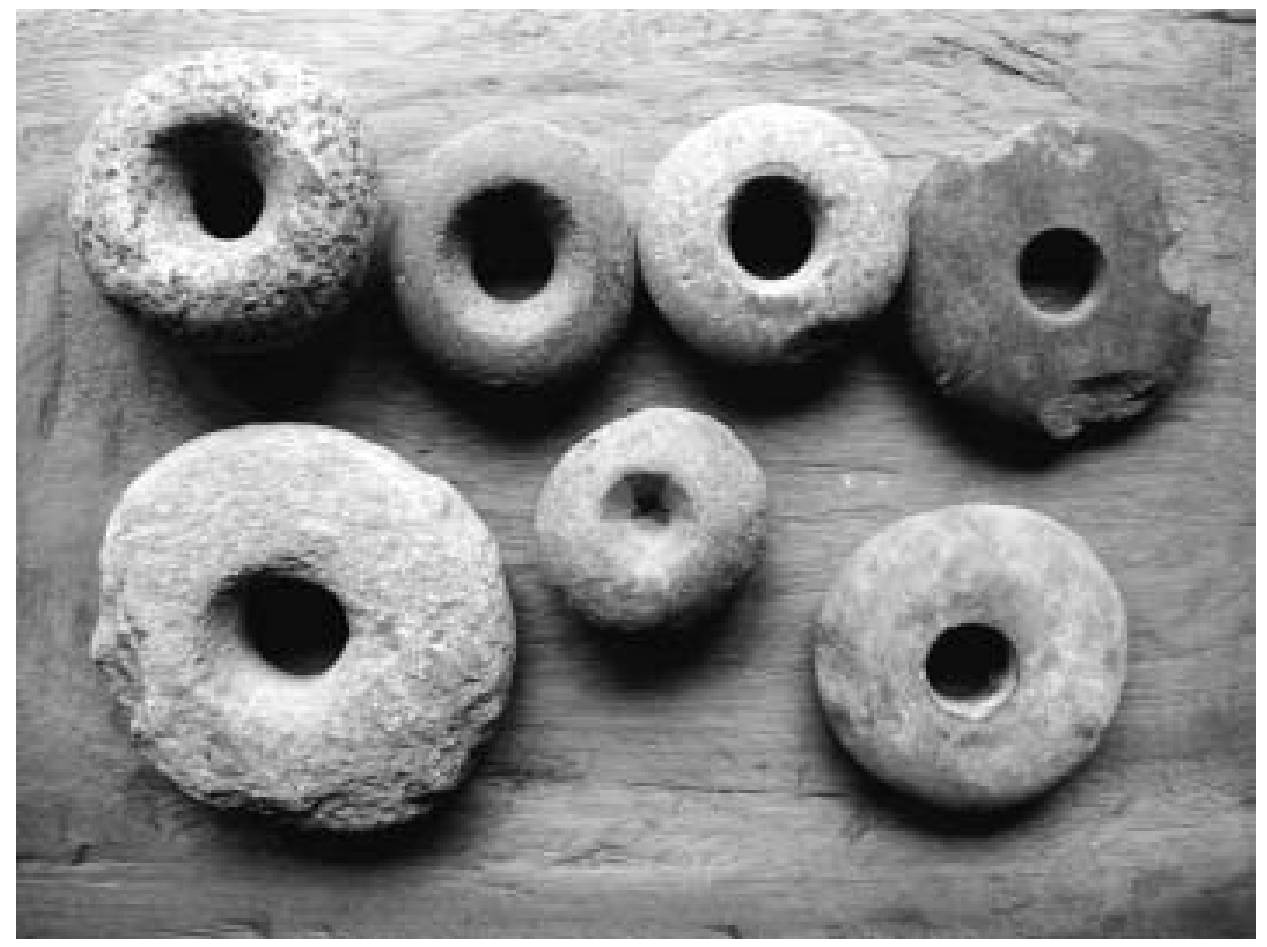

Fig. 6 - Piedras ahuecadas que provienen de las pampas de Pabur en el Alto Piura.

"La concurrencia simultánea de una composición aproximadamente constante y una proporción adecuada de arsénico, desde el punto de vista metalúrgico, apoyan la hipótesis de que el As fue utilizado intencionalmente y su contenido en las aleaciones controlado. Esta intencionalidad demuestra que los metalurgistas sabían las ventajas que ofrecía el arsénico al alearse con el cobre, tales como resistencia, dureza, maleabilidad, facilidad para el fundido (Shimada, Epstein y Craig 1982, 1983, Shimada y Merkel 1991) y que aprendieron a integrarlo al proceso de fundición evitando que éste se volatilice por completo (Epstein y Shimada 1983 [1984], Shimada y Merkel 1991). Según los estudios realizados por Shimada y su equipo, el arsénico proviene de la arsenopirita (FeAsS), presente en las minas de Cerro Mellizos, ubicadas cerca de los centros de fundición (Merkel, Shimada, Swann y Donan 1994)." (Vetter, 1996: 69-70).

Los lingotes de cobre arsenical eran martillados y recalentados para dar forma a las piezas, tratando de mantener un grano fino que aseguraba una mayor resistencia mecánica. Las puntas pesan unos 450 gr, 10 terminan en puntas en $\mathrm{V}$ y el resto en punta roma de $1 \mathrm{~cm}$. Tienen un cuerpo rectangular de más o menos $15 \mathrm{~cm}$, un receptáculo circular de unos $5 \mathrm{~cm}$ de largo y de 1 a $2 \mathrm{~cm}$ de diámetro. Recordando que cada taller tenía un promedio de cuatro hornos y que solo parece factible, por lo limitado del 
espacio, que hayan usado dos a la vez, un par primero y luego el otro par, en total se usaría una vez cada horno al día. En un taller, al día se lograría sacar un promedio de 2 kilogramos de metal, es decir 4 lingotes, de donde se obtendrían cuatro puntas (Vetter 1996: 70-74).

Muchas de las puntas que provienen de entierros, como las estudiadas por Luisa Vetter, no parecen haber sido utilizadas y no tienen acabado final:

"En ninguna de las 489 piezas se hallaron huellas de uso, los bordes del cuerpo se mantienen rectos y no presentan hendiduras o estrías propias del material gastado. [...] las piezas no muestran un acabado final. Se notan acanaladuras y surcos, ya que las piezas no tenían las exigencias utilitarias de un implemento agrícola, sino apenas, la de ser representación de tal en la composición de una ofrenda funeraria." (Vetter, 1996: 75, 77).

Sin embargo esta investigadora publica sobre una punta similar a las que estudió, conservada en el Museo Arqueológico de la Universidad Nacional de Trujillo y que ha sido encontrada con un palo de madera introducido en su receptáculo, lo que indica que debía haber servido (Vetter, 1996: 78).

Wendell Bennett excavó 38 tumbas en un montículo designado Lambayeque 1, ubicado a medio camino entre San José y Lambayeque y menciona que casi todas contenían cobre en alguna forma (Bennett, 1939: 95-106). En el material funerario encontró pesados instrumentos agrícolas y uno es una punta larga, con un extremo hueco en el que se podía insertar un palo (Bennett, 1939: 104; Lechtman, 1978: 505, nota 20). El análisis espectrográfico cuantitativo de esta herramienta puntiaguda de $55 \mathrm{~cm}$ de largo, reveló un contenido de 1,43 \% de arsénico, concentración suficiente para considerarlo bronce arsenical (Lechtman, 1978:505). Este sitio en la antigua terminología de Bennett es Chimú Medio. Según la opinión dada en 1976 a Lechtman por Kent Day del Royal Notario Museum de Toronto, quien trabajó en el departamento de Lambayeque, Lambayeque 1 probablemente pertenece a la fase Chimú Imperial, fechada aproximadamente entre 1150 y 1300 (Lechtman, 1978: 505 nota 20). Pero según Shimada el Chimú Medio de Bennett corresponde a la fase Sicán Medio y data del inicio del Período Intermedio Tardío (Shimada, 1995: 6-7).

Sabemos que instrumentos conservados en las colecciones del Museo Brüning de Lambayeque y en el Museo Arqueológico de la Universidad Nacional de Trujillo, fueron estudiados por Lechtman (1978; 1979; 1981; 1988) quién escribe:

"Estoy segura que la gran mayoría de las llamadas 'puntas de cobre' provenientes de los sitios 'Chimú Medio' y del Período Intermedio Tardío en el norte, son bronces arsenicales.” (Lechtman, 1978: 505).

Debemos también señalar que Eugen Mayer (1992: lamina 77, fig. 1542) ilustra una punta similar a las estudiadas por Luisa Vetter que fue encontrada en Sig Sig, Sierra del Cañar, Ecuador y que fue publicada por Verneau \& Rivet en 1912.

En el lote de metal que se vendía en Chulucanas había puntas similares, bien terminadas y con lo que parecen ser trazas de uso. Tienen 22 y $19 \mathrm{~cm}$ de largo, 2 y $1,5 \mathrm{~cm}$ de diámetro del receptáculo y, entre este y la punta son de forma rectangular. Las otras 
dos puntas son de 26 y 16,5 cm de largo, con 3 y $2 \mathrm{~cm}$ de diámetro del receptáculo pero entre este y la punta son de forma circular (fig. 5, detalles a, b, c). Sería interesante establecer una seriación estilística de estas puntas y tratar de ver a qué usos específicos corresponden las diferentes formas.

\section{2. 2. Las rejas}

Otros instrumentos, encontrados en una tumba de Huaca Menor en Batán Grande, fueron descritos por Pedersen e identificados como artefactos de labranza (Vetter, 1996: 76-77; Pedersen, 1976: 63-64):

"Artefacto de labranza: Largo total $140 \mathrm{~mm}$. Base en forma de embudo de $42 \mathrm{~mm}$ de diámetro de boca y $94 \mathrm{~mm}$ de profundidad con pared de $3 \mathrm{~mm}$ de espesor, longitudinalmente seccionada para ser ajustada a un cabo de madera. Cuerpo de sección rectangular de $24 \mathrm{~mm}$ por $31 \mathrm{~mm}$ en su base, terminado en forma de cuña de $28 \mathrm{~mm}$ de ancho con filo recto cortante. Peso total 450 gramos.

Artefacto de labranza: Largo total $252 \mathrm{~mm}$. Base en forma de embudo de $29 \mathrm{~mm}$ de diámetro de boca y $96 \mathrm{~mm}$ de profundidad con pared de $1 \mathrm{~mm}$ de espesor, longitudinalmente seccionada para ser ajustada a un cabo de madera. Cuerpo de sección rectangular de $17 \mathrm{~mm}$ por $19 \mathrm{~mm}$ en su base, terminados, en forma de cuña de $26 \mathrm{~mm}$ de ancho con filo semicircular cortante. En cada uno de sus planos laterales lleva una hilera de incisiones formando figuras antropomorfas vistas de frente, yuxtapuestas y separadas por líneas horizontales doble. Peso total 540 gramos." (Citado por Vetter, 1996: 76-77).

Bennett menciona que en las tumbas que excavó en el cementerio denominado Lambayeque 1, aparecen artefactos similares:

"Notable es un grupo de implementos agrícolas: herramientas pesadas en forma de cuña, con una cavidad hundida a lo largo de una cara para permitir agarrarla. En la parte inferior de la cavidad, la herramienta tiene una sección rectangular que se adelgaza gradualmente hasta la hoja cuña..." (Bennett, 1939: 104; Lechtman, 1978: 505, nota 21).

Otro de estos instrumentos proviene de una tumba Chimú Tardío, excavada también por Bennett en El Purgatorio, Túcume, en el valle de Lambayeque. Lo describe como "un cincel de cobre hueco" o un implemento hecho para ser utilizado con un mango de madera (Bennett, 1939: 116; Lechtman, 1978: 505, nota 21). Day opina que este sitio es Chimú-Inca y dataría entre 1450 y 1530 pero veremos que si bien presenta una ocupación inca, fue el centro administrativo y ceremonial Sicán Tardío entre 1100 y 1375 d.C.

También Eugen Mayer (1992: lamina 77, figs. 1542, 1543) presenta una reja conservada en la Casa de la Cultura de Guayaquil.

En el lote proveniente del Alto Piura hemos rescatado artefactos similares a los descritos por Pedersen, bien terminados y con lo que parecen ser trazas de uso. Tres tienen $15,15,5$ y $16,5 \mathrm{~cm}$ de largo, con $3,2,5$ y $3 \mathrm{~cm}$ de diámetro del receptáculo y la 
parte cortante, recta, es de unos $3 \mathrm{~cm}$. La tercera tiene $18 \mathrm{~cm}$ de largo, un receptáculo de 3,5 cm de diámetro y la parte cortante, ovalada, tiene unos 6,5 cm. Dos de estos instrumentos han sido muy bien manufacturados, todos están terminados, los filos son cortantes y presentan huellas de uso (fig. 5, detalles a, b, c).

Llamamos estos objetos rejas porque se diferencian de las puntas por ser más anchas y por lo tanto son cortantes.

\section{2. 3. La utilización y el reciclaje de las rejas y las puntas}

Sigue en curso un debate acerca de la naturaleza de las rejas y las puntas: se discute de si son símbolos de riqueza y poder o instrumentos utilitarios.

De hecho existen piezas que no muestran huellas de uso, otras que son porosas y por lo tanto frágiles o demasiado pesadas lo que indicaría, según Lechtman y sus seguidores que no son utilitarios (Lechtman, 1978: 505; 1979: 22; 1981: 96; Hosler et $a l ., 1990)$. Por ejemplo en cuanto al significado cultural del bronce y a propósito de los instrumentos de cobre arsenical escribe:

"Muchos de los que he visto obviamente no tuvieron uso ni se hicieron con fin utilitario. Algunos de los presuntos implementos agrícolas son demasiado pesados para ser funcionales como herramientas. Otros, vaciados, tienen decoraciones en relieve de serpientes u otros motivos sobre uno de los lados. Otros están mal vaciados o vaciados casi como lingotes, a pesar de tener forma de azada, con una superficie fuertemente cóncava, señal de que el metal fue probablemente vaciado en un molde chato, de una sola pieza, abierto hacia arriba. La característica distintiva de todos estos objetos, usados o no, es la cantidad de metal que contienen. Más que cualquier otra cosa parecen ser "depósitos" o "concentraciones" de metal. Parece evidente, por su peso, por haber sido enterrados en gran número, por el burdo acabado de algunos, por la apariencia de lingotes de otros, que en si el bronce era considerado valioso y como tal acumulado. Tal vez indicaba riqueza o status, tal vez tenía otro significado." (Lechtman, 1978: 508).

Sin embargo, por varias razones, pensamos que los argumentos de Lechtman, para sostener que muchos instrumentos que ha visto no se hicieron con fin utilitario, son discutibles.

En cuanto al peso de las puntas y rejas, nos parece que es funcional si se considera que estas herramientas se utilizaban para trabajar las tierras compactas y duras del piedemonte andino, especialmente de Lambayeque, Piura y Tumbes. Fueron justamente de gran utilidad porque eran a la vez pesadas y resistentes. Es más, hay que notar que en el lote de metal huaqueado en el Alto Piura se encuentran dos piezas circulares, una de 6 centímetros de diámetro, con un espesor de $1 \mathrm{~cm}$, otra de 5,6 cm de diámetro, con un espesor de 1,3 cm. El hueco central es más o menos similar, 2,5 cm. Es del mismo tamaño que la parte hueca de las puntas y rejas, y si se les insertan mangos las piezas circulares pueden ser añadidas para dar más peso a estos instrumentos. En las pampas niveladas por los sicán medio, entre Chanchape y Tongo, los campesinos recogen a veces piedras con un hueco en el centro, de las mismas dimensiones que el hueco de las piezas circulares, y de aproximadamente el mismo peso (figs. 5, 6). Pensamos que estas 
piezas circulares ahuecadas son pesos de metal, sea cobre o cobre arsenical, y de piedra que se añadían si era necesario a las rejas y las puntas para aumentar sus capacidades de penetración en las tierras. Actualmente, en el piedemonte como en las vertientes de los Andes del extremo norte delPerú, se utilizan pesados instrumentos, barretones que son rejas de fierro o de acero con mangos de palo, barretas y barretillas de una sola pieza de estos metales, que tienen una punta a un extremo y una reja al otro (Etesse, $1991 \mathrm{y} \mathrm{fig.} \mathrm{7).}$

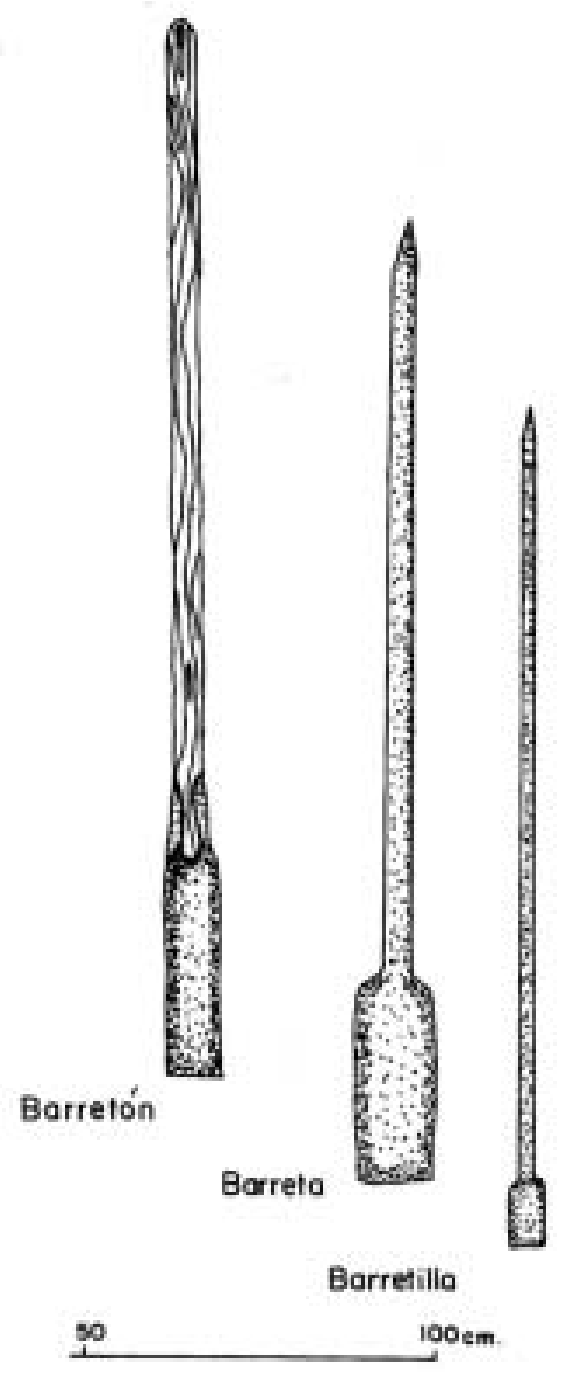

Fig. 7 - Instrumentos de labranza actuales, el mango del barretón es de madera, los de la barreta y barretilla, de fierro (Étesse, 1991). 
En cuanto a las decoraciones de algunas herramientas y a los defectos de otras, no son pruebas de que estos instrumentos no podían ser funcionales. Como todos los instrumentos de trabajo, algunos pueden haber sido decorados o llevar las marcas de quienes las elaboraron o utilizaron y otros pueden ser de muy distintas cualidades. En el Museo Brüning de Lambayeque pudimos ver una reja muy bien elaborada y decorada con personajes sicanes (MB-M- 09259) que podría haber tenido un uso ceremonial, así como cantidades de rejas sin decoraciones, que podrían haber sido utilizadas, y algunas mal vaciadas que no podrían haber servido como instrumentos, pero podrían haber sido conservadas por el valor del metal.

En cuanto a las huellas de uso, considerando que la gran mayoría de las que reconocen formaban parte de un material funerario, es muy posible que sean piezas nuevas que formaban parte de bienes almacenados que en otras circunstancias hubieran podido ser utilizadas, pero que al momento de enterrar al difunto fueron depositadas en su tumba como símbolo de estatus, atestiguando de su riqueza y poder y para servirle en el otro mundo. De hecho, según las creencias andinas, en el otro mundo los difuntos "recogían sus pasos", volvían a seguir el camino de su vida, conservando sus rangos y funciones, cumpliendo con sus deberes y obligaciones (Hocquenghem, 1997; 1998: 197-212). Actualmente barretones, barretas y barretillas como machetes y otras herramientas nuevas, almacenadas en una ferretería no presentan huellas de uso, pero sí son instrumentos utilitarios. Es más nos parece evidente que las herramientas que de hecho sirvieron para trabajar, y que por lo tanto tenían huellas de uso, difícilmente van a ser encontradas por los arqueólogos donde hubieran podido extraviarse o romperse. Esto porque no muchas deben de haberse perdido. Sumamente valiosas, debían guardarse y conservarse, lo mismo que las primeras rejas de fierro y otras herramientas del mismo metal durante la colonia que se heredaban o vendían con las haciendas y figuraban en los testamentos y las actas de ventas (Schlüpmann, 1993-1994: anexos). Si acaso se rompían, debían ser recogidas y, a partir del metal otra vez fundido en lingotes, se debían forjar nuevos instrumentos. Finalmente, si de casualidad alguna punta o reja se perdían, el campesino que las encontrarían hoy las volverían a utilizar, o como el huaquero, las venderían para ser fundidas y el bronce sería reciclado. Los instrumentos utilitarios, en particular los de metal que son de más valor, siempre se cuidan, se arreglan, se reutilizan y finalmente se reciclan.

Lo cierto es que existen huellas de uso en varias rejas y puntas y que, además, existen evidencias de la utilización de estos instrumentos y que son rejas las que habrían servido para cavar las tumbas Sicán Medio:

"El enterramiento de la Huaca Loro es un buen ejemplo de una tumba en forma de pozo, con cámaras laterales o nichos (Fig. 29, 30 A, B). Fue cavada en un terreno compuesto de una serie de finos depósitos estratificados de arena - cieno- arcilla... Afortunadamente para nosotros el terreno en su conjunto estaba bastante compactado y sólido, de tal manera que durante los seis largos meses de excavación (octubre de 1991-marzo de 1992) no hubo amenazas serias de derrumbe. Las paredes del foso funerario, desde la cima hasta el fondo, conservaban unas marcas algo regulares y poco profundas en forma de surco de unos 2,5 a 3,0 cm de ancho y $15-20 \mathrm{~cm}$ de largo-, que probablemente fueron 
hechas por los instrumentos de cobre arsenical usados para cavar este foso hace 1000 años..." (Shimada, 1995: 53).

Pensamos por lo tanto que las puntas y las rejas son partes de instrumentos utilitarios que fueron depositados en las tumbas, habiendo o no servidos. En el contexto funerario, como bienes del difunto, se convierten en símbolos de su riqueza y poder. Pero el carácter simbólico que adquieren estos implementos, al ser depositados en una tumba, no les quita el carácter utilitario que tuvieron o podrían haber tenido en otros contextos. Es necesario recordar que no solamente las puntas y las rejas, sino también los deshechos metálicos, se valoraban y se depositaban en las tumbas Sicán donde adquirían un carácter simbólico al atestiguar la riqueza y el poder del difunto (Shimada 1995: 162-163).

\section{2. 4. Los múltiples usos de las herramientas de cobre arsenical}

Insertadas en cabos de palos, las pesadas rejas y las puntas de cobre arsenical forman parte de las herramientas a percusión que se arrojan con la fuerza del brazo y a las cuales se podían en caso necesario añadir peso, con las piezas circulares y ahuecadas de metal o de piedra, para conferirles más eficacia. Las cualidades del cobre arsenical, son las que se requieren para la elaboración de puntas y rejas que son utilizadas en tierras duras, compactas, pedregosas, cubiertas de bosque seco, como las que se extienden desde el valle de La Leche hasta Tumbes, del litoral pacífico al piedemonte andino, y en las partes bajas de los valles de cuenca del Marañón, o las dos vertientes andinas, pacífica y amazónica, de fuertes pendientes cubiertas de selva alta.

En estas dos ecorregiones del extremo norte andino donde se sigue practicando una agricultura migratoria, se utilizan hoy las hachas, los machetes y los calabozos para desmontar y para las tareas relacionadas tanto con la agricultura migratoria de secano como la agricultura permanente con riego, las muy pesadas barretas, las barretillas, así como los barretones y pequeñas lampas que son un poco más anchas que las rejas. Las puntas de las barretas y barretillas se utilizan para sembrar y las rejas para la preparación de terrenos para la agricultura, la roturación de las tierras, el barbecho después de las temporadas secas cuando se anuncian las lluvias y antes de soltar las aguas de los reservorios o abrir las tomas de los canales, y la cosecha. Los barretones sirven para cosechar tubérculos. Las lampas se usan para dirigir el agua, limpiar las acequias, mantener los camellones. Es muy importante notar que las barretas y barretillas no solamente sirven para la producción agrícola; se utilizan también en la construcción de obras públicas o privadas, sean plazas, iglesias o casas así como la apertura y el mantenimiento de acequias, caminos y vetas de minerales. Según la consistencia de los terrenos se usan diferentes formas de rejas, de corte ancho para los terrenos blandos, o mediano y rectangular para los arenosos, angostos para los arcillosos duros, y las puntas pueden ser útiles en los cascajosos o rocosos. Las barretas y barretillas son, por lo tanto, herramientas multiusos.

Se puede pensar que las puntas y rejas sicanes de cobre arsenical eran parte de instrumentos multiusos que se utilizaban en el contexto de las diversas actividades de producción agrícola a lo largo del año. Pero en otros contextos debían servir para cavar, 
cortar, palanquear y labrar. El peso y el filo de las rejas debían facilitar el desmonte para el acondicionamiento de los suelos agrícolas, que requiere el corte y la extracción de las raíces, a modo de cuñas. Asimismo las puntas y rejas debían utilizarse para la remodelación de pendientes pedregosas que implicaban la extracción de bloques de piedras, para la construcción de andenerías, de canales, de reservorios de agua, como para la nivelación de las tierras irrigadas, o la construcción de camellones. Además debían facilitar el mantenimiento y la extensión de las vías de comunicación, la construcción y remodelación de diferentes estructuras arquitectónicas que implicaban, entre otras tareas, excavaciones de zanjas, cimientos o tumbas y extracciones de grandes volúmenes de material de relleno. Asimismo debían ser muy útiles en los trabajos de minería.

Las puntas y rejas de cobre arsenical deben ser también los antepasadas de las actuales cuchillas de fierro o acero que forman parte de diversos instrumentos más especializados, que sirven para cumplir con más facilidad y eficacia una tarea específica, que se utilizan actualmente en los Andes del centro y del sur, entre otros, los allachus y kituchis, las chaquitacllas que son arados de pie incaicos descritos por varios investigadores (Bourliaud et al., 1988; Morlon ed., 1996: 80-81; Pino, 2001: 265, 284, 277, 267). El allachu sirve para la cosecha de tubérculos, el kituchi como escarificador del suelo en el deshierbe, siembra, replante y cosecha, y la chaquitaclla, que aprovecha el peso del hombre, para el barbecho, y adicionalmente de los aporques o el arreglo de canales, pero que se utiliza en el contexto de una agricultura permanente, en tierras limpias de piedras, de raíces de árboles, de pocas pendientes o en andenerías.

Volviendo a las puntas y rejas de cobre arsenical y sus cabos de madera, pensamos que son las herramientas que permitieron, a inicios del Período Intermedio Tardío, ampliar la frontera agrícola en el bosque seco piurano y tumbesino, desmontando y extendiendo los sistemas de irrigación en los valles, estableciendo andenerías en el piedemonte del extremo norte andino así como en los valles secos de la vertiente amazónica y la vertientes de selva alta de las serranías de Huancabamba, Cajamarca y Chachapoyas. En estas zonas hay indicaciones del cambio, a fines del primer milenio de nuestra era, de una agricultura migratoria, de roza y quema en las fuertes pendientes cubiertas de selva alta, a una agricultura permanente de secano en andenerías.

Nos parece que los argumentos de Lechtman y Hosler, autoridades en cuanto al estudio de los objetos de metal, y en particular de bronce prehispánico, para considerarlas ante todo como símbolos de riqueza y estatus, pesaron y siguen pesando demasiado. Esto impidiendo que se aprecie los múltiples usos de estas herramientas y evalúe sus impactos en cuanto a ampliaciones de la frontera agrícola, aumentos de la producción y de la recaudación del tributo, extensiones de las rutas de intercambios a larga distancia y los incrementos del caudal de la circulación de los bienes exóticos y de sus beneficios, el rápido desarrollo administrativo y ceremonial, cambios que según la definición de Lechtman marcan el inicio de la Edad de Bronce en el Viejo Mundo y por lo tanto igualmente en el Nuevo.

Pero avancemos por partes, veamos ahora las evidencias de una ampliación de la frontera agrícola en los valles del extremo norte andino a partir de 900 d.C. bajo control de las elites de la teocracia Sicán Medio, las huellas de canales de irrigación, 
andenerías, pircas, reservorios de agua, chacras hundidas o acondicionamientos de suelos agrícolas en los lechos de las quebradas. Son partes de infraestructuras productivas que deben haber requerido para sus construcciones la remoción de grandes cantidades de tierras que podrían haber sido facilitadas y aceleradas con la utilización de herramientas de cobre arsenical (Hocquenghem, 1998: 160-172; 1999; 2001).

\section{LA AMPLIACIÓN DE LA FRONTERA AGRÍCOLA Y EL CRECIMIENTO DEMOGRÁFICO Y TRIBUTARIO}

\section{1. El sistema de irrigación y otras infraestructuras de producción}

\section{1. 1. En el valle del Piura}

El canal del Alto Piura

En 1993 redescubrimos el canal que los sicán medio construyeron entre $900 \mathrm{y}$ 1100 d.C., para conducir las aguas que bajan durante la estación de lluvias de la sierra de Huarmaca, antes de que se pierdan en el ancho pedregal de Hualcas. Va bordeando el piedemonte al sur del valle de Piura y ubicamos largos trazos bien conservados a lo largo de su recorrido de unos $150 \mathrm{~km}$. Calculamos que su zona de influencia podía ser de unas 25000 hectáreas. Es cierto, sólo el valle del río Piura ofrece condiciones naturales que permiten realizar una obra de tanta magnitud, porque se extiende en la parte de la costa donde el piedemonte está más alejado del litoral y tiene una pendiente poco acentuada (figs. 8, 9, 10, 11).

La toma del canal captaba las aguas del río Piura en el sitio de Mamayacu, toponimia quechua que significa origen o fuente de agua, y además encausaba las aguas de las quebradas que bajan del piedemonte entre Hualcas y Tongo, así como las que se escurren cuando caen los fuertes aguaceros en el despoblado. La toma se ubicaba encima de Hualcas, no pudimos ver sus huellas, los campesinos dicen que se ven cerca del sitio denominado El Molino, justo donde el río de Huarmaca entra en el valle por una estrecha puerta entre apretados cerros que solo pudimos apreciar desde un helicóptero.

El canal pasaba al sur de Hualcas para ir a recoger, a unos 300 metros de altura, las aguas que vienen de las quebradas de Chignia y de Domiguillo. En esta parte las crecidas del río lo destrozaron y luego, de Serrán a Hualas, la construcción de la carretera que viene de Piura a Huancabamba lo malogró en gran parte. Pasaba Río Seco y entraba por las pampas de La Ala, a las de Buenos Aires. Seguía encima de la toma de un antiguo canal mochica, al pie del cerro de Carrasquillo, avanzaba hasta los cerros de Chanchape y cruzaba hasta el cerro Tongo. Continuaba hacia el río Piura por la Matanza, dejando a mano derecha la Loma Negra. Dejaba en su margen derecha Huaca Nima, entraba en lo que es ahora el pueblo de Vicús, bordeaba el cerro por Linderos de Vicús y Huasimal. Cruzaba lo que es hoy la moderna carretera a Chulucanas y se dirigía hacia Huápalas. Pasaba por Ñomala donde el río lo cortó cerca de lo que fue la casa hacienda y terminaba en La Rita, por Malinguitas (figs. 5, 9).

La obra mantenía una caja similar hasta Tongo. De la evaluación de un corte, en Chanchape, resultan las siguientes características: un ancho superior de unos 18 metros, una plantilla de 4 metros y 2,50 metros de altura. En Tongo, cuando se alejaba del 

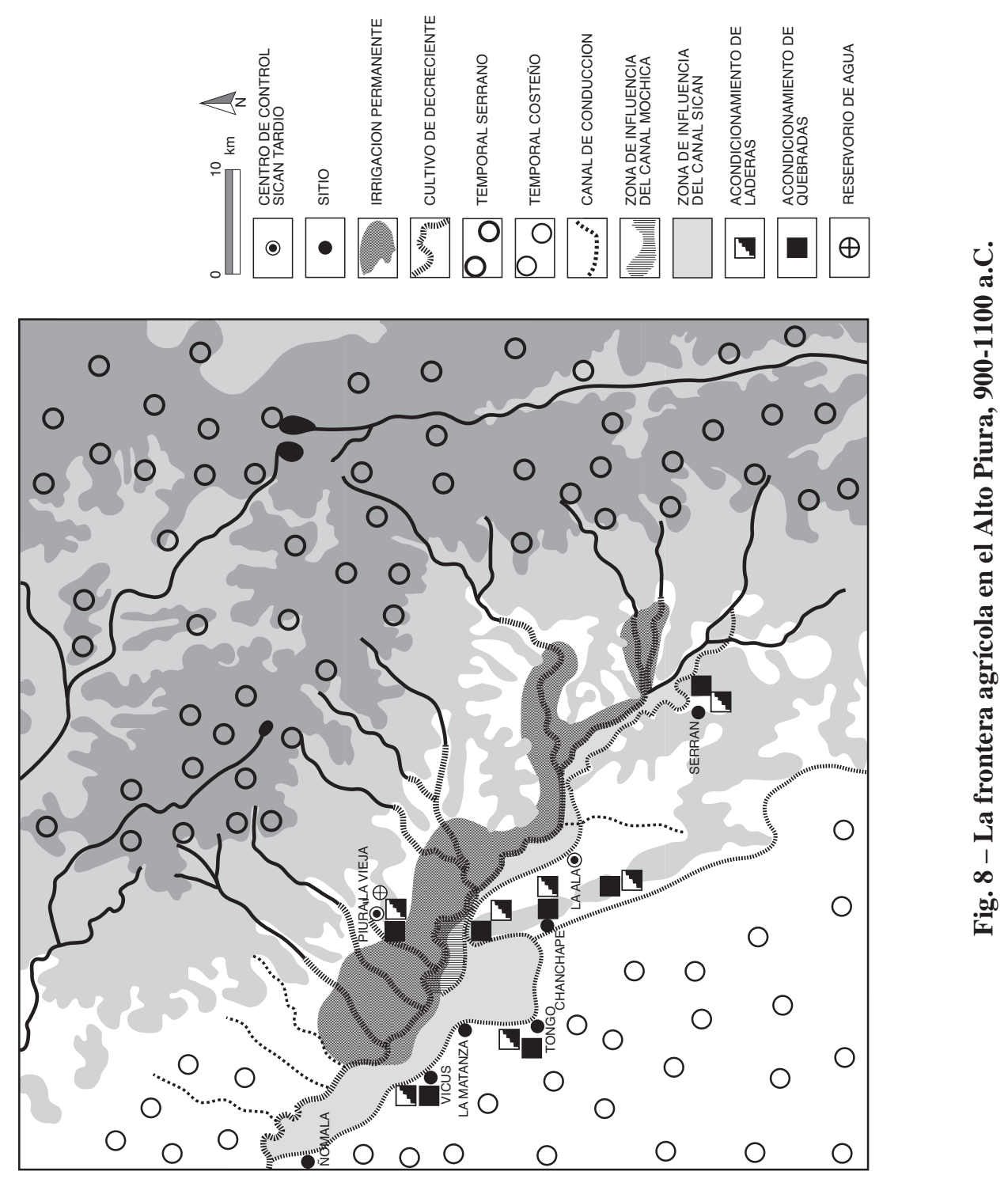


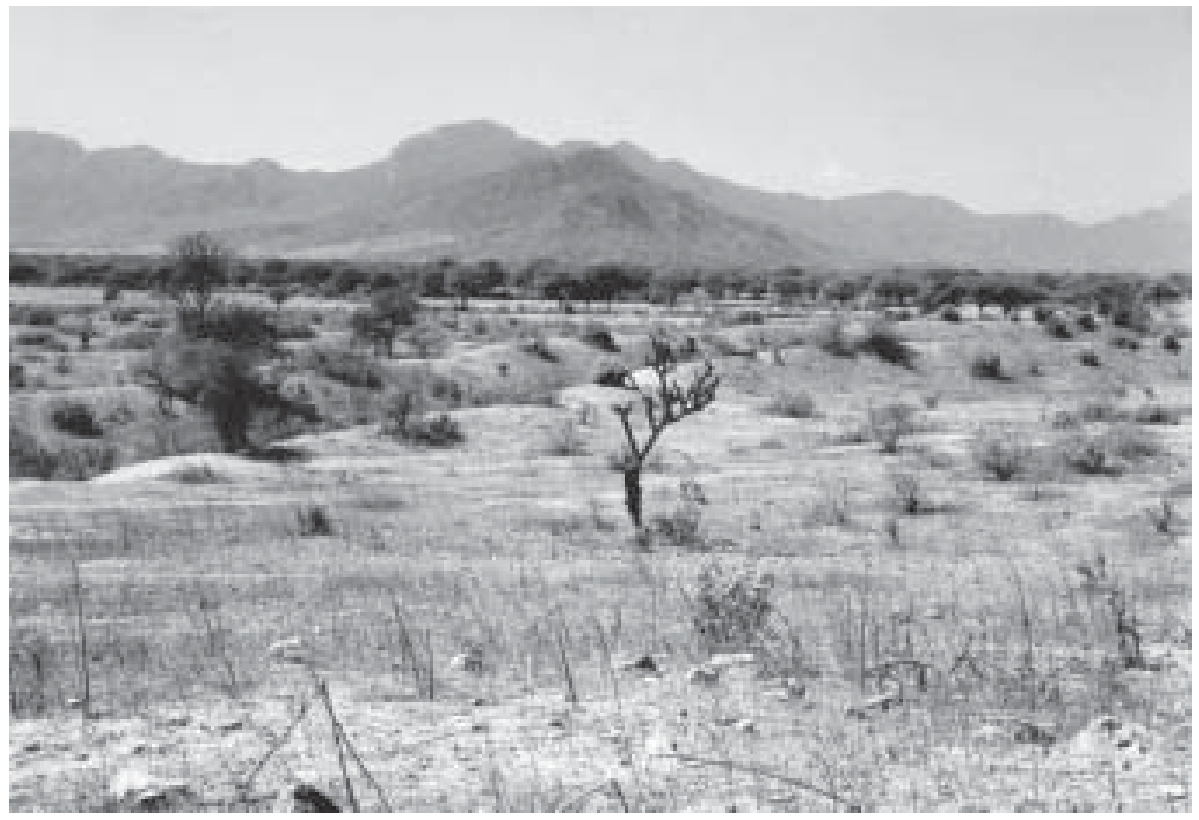

Fig. 9 - El canal del Alto Piura entre Tango y Chanchape.

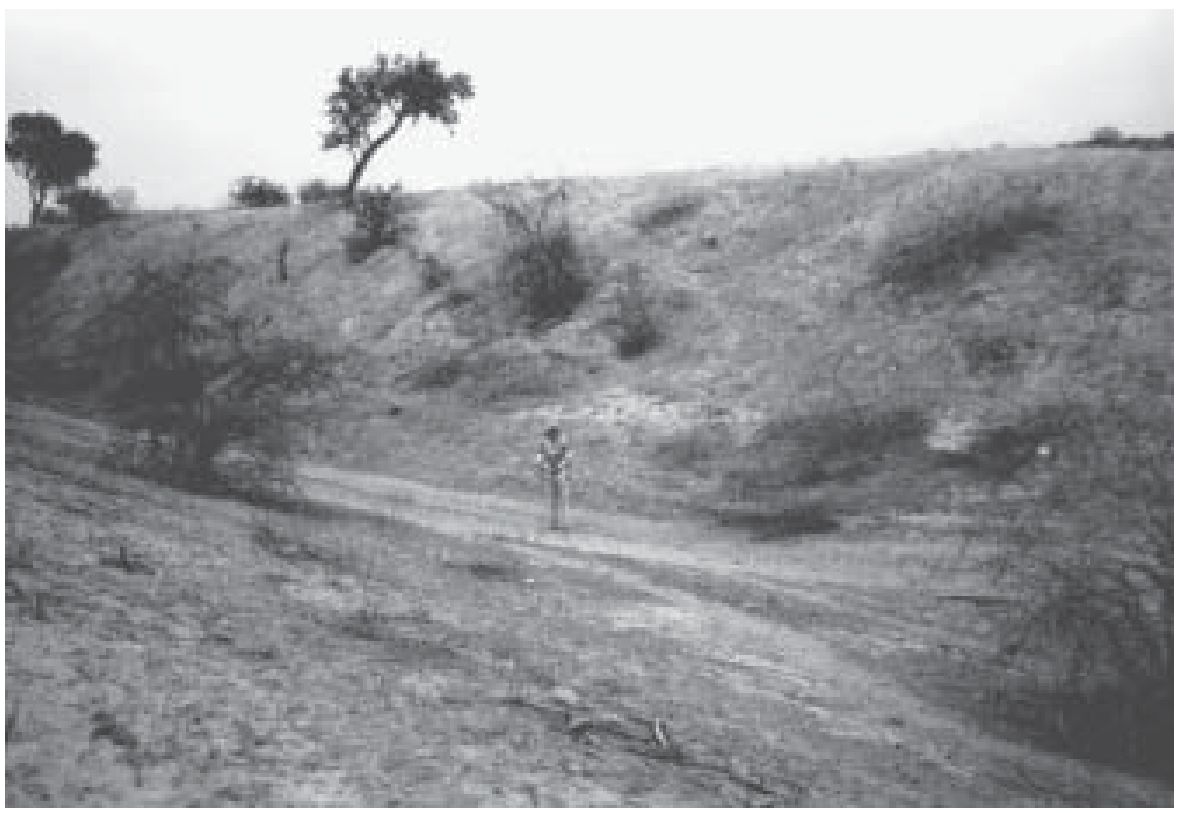

Fig. 10 - El canal del Alto Piura en Tongo. 


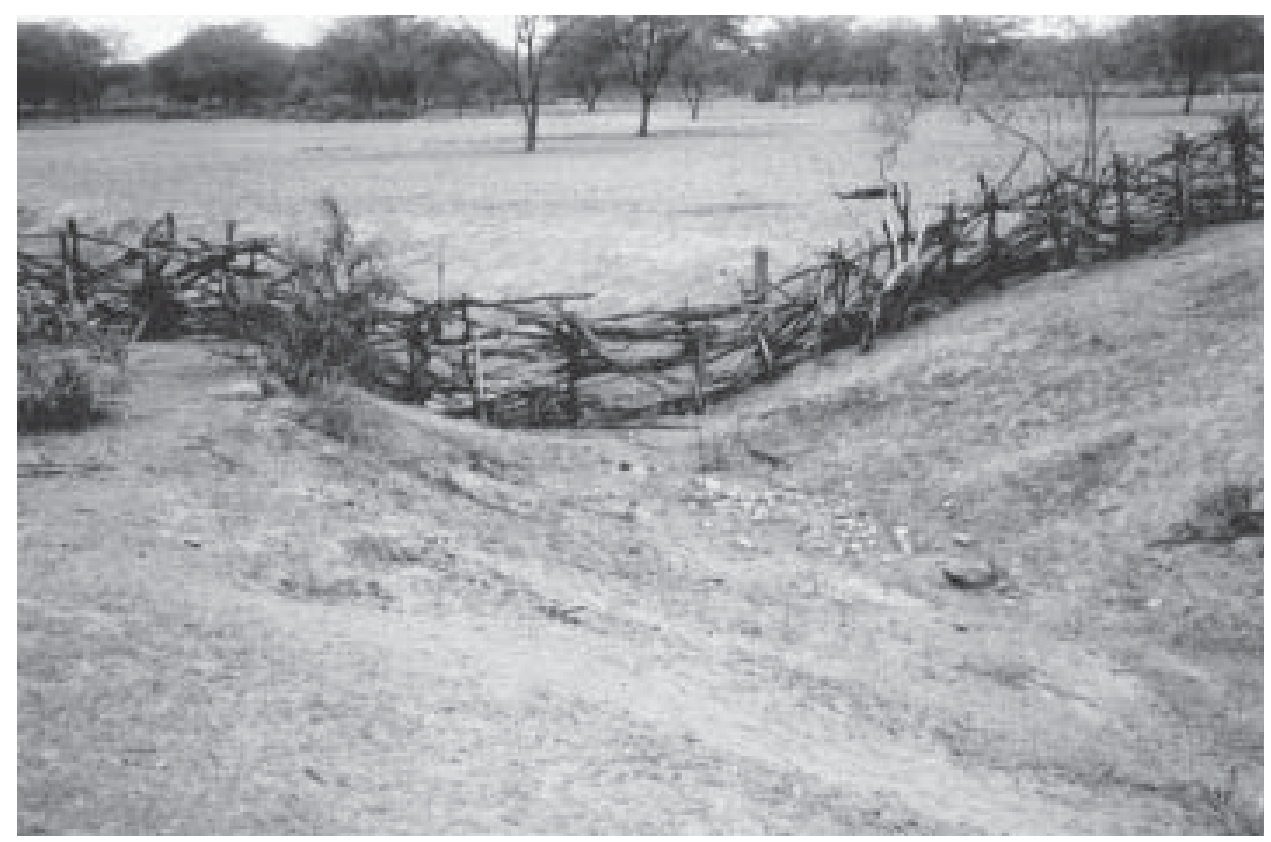

Fig. 11 - Un canal secundario en Tongo.

piedemonte su ancho superior llegaba a unos 30 metros con una altura de 4 a 5 metros, una plantilla de 4 metros. De hecho en época de lluvia, canalizaba no solo las aguas crecidas que bajaban de la sierra de Huarmaca sino también soportaba las de un canal de recarga que recogía las aguas del Naupe y de la vertiente oeste del cerro Tinajones y, en caso de lluvias extraordinarias, a partir de Carrasquillo debía servir de aliviadero del río Piura. Queda por determinar sus características hidráulicas. Lo cierto es que su caudal variaba según la cantidad de lluvias que caían en la sierra de Huarmaca y el piedemonte.

A la altura de Chanchape pudimos observar la entrada del canal de recarga y en Tongo un aliviadero. En cuanto a canales secundarios o de riego, en Tongo logramos observar tres tomas, pero hay más. Medimos uno de estos canales que se dirigen hacia las pampas de Pabur. Resultó tener un ancho superior de 8 metros, 2,50 metros de plantilla y una altura de 1,80 metros. Queda por determinar sus características hidráulicas.

En su mayor parte el canal fue cavado en la tierra pedregosa y compacta, con sus bordes, o bancales, construidos por grandes bloques de piedras consolidados con el material de excavación. Para evitar la pérdida de agua por la infiltración, se revistió con piedras lajas.

Se notan rastros de un sistema de protección, cuando el canal se acercaba al río o pasaba quebradas que arriesgaban destruirlo en tiempos de grandes avenidas causadas por las fuertes lluvias que suelen caer en los valles del extremo norte. La protección la constituye muros de contención en los lechos de las quebradas y canales laterales en las 
vertientes de los cerros que encausan las aguas y las dirigen en forma suave hacia el canal. Estas defensas las pudimos observar en Serrán, La Ala, Carrasquillo, Chanchape y Tongo.

Se entiende que esta obra fue concebida para irrigar las pampas de La Ala, Buenos Aires, Pabur, La Matanza, Vicús, Huápalas, Ñomala y Malinguitas, donde aseguraba una cosecha por año. Es cierto que en caso de extrema sequía el agua podía faltar. Y si impacta el tamaño del canal no dejan de impresionar las extensiones de tierras que fueron desmontadas y niveladas para luego ser barbechadas y sembradas cuando llegaban las aguas de la sierra de Huarmaca (figs. 12, 13).

Los campesinos que conocen partes de esta obra la llaman "el canal de los incas", pero pensamos que ha sido construido a fines del primer milenio de nuestra era. Es claro que se necesitan excavaciones para determinar con más precisión la fecha de esta construcción, pero la presencia de cerámica Sicán Medio, entre La Ala y Buenos Aires en la Huaca Nayo, así como en La Matanza, confirma nuestra idea. Se deberían mapear y estudiar todos los sitios asociados al canal para entender cómo se distribuían sus aguas.

Tanto la construcción del canal principal, del canal de recarga, de los canales secundarios, de los aliviaderos y otras estructuras de protección, como el desmonte y la nivelación de las pampas, que requiere grandes remociones de tierras, excavaciones, extracciones de piedras, cortes de raíces y cada año el trabajo de barbecho y de siembra, deben haber sido tareas facilitadas y aceleradas por el uso de instrumentos de cobre arsenical.

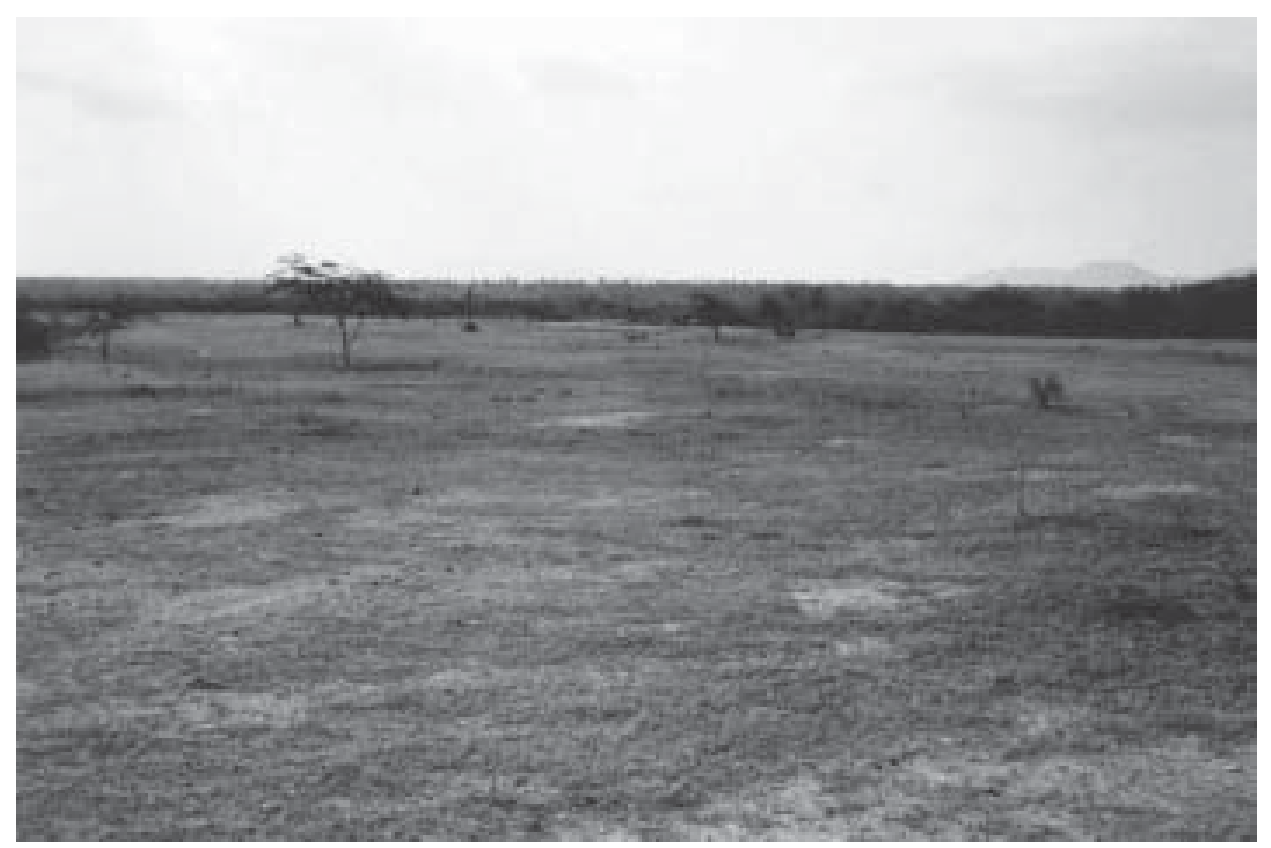

Fig. 12 - Las pampas de Pabur en marzo de 1995 con las primeras lluvias. 


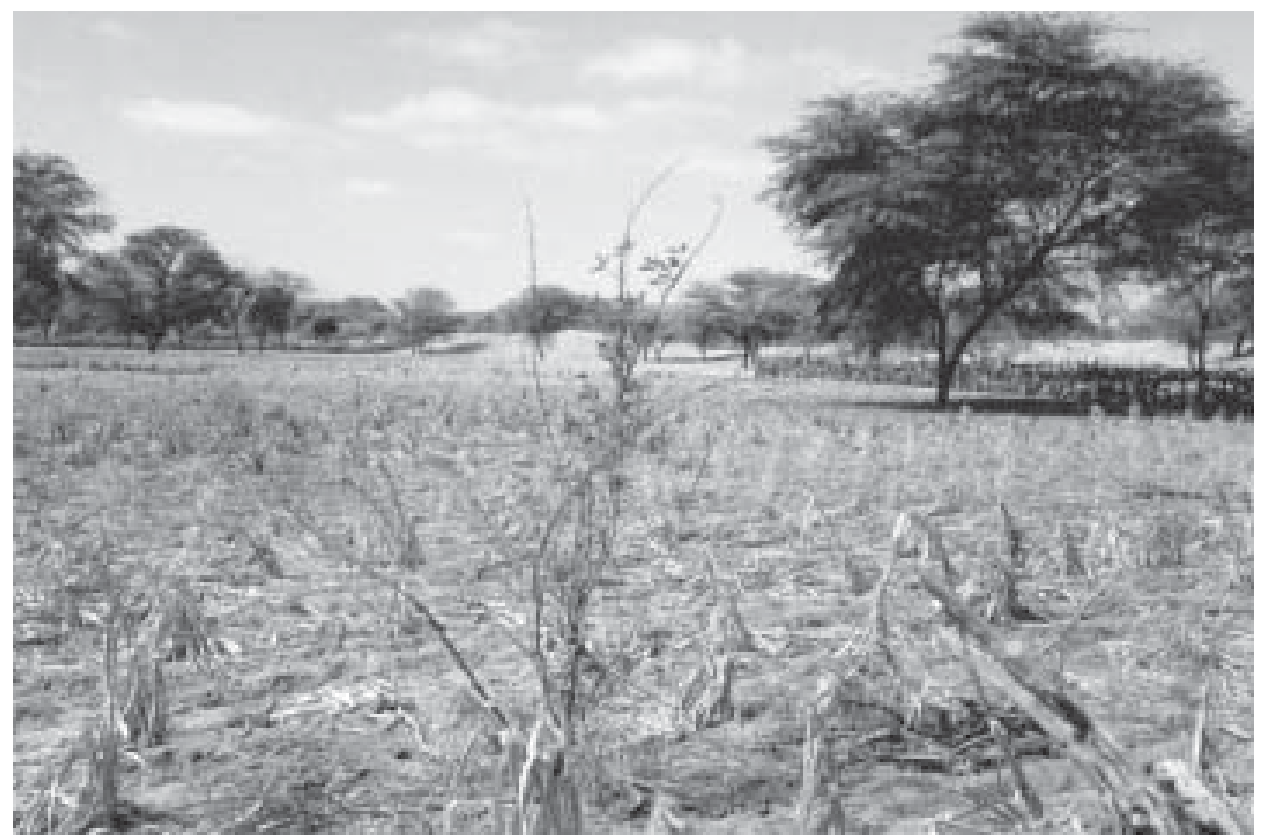

Fig. 13 - Las pampas de Pabur en julio de 1995: en el fondo, una estructura asociada al canal.

El reservorio de agua del Boliche

En el Alto Piura, para almacenar las aguas de lluvia que traen las quebradas, se construyeron reservorios en las faldas de los cerros. Un ejemplo de estas obras es el "Boliche", en las faldas del cerro Pilán, encima de la quebrada de las Damas, no lejos de Piura la Vieja (figs. 14, 15, 16, 17).

El reservorio tiene en su parte superior interna una forma circular con un diámetro de unos 100 metros y en su parte inferior interna presenta una forma cuadrada de unos 50 metros por lado, resultando una transición en uno de sus vértices que hace presumir el punto de evacuación de las aguas. Sin embargo, la sedimentación acumulada en el fondo del reservorio no deja ver este punto de evacuación. Desde el fondo actual de la estructura hasta la plataforma medimos unos 10 metros de altura en el lado norte, y unos 15 metros por el lado sur. Estimamos la colmatación por sedimentación en el fondo, considerando los niveles de la quebrada contigua, en unos 3 a 4 metros de altura.

En base a estas dimensiones, determinamos que la capacidad de almacenamiento de esta obra alcanza unos 50000 metros cúbicos de agua. Considerando la estimación de colmatación en el fondo, se puede aumentar la capacidad a unos 60 a $70 \quad 000$ metros cúbicos.

Una cuarta parte de la plataforma se apoya en la falda del cerro. Las tres cuartas partes están construidas con un material de relleno, en parte transportado de otro lugar y en parte constituido por el material de la excavación. Compactado con piedra del cerro 


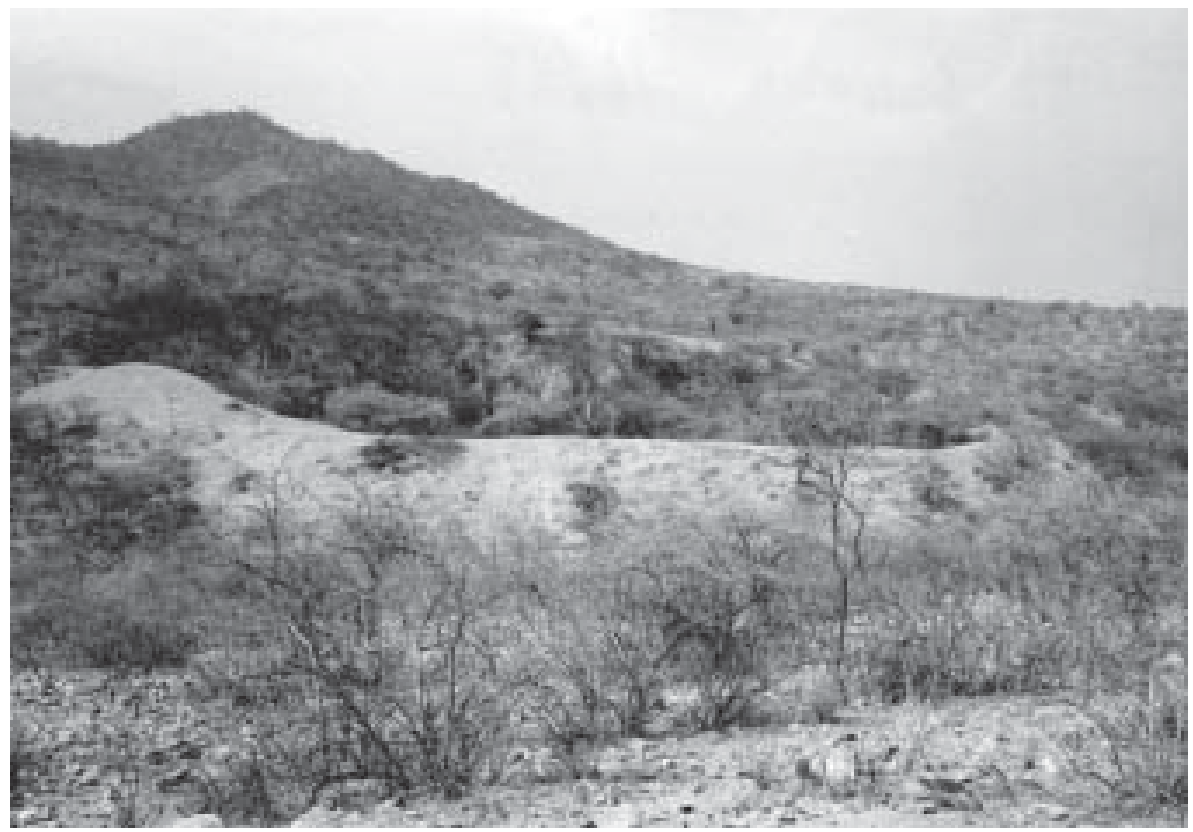

Fig. 14 - El reservorio del Boliche al pie del cerro Horcones cerca de Piura la Vieja.

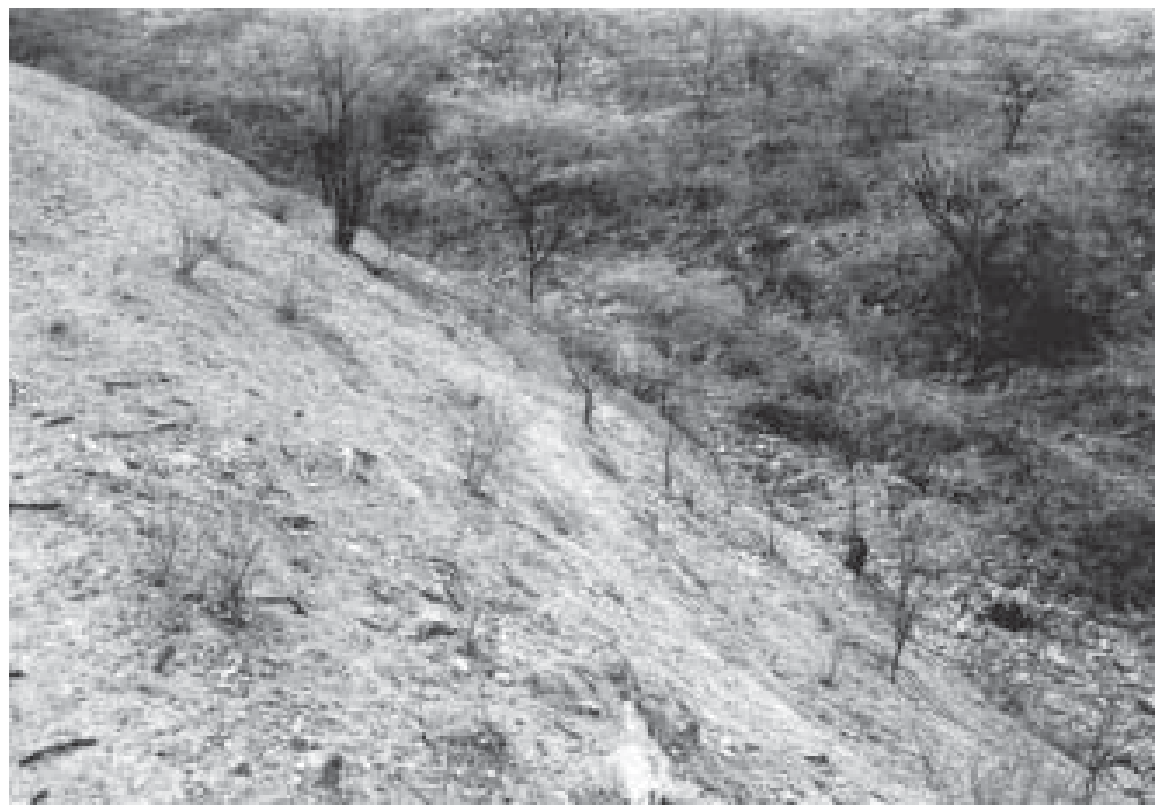

Fig. 15 - Muro de contención del reservorio del Boliche y lecho de la quebrada. 


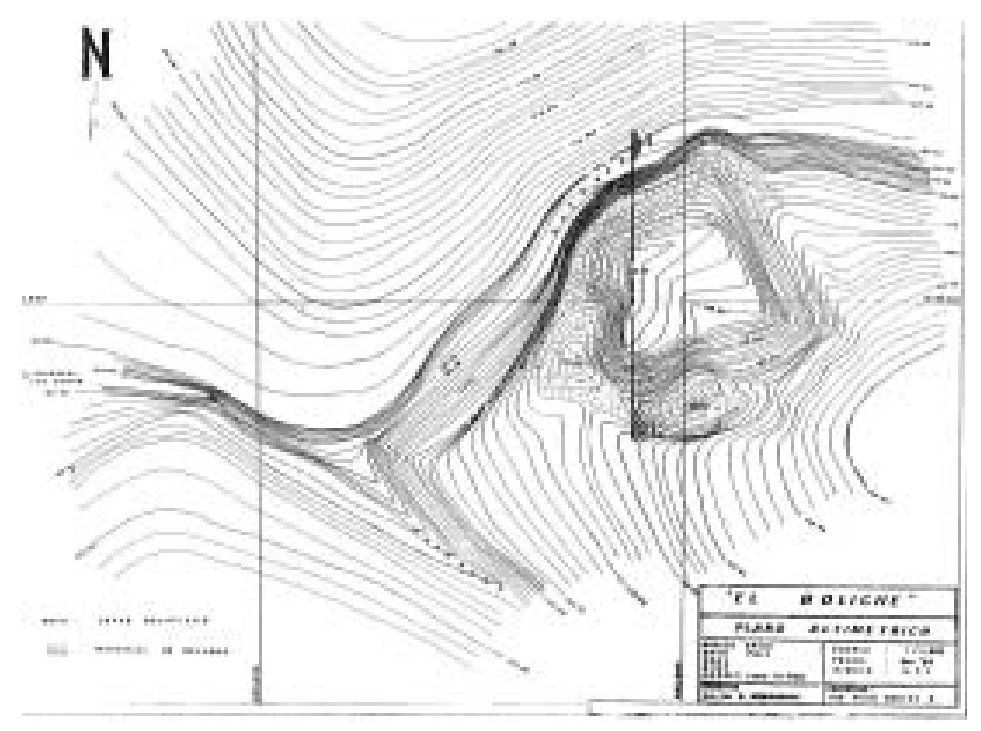

Fig. 16 - Reservorio el Boliche: plano.

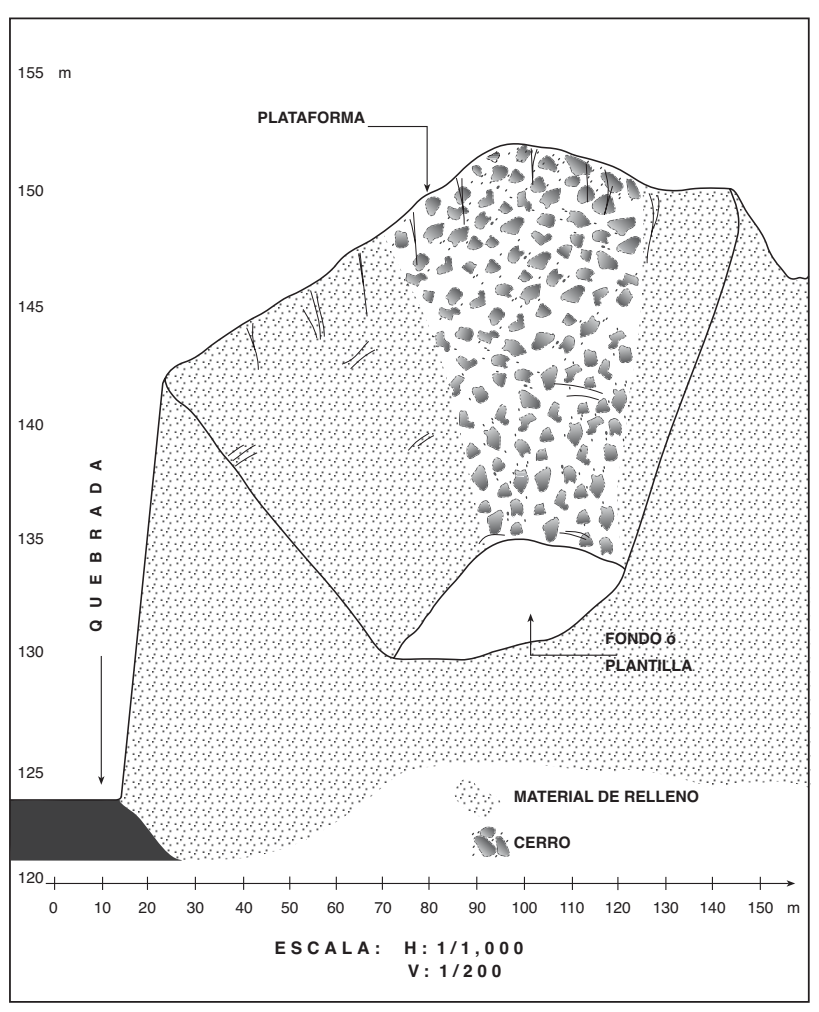

Fig. 17 - Reservorio el Boliche: corte. 
forma los muros de contención del reservorio. En los taludes internos del Boliche se puede apreciar aún la presencia de piedra laja, lo que hace presumir el revestimiento de estas paredes para evitar las pérdidas de agua por efecto de filtración.

En lo que respecta a la alimentación de este reservorio, y por la cantidad de agua almacenada es posible pensar que la fuente es la quebrada que baja por el lado sur y pasa sobre la plataforma del reservorio. Ubicamos en esta quebrada vestigios del cauce de un canal que conduce las aguas hasta el Boliche y cuyo trazo permitiría una velocidad adecuada para minimizar los efectos de la erosión en el momento de caer al fondo de la estructura. Este reservorio sigue almacenando aguas en tiempos de lluvias, sirviendo hoy de bebedero para las cabras en los años secos.

Tomando en cuenta el uso racional que se da al agua, fácilmente bien podría haberse conducido entre 15 y 20 hectáreas de cultivos. De hecho, al pie del Boliche se extiende una llanura artificial que más o menos posee esta extensión, y por los restos de infraestructura en esta área, cabe la posibilidad que haya sido utilizado para cultivarla con el agua almacenada en el reservorio en época de lluvia. Contando con las lluvias y luego con las aguas acumuladas, se podían mantener cultivos permanentes (fig. 18).

Hasta ahora no es posible saber cuándo se construyó el Boliche. Los sitios cercanos establecidos a lo largo de la Quebrada de Las Damas presentan cerámica Sicán, Chimú, Inca y Colonial muy temprana. Pensamos que esta obra podría datar del inicio

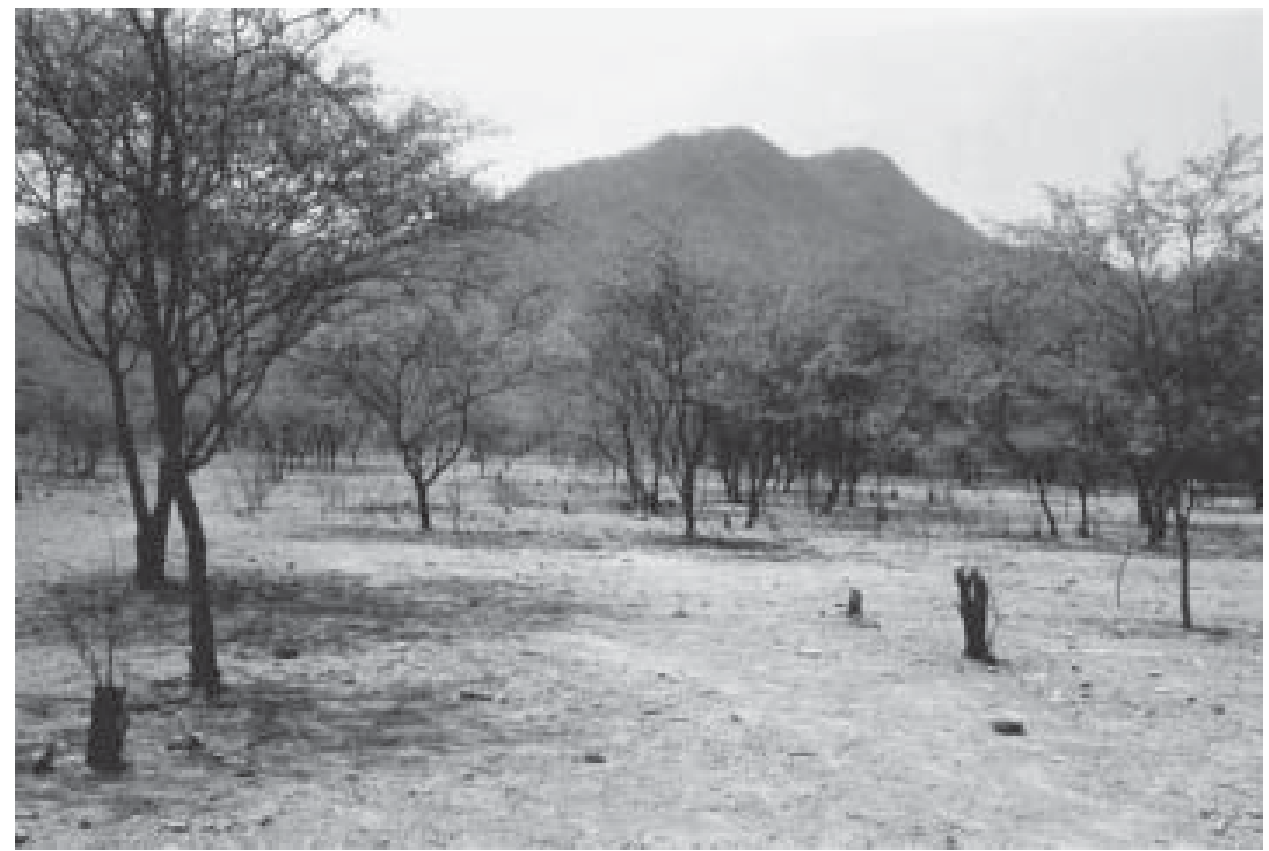

Fig. 18 - La pampa asociada al Boliche hacia la quebrada de las Damas. 
de primer milenio de nuestra era, pero también podría haberse construido para aprovechar las abundantes lluvias a fines del Periodo Intermedio Tardío. Nuestra contribución queda por ahora en haber rescatado este reservorio del olvido e indicado que, considerado el volumen de tierras removidas, los instrumentos de cobre arsenical deben de haber facilitado y acelerado su construcción.

\section{Las andenerías}

Los andenes son superficies de cultivo niveladas en las pendientes con muros de contención de piedras. Pueden tener una capa de cascajo debajo, o dentro, o detrás del muro, para facilitar el drenaje en años de fuertes lluvias así como la oxigenación de la tierra. Con las andenerías se buscaba conservar el suelo agrícola existente evitando el deslizamiento de la tierra, mejorarlo abonándolo y sembrándolo cuando se anuncian las lluvias.

En el Alto Piura, entre 900 y 1100 d.C., se acondicionan las partes bajas de laderas, las faldas de los cerros. Se pueden observar andenerías en el cerro Vicús asociadas con cerámica Sicán Medio, así como en los cerros situados entre Monte de los Padres y Piura la Vieja, también asociadas a sitios con cerámica del mismo período (figs. 19-20).

Obviamente los instrumentos de cobre arsenical deben haber reducido considerablemente el trabajo de acondicionamiento de las laderas para una agricultura permanente de secano, que requiere, vale la repetición, remoción de grandes volúmenes de tierra, excavaciones de zanjas, extracción de piedras, corte de raíces, así como cada año barbecho y siembra.

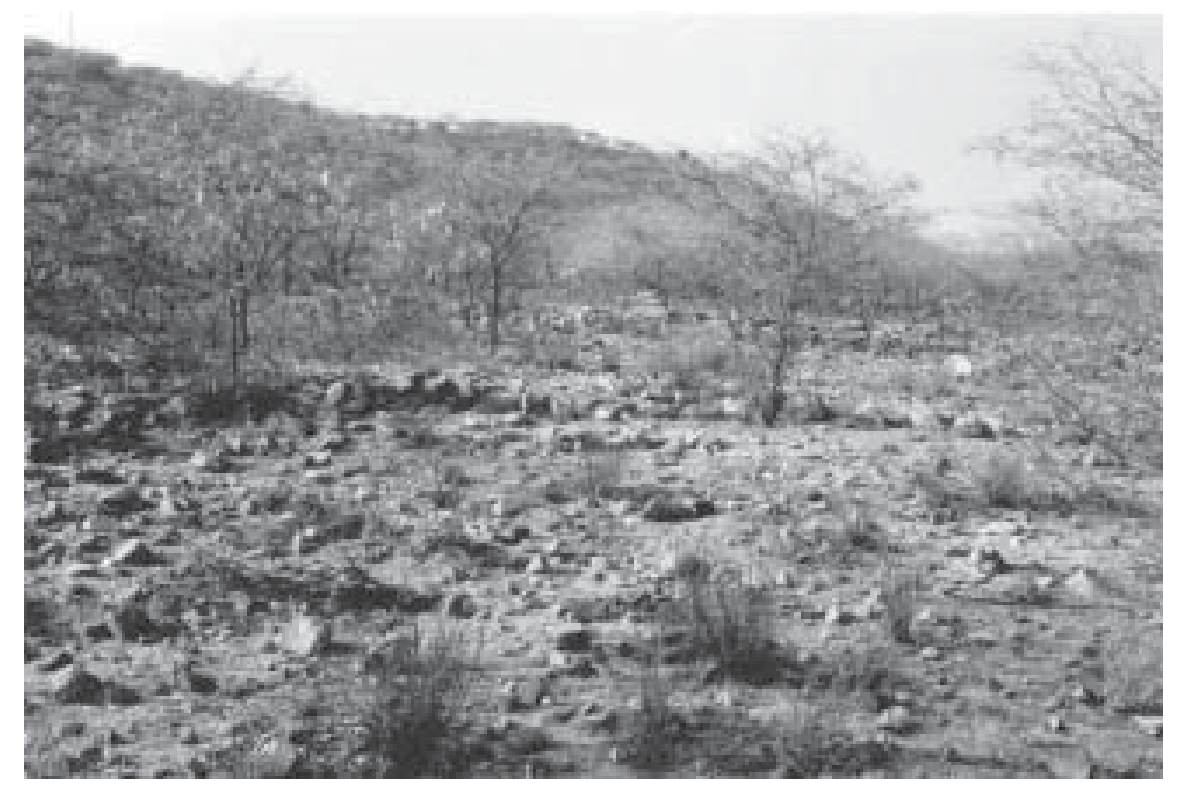

Fig. 19 - Andenerías por la Bocana cerca de Piura la Vieja. 


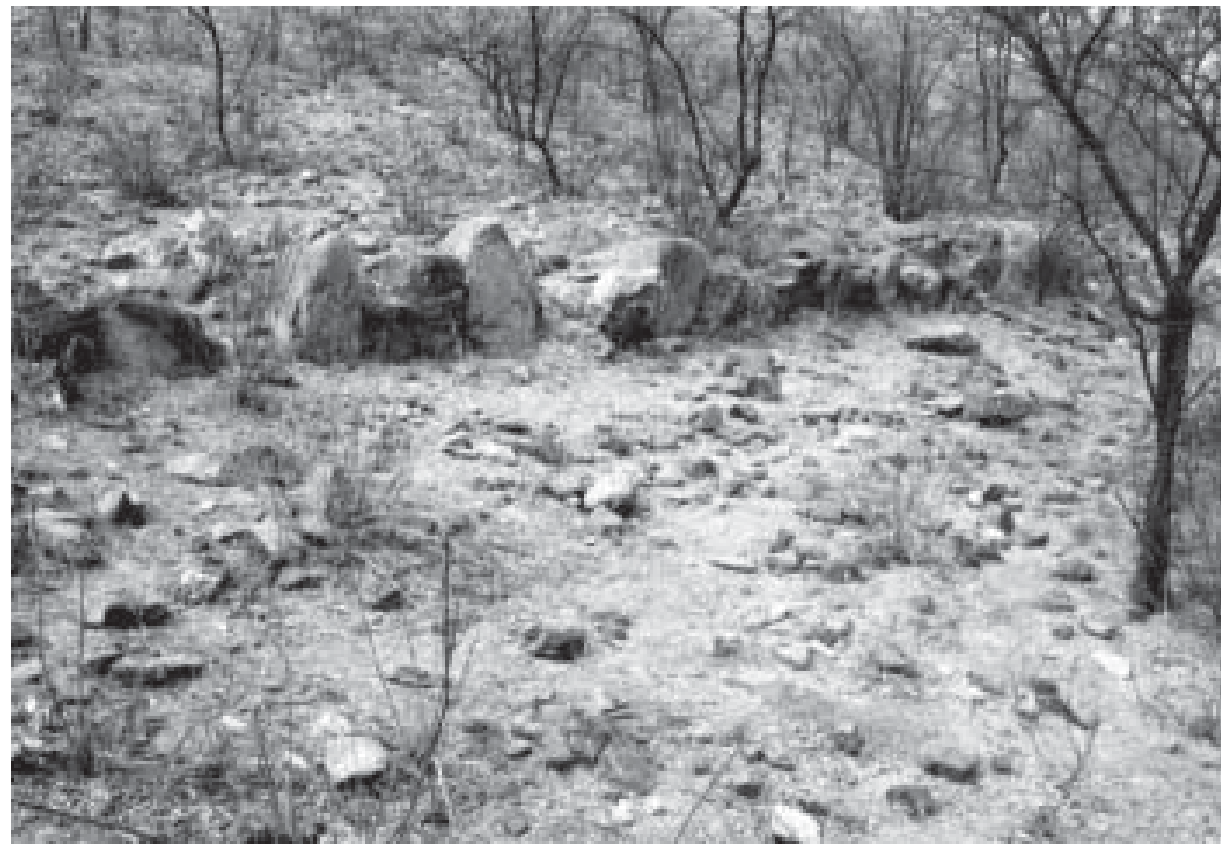

Fig. 20 - Anden cerca de Linderos de Vicús.

Las pircas

Se puede observar en el piedemonte del Alto Piura una transformación del paisaje natural relacionada con el manejo de los hatos de camélidos y asociada a sitios con cerámica del Sicán Medio. Son grandes zanjas de las cuales se extraían la tierra y las piedras, material que servía para construir los muros, pircas, que dividen los cerros cercanos. Suponemos que servían de cercos para mantener los rebaños. También para estas obras debían ser muy útiles las puntas y rejas de cobre arsenical.

\section{Las chacras hundidas}

En esta parte baja del valle donde el agua falta durante meses se puede observar las huellas de una producción agrícola muy particular en chacras hundidas. Sabemos, por documentos coloniales inéditos transcritos por Oswaldo Fernández Villegas, que existían en las cercanías de Narigualá y de la Legua, tierras que producían a lo largo del año y por el uso de las cuales se disputaban caciques e indios tributarios (Fernández Villegas, 1991).

Una chacra hundida muy bien conservada se puede observar a más de $50 \mathrm{~km}$ del mar, en lo que fue la hacienda de Coscomba, en el Parque Ecológico Municipal Kurt Beer, de Piura. Se extiende sobre unas 150 hectáreas y ha sido excavada a una profundidad de unos dos a tres metros. La cerámica observada en los sitos ubicados en su entorno no atestigua ocupación anterior al inicio del Período Intermedio Tardío (Hocquenghem et al., 1995) (figs. 21,22). Esta notable remoción de tierras como las que 


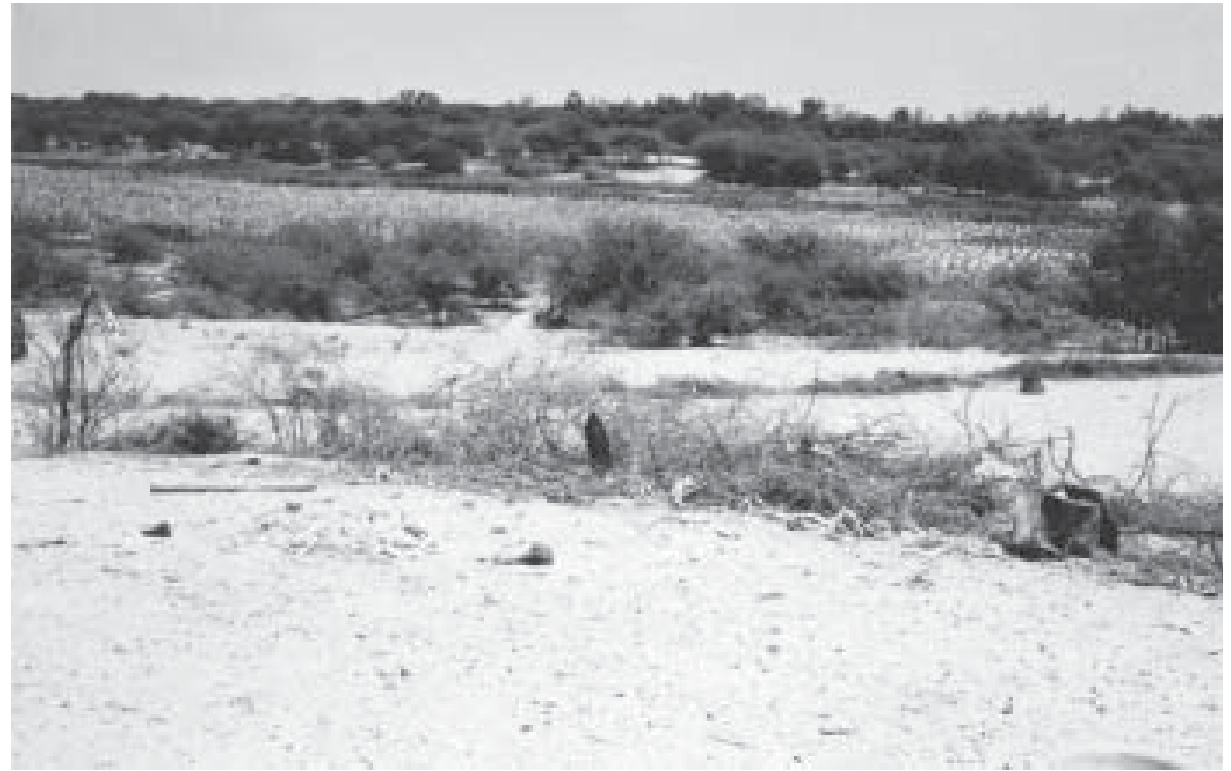

Fig. 21 - La chacra hundida de Coscomba cerca de la ciudad de Piura.

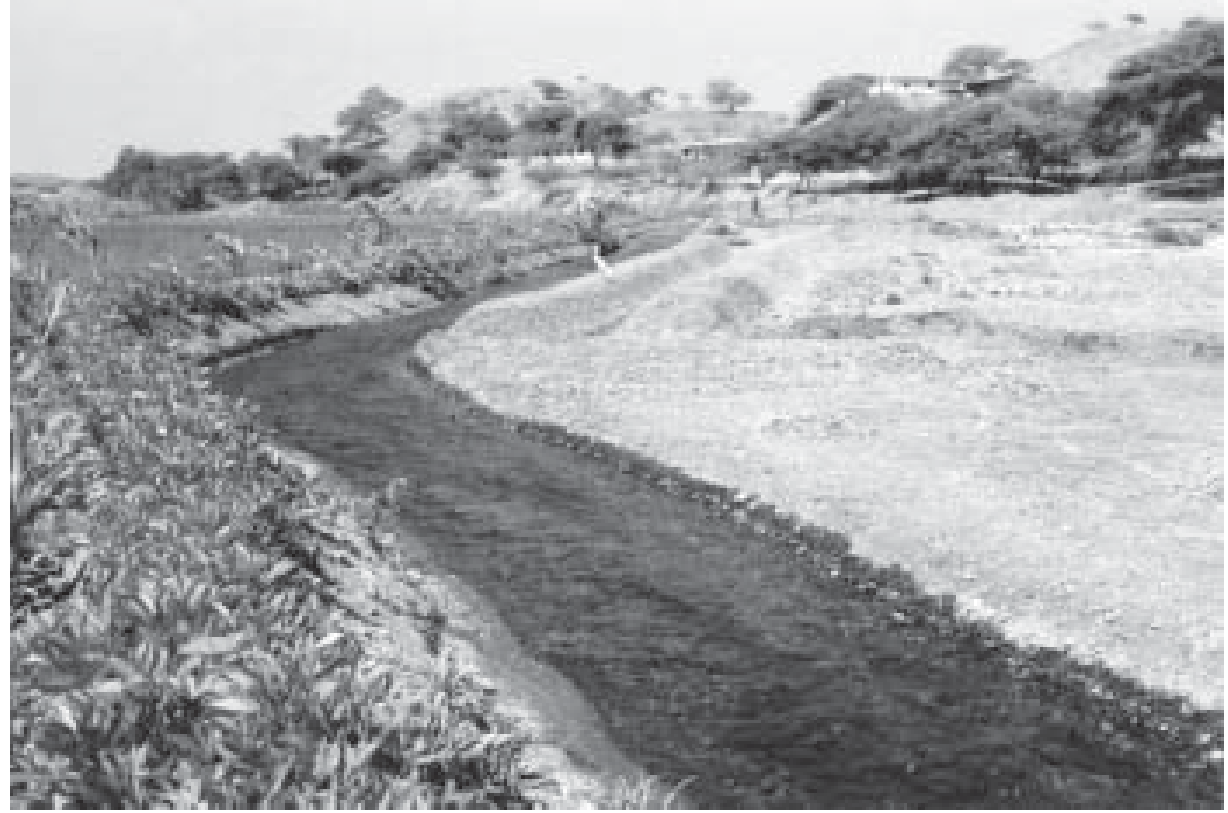

Fig. 22 - Acondicionamiento de suelos agrícolas en el lecho de la quebrada de Jaguey Negro. 
implican la creación de otras chacras hundidas en la margen izquierda del río, también debe haber sido lograda en base a las herramientas de cobre arsenical.

En el Bajo Piura se deben haber extendido, en la medida de lo posible, los canales de las dos márgenes del río que permitían repartir las aguas cuando llegaban, pero la moderna red de irrigación borró las huellas del sistema de riego prehispánico, que solo se utilizaba durante unos cuatro meses por año.

\section{1. 2. En el valle del Chira}

En la margen derecha del valle del río Chira hay un canal prehispánico que fue en parte rehabilitado a comienzos de este siglo. Su toma se sitúa abajo de lo que es hoy el reservorio de Poechos, donde hay evidencias de cerámica Sicán. Pasaba por Marcavelica y pensamos que regaba el tablazo hasta la altura de Monte Lima, un sitio que queda por estudiar que podría datar de la fase Sicán Medio, que se amplia durante la fase Sicán Tardío y que tiene ocupación Chimú e Inca.

\section{1. 3. En el valle del Tumbes}

El canal de irrigación que observamos en la margen izquierda del valle del río Tumbes, asociado a cerámica Sicán, se debe haber construido a inicios del primer milenio de nuestra era. Su toma se sitúa a la salida del cañón del Tigre. Lo vimos pasar, antes de su destrucción en 1993 a raíz de la construcción de un moderno canal, por El Oidor y, desde allí, llegar al pie de Corrales. Existen referencias de fines del siglo XIX y comienzos del siglo XX en cuanto a restos de un canal en la margen derecha del río que deben datar de la misma época. No hemos podido hasta ahora recorrer sistemáticamente la margen derecha del río Tumbes. Nos falta además explorar el valle del río Zarumilla.

\section{1. 4. En los cerros Amotape}

Las andenerías y el acondicionamiento de suelos agrícolas en los lechos de las quebradas

Siguiendo el camino prehispánico de la costa, entre Poechos y Tumbes, en los cerros Amotape hoy cubiertos por un espeso bosque seco, pudimos observar las huellas de una densa población así como de andenerías en los cerros donde, con las lluvias se podía sembrar maíz.

Actualmente en la quebrada de Jaguey Negro los agricultores siembran con las lluvias en los temporales de las alturas y mantienen una agricultura de decrecientes acondicionando suelos aptos a la agricultura en los anchos lechos pedregosos de las quebradas, con barretones, barretas, barretillas y puntas. Lo hacen sacando, después de las fuertes lluvias que caen cada tres o cuatro años, las rocas y las raíces traídas por las avenidas. Bajando tierra de los cerros para depositarla sobre las piedras del cauce, abonándola con guano animal, armando camellones y manejando, entre estos, el agua que sigue corriendo en el centro del lecho. En estas chacras se puede cosechar todo el año, y todos los años, hasta que fuertes aguaceros provoquen grandes crecidas que se 
lleven los cercos, los sembríos, las tierras. Pasada la temporada de lluvias se vuelven a armar las chacras. Es una agricultura de decreciente de alto costo en mano de obra, pero también de alto rendimiento (figs. 22, 23). Considerando la densidad de sitios arqueológicos, con evidencia de cerámica Sicán, Chimú e Inca, a lo largo de las quebradas de los cerros Amotape, pensamos que, a partir de 900 d.C. y hasta la llegada de Pizarro y sus huestes, además de los cultivos de temporal en las andenerías se sembraba y cosechaba a lo largo del año en chacras acondicionadas en los lechos de las quebradas.

Una vez más, pensamos que son los instrumentos de cobre arsenical los que facilitaron la construcción de andenerías y de chacras en los lechos de las quebradas de los cerros Amotape.

\section{2. El crecimiento demográfico y tributario}

Estos ejemplos de construcción de infraestructuras de producción, establecimiento, mantenimiento y aprovechamiento de sistemas de irrigación, de andenerías, de pircas, de chacras hundidas y acondicionamiento de las chacras en los lechos de las quebradas, en los valles del Piura, Chira y Tumbes y en los cerros Amotape, bastan para indicar la relación entre la producción de cobre arsenical y la ampliación de la frontera agrícola en los valles del extremo norte andino (fig. 24).

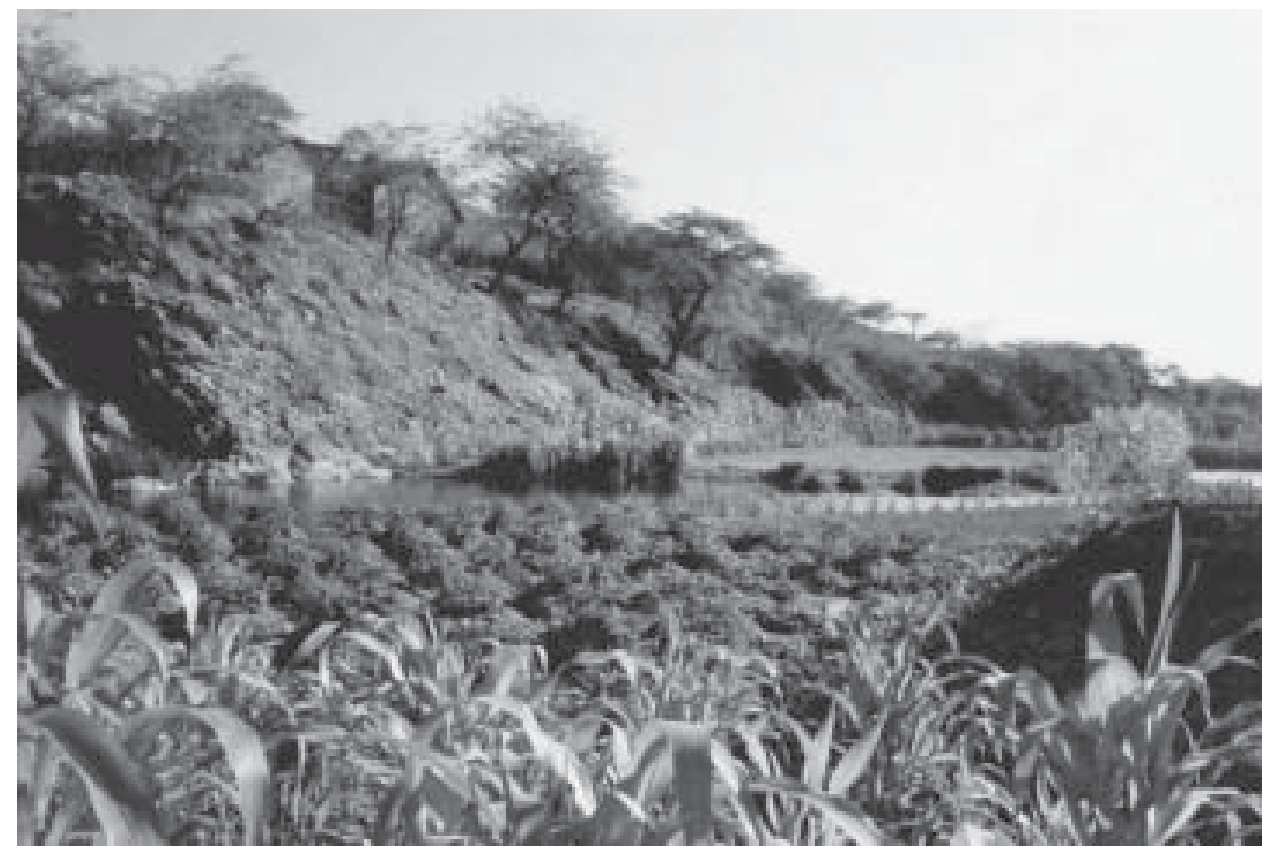

Fig. 23 - Chacra acondicionada en el lecho de la quebrada de Jaguey Negro. 

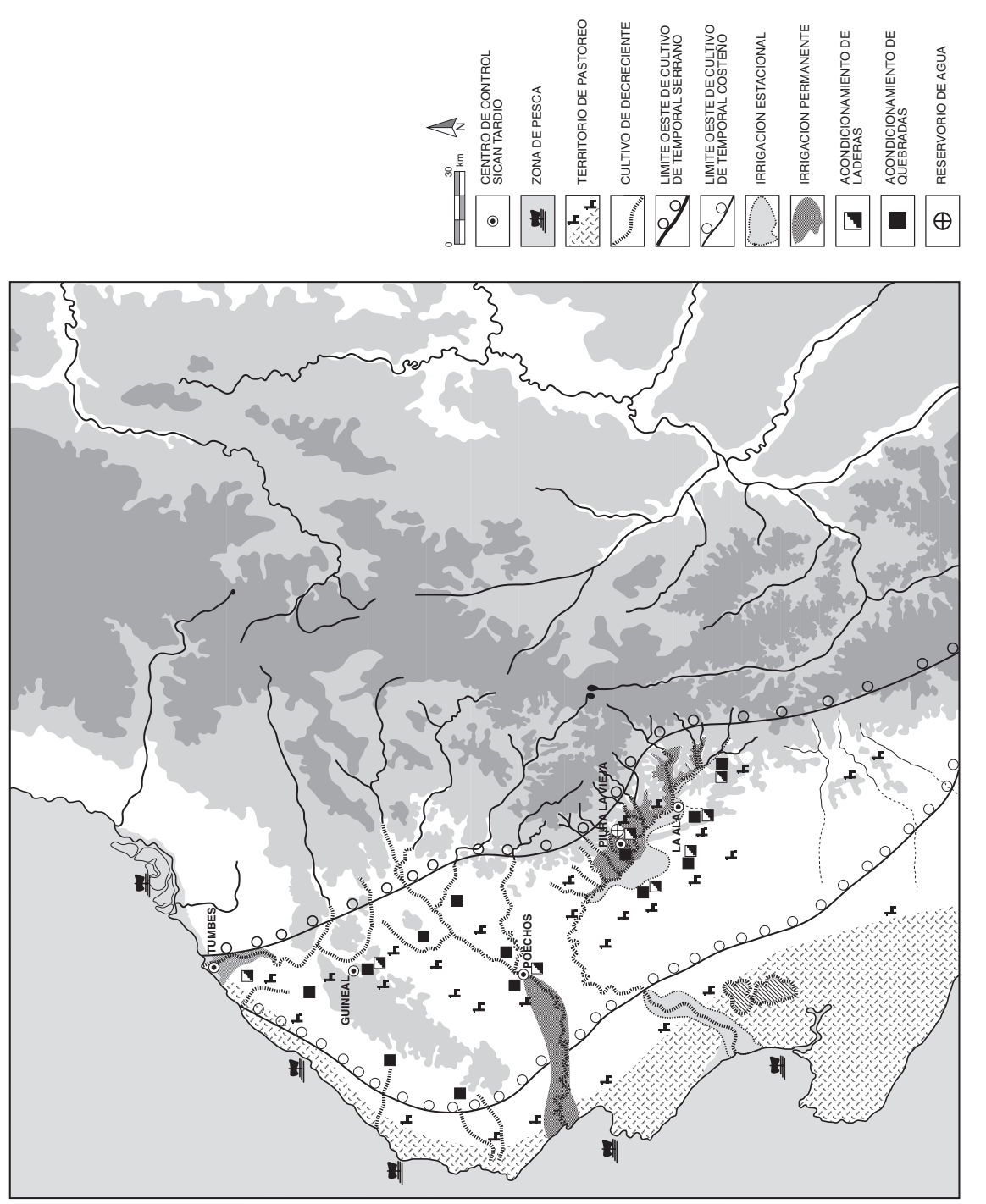

是 
El desarrollo territorial a gran escala que lograron los sicán medio con las herramientas de cobre arsenical, demandaba mano de obra y permitía a la vez un rápido crecimiento poblacional, asegurando un considerable aumento de la recaudación tributaria. Los beneficios del tributo, en trabajo y productos se debían, en parte, invertir en la extensión y reorganización de las vías de comunicación así como en el aumento del volumen, la calidad y el valor de los productos exóticos que transitaban longitudinalmente entre los Andes Centrales, los Andes Septentrionales y Mesoamérica y transversalmente entre las vertientes pacíficas y amazónicas.

\section{LAEXTENSIÓNDELA REDDEINTERCAMBIOS ALARGADISTANCIA Y LA ACUMULACIÓN DE LOS BENEFICIOS}

\section{1. Los intercambios}

\section{1. 1. Las rutas}

Los instrumentos de cobre arsenical deben haber permitido no solo la construcción de las obras de arte necesarias para ampliar la frontera agrícola en los valles del Piura, Chira y Tumbes sino, a la par, la extensión y el mantenimiento de los caminos por los cuales hombres y bienes circulaban en estos valles. En trabajos anteriores hemos tratado de indicar el interés estratégico para los sicán medio de la apertura y el control del camino entre el valle del Chira y el de Tumbes. A partir del puerto de Tumbes los sicán medio lograron controlar directamente los intercambios de productos que entraban y salían por la ruta marítima en las balsas y bordeaban el litoral entre el suroeste ecuatoriano y el occidente mexicano (Hocquenghem, 1989; 1993; 1994; 1995; 1998: 128-134; 1999) (fig. 25).

Además los sicán medio, desde los valles del Alto Piura y el Alto Chira, seguían controlando las entradas y salidas de los productos que circulaban por las serranías entre Piura, Loja, Azuay y más al norte hasta Colombia.

Estamos ahora realizando investigaciones sobre el antiguo sistema de comunicación entre las vertientes pacíficas y amazónicas en el extremo norte peruano y pensamos que los sicán medio extendieron los caminos y controlaron circulación y los intercambios de productos entre el valle de Lambayeque, Olmos y, por la abra de Porculla, los valles de los ríos Chamaya y Alto Marañón y los de sus afluentes, en la margen derecha, Huancabamba, Guayllabamba y Chinchipe y en la margen derecha Chotano y Utcubamba.

\section{1. 2. Los flujos medidos en Spondylus}

Los dos productos más valiosos que transitaban entre los Andes Centrales, los Andes Septentrionales y Mesoamérica, eran metales y conchas Spondylus. Estas últimas no se recolectaban en las aguas frías del litoral centro andino, pero eran el manjar preferido de los ancestros míticos y las ofrendas más valiosas que se podían presentar a los antepasados, por lo tanto tenían en los Andes Centrales más valor que el oro (Murra, 1975; Marcos, 1985; 1995; Hocquenghem, 1987: 79-85, Figs. 33-34; 1993; 1995a; 1999; Taylor, 1987, cap. 23: 347). 


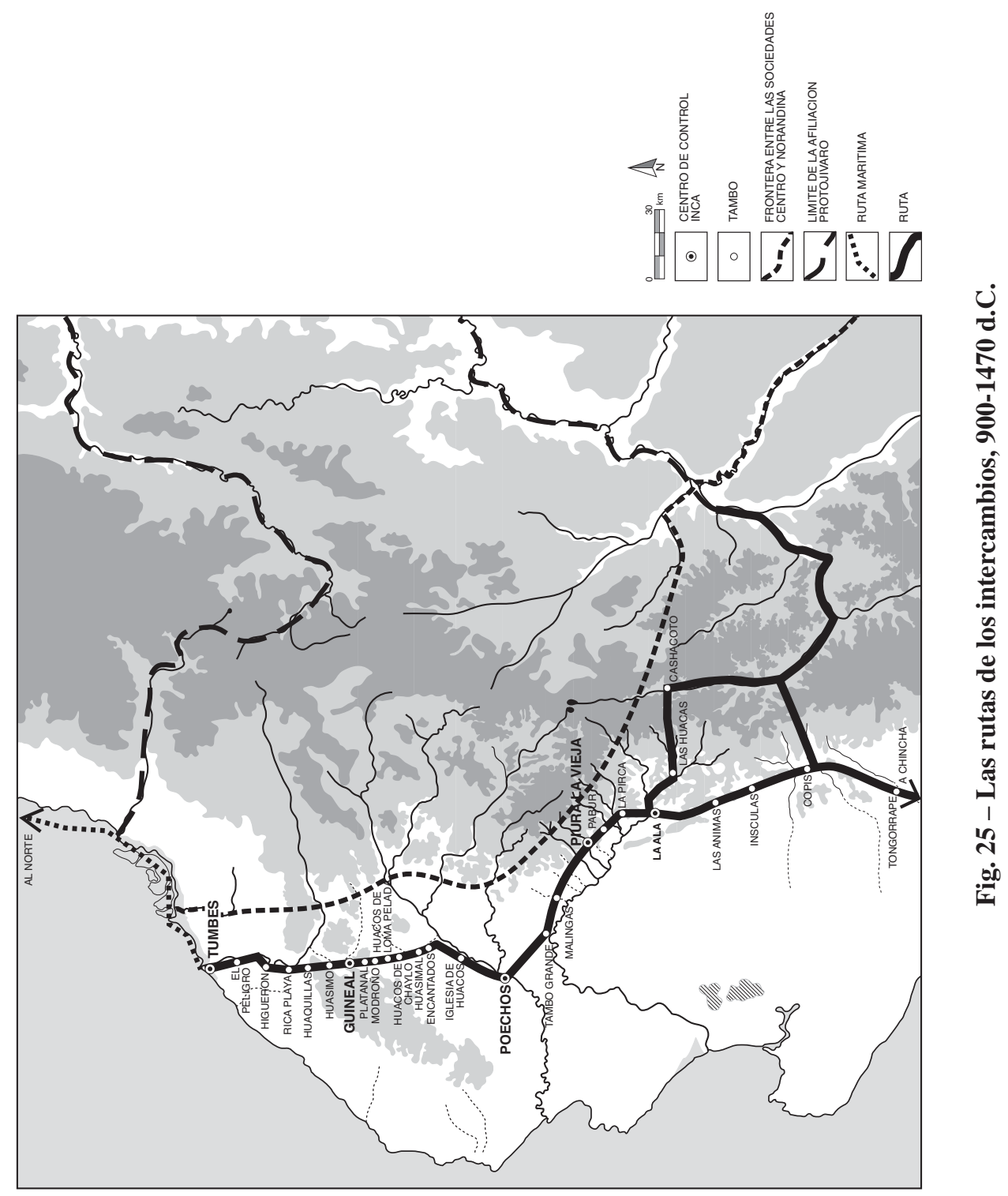


Los malacólogos conocen diferentes especies de Spondylus (Alamo \& Valdivieso, 1987; Skoglund \& Mulliner, 1996; Bussy, 1996-1997; Béarez, 1996; Mogollón Avila, 1999), pero los arqueólogos distinguen dos (fig. 26):

- El calcifer de grandes y espesas conchas de más de $20 \mathrm{~cm}$, con bordes de colores que varían de morado a anaranjado, se recolectan actualmente en las costas tumbesinas y manabitas así como más al norte hasta el golfo de California.

- El princeps, de conchas de menos tamaño, pero de bellas formas ovaladas con bordes de color rojo intenso, se recolectan hoy ante todo frente a las costas del occidente mexicano.

Si bien las dos especies aparecen desde épocas remotas en los sitios de los Andes Centrales, hasta inicios del Período Intermedio Tardío los hallazgos de ofrendas de conchas princeps enteras, son escasos. En los rituales se utilizaban más frecuentemente las valvas de Spondylus calcifer jóvenes, del tamaño de las de princeps adultos, relativamente finas y de formas ovaladas. Las chaquiras, placas y pequeños ornamentos, se elaboraban ante todo a partir de las valvas de Spondylus calcifer adulto. En un sitio Moche Temprano del Alto Piura, Cerro Hualtacal, relacionado sin duda con las celebraciones de ritos tendientes a obtener agua cuando se presentaban años secos, pudimos observar grandes cantidades de valvas de Spondylus calcifer jóvenes entre las cuales no vimos princeps.

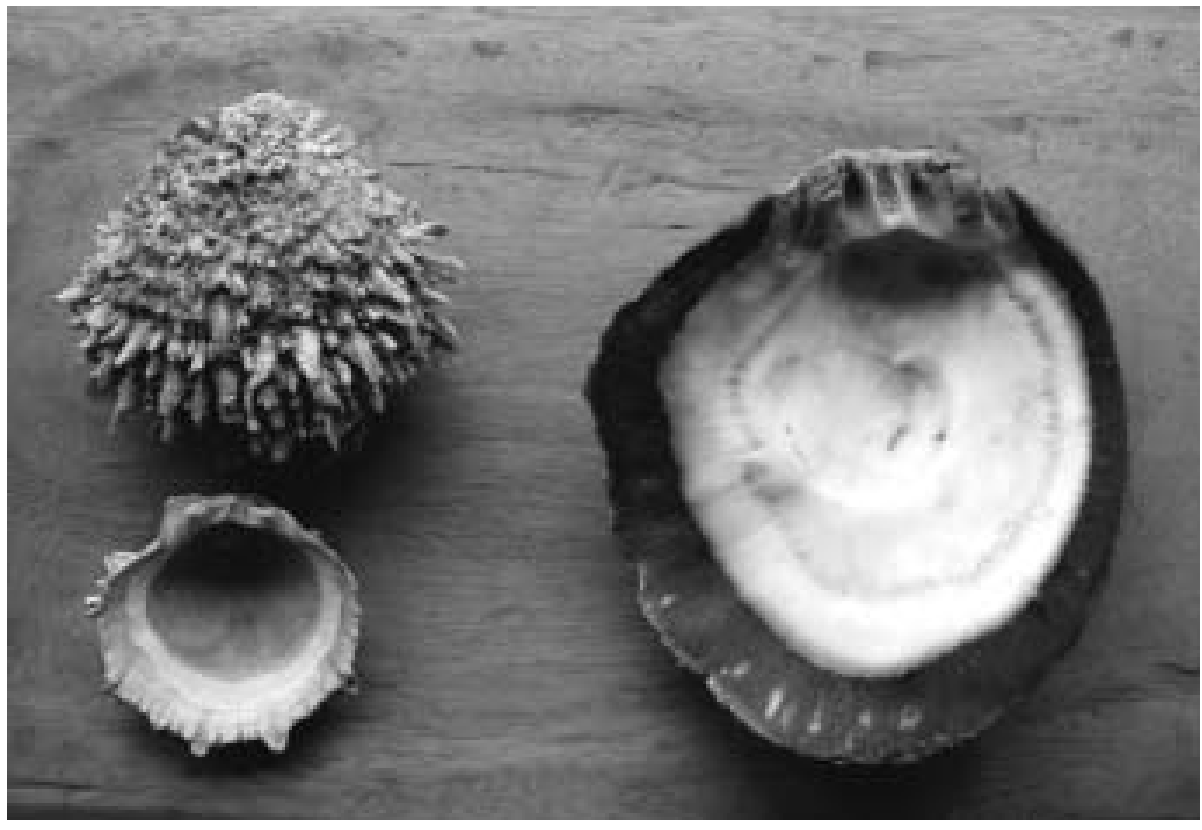

Fig. 26 - Spondylus princeps moderno y valva prehispánica que ha perdido su intenso color, recogida en un pozo de huaquero en La Ala; Spondylus calcifer moderno. 
A partir de 900 d.C. esta situación cambia drásticamente. En los sitios Sicán Medio del Alto Piura abundan las ofrendas de Spondylus princeps enteros o de valvas $\mathrm{y}$, alrededor de los pozos de huaqueros, se pueden observar algunas de tamaño mediano. Sin embargo no hay ofrendas de conchas de Spondylus calcifer. Si bien se continuaba elaborando a partir de calcifer chaquiras, placas y otros ornamentos, estos objetos se producen también a partir de princeps.

Shimada nota que en la tumba este de Huaca Loro de Sicán:

"La cantidad de conchas enteras y de cuentas de Spondylus en la tumba de la Huaca Loro es hasta la fecha la más grande encontrada en el Perú. El inusual gran tamaño de las conchas enteras sugiere que éstas fueron cuidadosamente seleccionadas para esta tumba. La concha también fue usada en una escala sin precedentes como ofrenda dentro de cajas cuadrangulares que sostenían la base de las columnas ubicadas en la cima de los templos Sicán Medio. Las explícitas representaciones de 'buzos' recolectando mullu en el arte Sicán (Cordy-Collins 1990, Shimada 1990a, 1992), así como la presencia de cerámica Sicán en el principal centro de recolección en la isla de la Plata en las costas ecuatorianas, sugiere que el Estado Sicán Medio bien pudo haber controlado su obtención y posterior distribución hacia el sur". (Shimada, 1995: 157-158).

Como las conchas Spondylus son la contraparte del cobre arsenical, esta inusual cantidad y calidad de Spondylus princeps acumulada en una tumba Sicán Medio se debe haber obtenido por un volumen de valor correspondiente de este metal. Lo da una medida del incremento del caudal de los intercambios a partir de 900 y hasta 1100 d.C.

Ahora bien, para facilitar los intercambios entre materiales y objetos diversos que representaban diferentes inversiones en mano de obra y valores de uso, aparecen a partir de 900 d.C. monedas primitivas de cobre arsenical y pensamos de concha Spondylus princeps, los dos productos más valiosos que circulaban entre las sociedades de los Andes Centrales, norteños y mesoamericanas.

\section{1. 3. Las monedas primitivas}

Los "naipes" de cobre arsenical

Entre los instrumentos y ornamentos de cobre arsenical que aparecen en el material funerario de las tumbas de Lambayeque, Piura, Tumbes, el Oro y Guayas figuran "naipes" en forma de I y "hachas monedas" en forma de T. Los "naipes" se elaboraban a partir de láminas martilladas de cobre arsenical con 3,5 \% a 4,5\% de arsénico aproximadamente, delineando y cortando piezas que son resistentes a pesar de ser delgadas. Se encuentran en las tumbas (fig. 27)

"[...] en atados — de 5 a 13 naipes, dependiendo de su tamaño- amarados con cuerdas de fibra vegetal. La cantidad de naipes encontrados en los enterramientos se correlaciona con la posible posición social del muerto”. (Shimada, 1995: 158).

"[...] han sido hechos a mano, presentan ciertas variaciones; pero como conjunto parecen haber sido igualados en cuanto a tamaño y forma. De este modo se ha identificado cinco tamaños distintos, siendo el más pequeño de $2,8 \mathrm{~cm}$ de ancho 


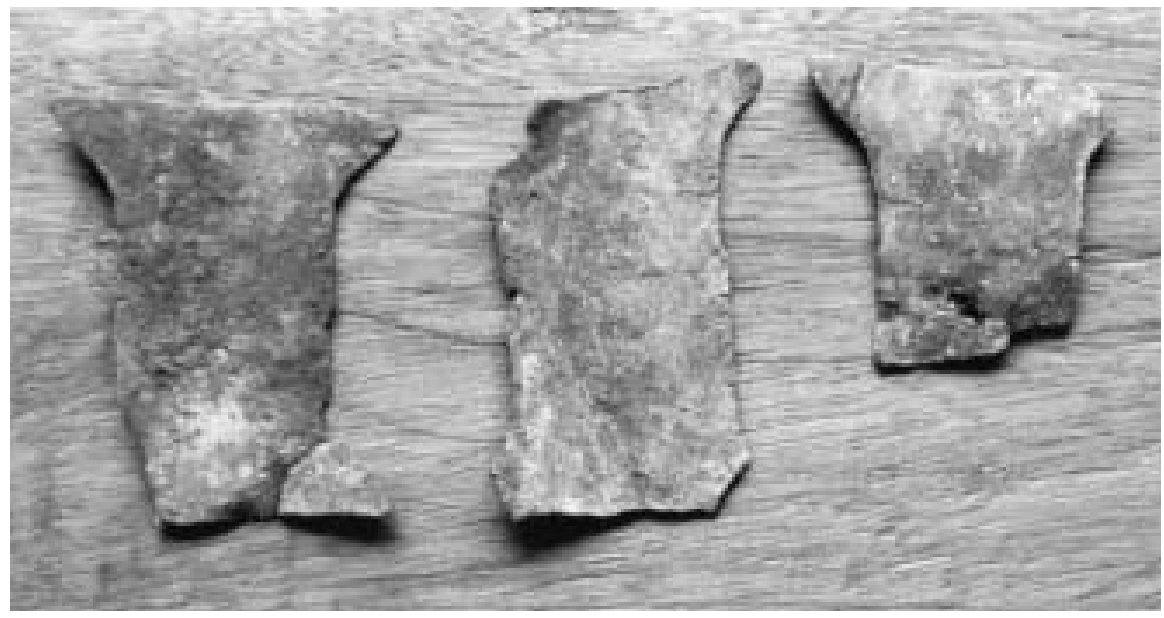

Fig. 27 - "Naipes” Sicán del Alto Piura.

por cuatro $\mathrm{cm}$ de largo, y el más grande de aproximadamente $8,5 \mathrm{~cm}$ por lado. El grosor de la lámina de metal se incrementa más o menos en proporción al tamaño y forma. Aunque creemos que los naipes de cada tamaño fueron uniformados en cuanto al peso, la corrosión de los especimenes excavados hace difícil clarificar este punto." (Shimada, 1995: 26).

Tomando en cuenta el tamaño, la forma y el peso similar, así como el material uniforme de los "naipes" se puede suponer que tenían un valor de intercambio definido (Shimada, 1985a: 358, 376, 384, 386, 390-391, 392; 1985b; 1987; 1995: 158-159). Estos objetos durables podían atesorarse o cambiarse para adquirir bienes de igual valor $\mathrm{y}$, en caso de necesidad, fundirse rápidamente para elaborar instrumentos u ornamentos necesarios o deseados. Hasta la fecha todos los que han sido recuperados por los arqueólogos provienen de tumbas Sicán Medio del área de Lambayeque, Piura y Tumbes y pueden existir algunos ejemplares falsos (Wassén, 1972; Pedersen, 1976; Holster et al., 1990: 66).

La presencia de numerosos "naipes" en las tumbas en las cuales se depositaron grandes cantidades de cobre arsenical, no sorprende entonces y parece fundada:

"La hipótesis de que la entidad política Sicán verdaderamente produjo los naipes y los usó para adquirir bienes exóticos de tierras distantes, bien puede explicar gran parte del poder político y la riqueza económica inferidos a partir de las construcciones monumentales y los bienes funerarios huaqueados." (Shimada, 1995: 26).

Ahora bien se deben mencionar otras piezas de cobre arsenical que aparecen en Ecuador y México al inicio del primer milenio de nuestra era y que si bien variaban en cuanto a formas podían haber cumplido una función similar a los "naipes". Son las "hachas monedas" del Período de Integración encontradas en tumbas del área cultural 
Huancavilca-Manteña y Milagro-Quevedo de la costa sur ecuatoriana (Estrada, 1957; 1962; Holm; 1966-1967; 1975; 1981; 1982; Mayer, 1992) y las que provienen del occidente de México (Easby et al., 1967; Bray, 1985; Holser, 1986a; 1986b; 1990; 1997a; 1997b; 1998; Hosler et al., 1990).

En el artículo de Hosler et al. de 1990, se puede encontrar un minucioso estudio de las "hachas monedas" mexicanas y ecuatorianas así como de los "naipes" sicanes, con descripciones e interpretaciones. Se constata que estos objetos aparecen atesorados en tumbas y cada uno muy relacionado con un territorio específico. Por lo tanto si circularon, fueron en sus áreas de producción. Es interesante notar que en Tumbes donde los balseros intercambiaban los productos norteños con los sureños que traían los sicán medio se encuentran tanto "hachas monedas" como "naipes".

Contando con los abundantes y muy precisos datos sobre la producción de cobre arsenical Sicán Medio de Lambayeque y las escasas informaciones sobre este tema en el sur del Ecuador y oeste de México, se tiende a pensar que la tecnología del cobre arsenical se inicia en Lambayeque, se transmite por vía marítima a lo largo de la costa pacífica, se asimila rápidamente y se adapta a las necesidades locales en los Andes Centrales y Mesoamérica. Esto explicaría la aparición casi simultánea de diferentes formas de las monedas primitivas, desde Lambayeque hasta el occidente mexicano.

\section{Los Spondylus princeps}

Ahora bien, al igual que el cobre arsenical las conchas Spondylus princeps son materiales durables, con variaciones de tamaños y colores fácilmente sorteables, que por unidades, cortadas en placas similares, o labradas en chaquiras, conservaban un valor de cambio definido (Hocquenghem \& Peña Ruiz, 1994). Pensamos que servían también de primitivas monedas de intercambio y que se atesoraron y cambiaron por otros bienes.

\section{1. 4. El doble monopolio}

Podemos percibir que la producción de cobre arsenical Sicán Medio no solamente facilitaba la ampliación de la frontera agrícola, lo que permitía, es cierto, una mayor recaudación del tributo de los valles más productivos de la costa pacífica, sino ante todo debía ser la base del crecimiento de la economía Sicán Medio. De hecho esta conservó durante casi dos siglos, entre 900 y 1100 d.C., un doble monopolio: el de la producción y distribución del cobre arsenical y el de la redistribución de su contraparte norteña los Spondylus, cuyas entradas marítima y terrestre controlaba a partir del puerto de Tumbes y de los sitios de las partes altas de los valles de los ríos Chira y Piura.

A las sociedades del norte, por medio de los balseros del extremo norte peruano y sur ecuatoriano, los sicán medio debían ofrecer el cobre arsenical y, considerado el alto valor de la aleación, debían recibir en cambio cantidades apreciables de conchas de Spondylus princeps de buena calidad y productos de los Andes Septentrionales y de Mesoamérica.

A las sociedades del sur los sicán medio debían proporcionar igualmente cobre arsenical y además las conchas Spondylus y otros productos norteños a cambio de los 
sureños. Suponemos que trataban con las elites de las teocracias centro andinas de la costa norte y central, en particular de los centros administrativos y ceremoniales, Pacatnamú y Pachacamac, y quizás de la sierra. Sabemos que en Pikillacta, en el valle de Cusco, se encontraron objetos de cobre arsenical similar a los de la costa norte (Lechtman, 1998: 11-12).

\section{2. La acumulación de los beneficios}

Los beneficios de los intercambios se acumulaban en el centro administrativo y ceremonial de Sicán y no extraña entonces su surgimiento y desarrollo rápido, en algo de un siglo, así como la extraordinaria y jamás vista acumulación de bienes de diferentes índoles y orígenes descubiertos en las tumbas de los miembros de la élite Sicán Medio. Basta recordar los tesoros huaqueados en el valle de La Leche y los descubrimientos arqueológicos en la Huaca Loro. Se amontonaban según Shimada (1995: 167-168):

- Por un lado los productos sureños, cinabrio, crisocola o falsas turquesas, sodalitas, turquesas y lapislázuli que abundan en la zona cuprífera del desierto de Atacama, así como quizás plata.

- Por otro lado los productos norteños, conchas Spondylus, esmeraldas colombianas, ámbar que podría ser dominicano o costarricense o sino colombiano, turquesa cuyo origen se debe investigar con más precisión, pero que parece podría ser norteamericana.

- Finalmente, los productos del oriente, entre otros el oro de los ríos amazónicos.

El crecimiento demográfico y tributario debía permitir y requerir a la vez el de un sector administrativo y ceremonial. Busquemos sus huellas en los valles del extremo norte.

\section{EL CRECIMIENTO ADMINISTRATIVO Y CEREMONIAL Y EL INCREMENTO DE PODER DE LA TEOCRACIA SICÁN MEDIO}

\section{1. Los centros administrativos y ceremoniales}

\section{1. 1. En el valle del Piura}

En el Alto Piura el centro administrativo de Laynas, ocupado desde 500-550 d.C., presenta evidencias de cerámica Moche V y luego Sicán, pero surgieron nuevos sitios a partir de 700 d.C. donde no hay indicios de ocupación mochica. Estos sitios crecen, proliferan y se diversifican rápidamente a partir de 900 d.C. La especialización de las diferentes estructuras indica una creciente complejidad del sistema ceremonial y administrativo. Además se percibe una extensión de las zonas de habitación, encima de las tierras irrigadas o asociadas a los andenes, que atestigua un crecimiento de la población. Es cierto, ubicamos los sitios, pero no excavamos y la investigación arqueológica queda por realizarse. Solamente observamos la cerámica en la superficie, las huellas de las actividades de los huaqueros y los impactos de las lluvias torrenciales que exponen partes de las estructuras.

En la margen izquierda del río Pusmalca, que baja de la sierra de Huancabamba, cerca de su confluencia con el río Piura, se ubica el importante centro administrativo y 
ceremonial de Las Huacas y, en la margen izquierda del río, cerca de Laynas, el de La Matanza. Están situados en posiciones estratégicas en relación a los sistemas de irrigación y de comunicación Sicán Medio. Las Huacas controla un camino del valle de Piura a la sierra de Huancabamba, una entrada a los valles amazónicos de los ríos de Chamaya, Marañón, Chinchipe y Utcubamba, y un camino al valle de La Leche así como la gestión de las aguas del Pusmalca que alimentan el río Piura y la parte alta del canal del Alto Piura. La Matanza controla la ruta de la costa que viene del valle de La Leche, pasa por el del Piura hacia los del Chira y del Tumbes, y la parte baja del canal del Alto Piura. En estos dos centros se observan grandes estructuras de adobes que parecen ser construidas por medio de cámaras rellenas de tierra y materiales de demolición. Son rodeadas por diversas plataformas, muchas con tumbas huaqueadas y hay restos de cerámica Sicán Medio.

Numerosos sitios se relacionan con el canal del Alto Piura, se ubican encima de esta obra, a la entrada de canales colectores, de tomas de canales secundarios, del aliviadero de Tongo. Otros son tambos asociados a la red de caminos. Quedan cimientos de piedras y partes de paredes de tabique, madera con barro, que extienden atestiguando la conformación de extensas zonas urbanas, en La Ala y Tongo, y algo menos impactantes en Huaca Nayo, Chanchape, Vicús o Nomala. Lo que queda de estas estructuras atestigua una gran diferenciación funcional. En las faldas de los cerros asociados a las andenerías quedan las huellas de una gran densidad de habitaciones. Una situación similar se observa en toda la margen derecha del río, por La Pirca y en particular a lo largo de la quebrada de Las Damas en torno al sitio de Piura la Vieja (figs. 28, 29).

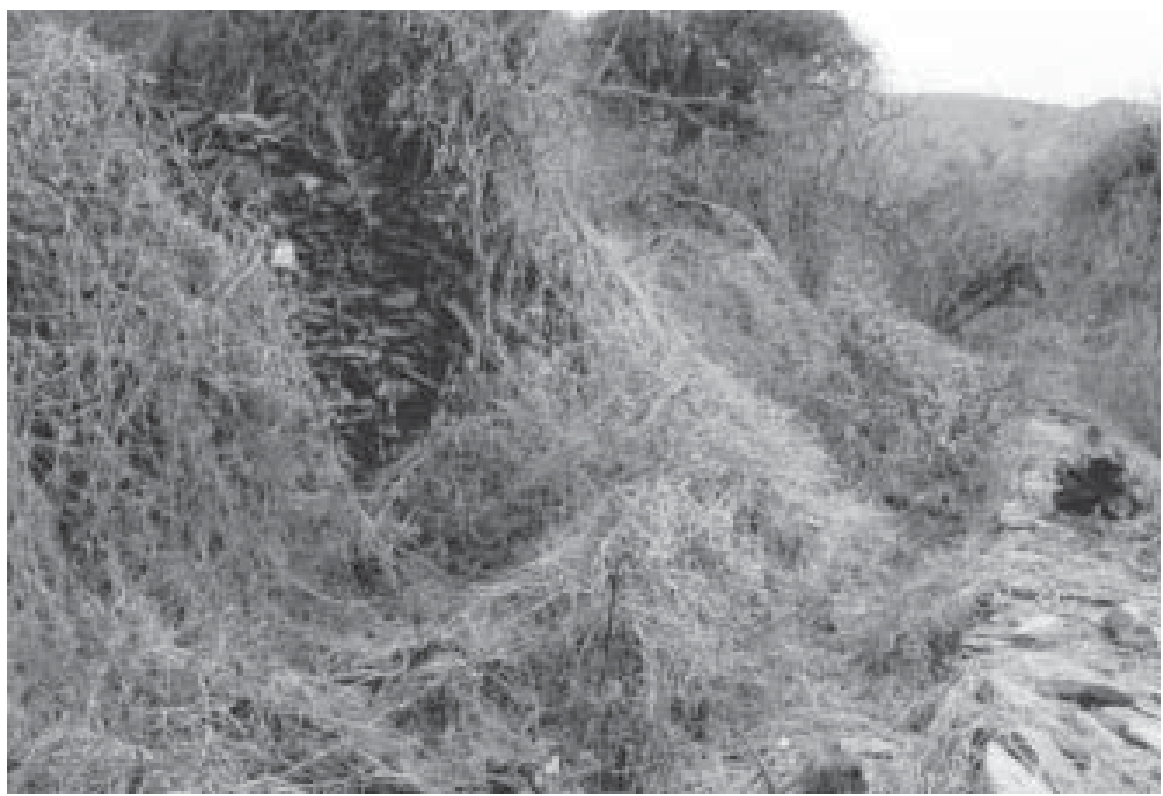

Fig. 28 - Estructuras de la Ala en la margen izquierda del río Piura. 


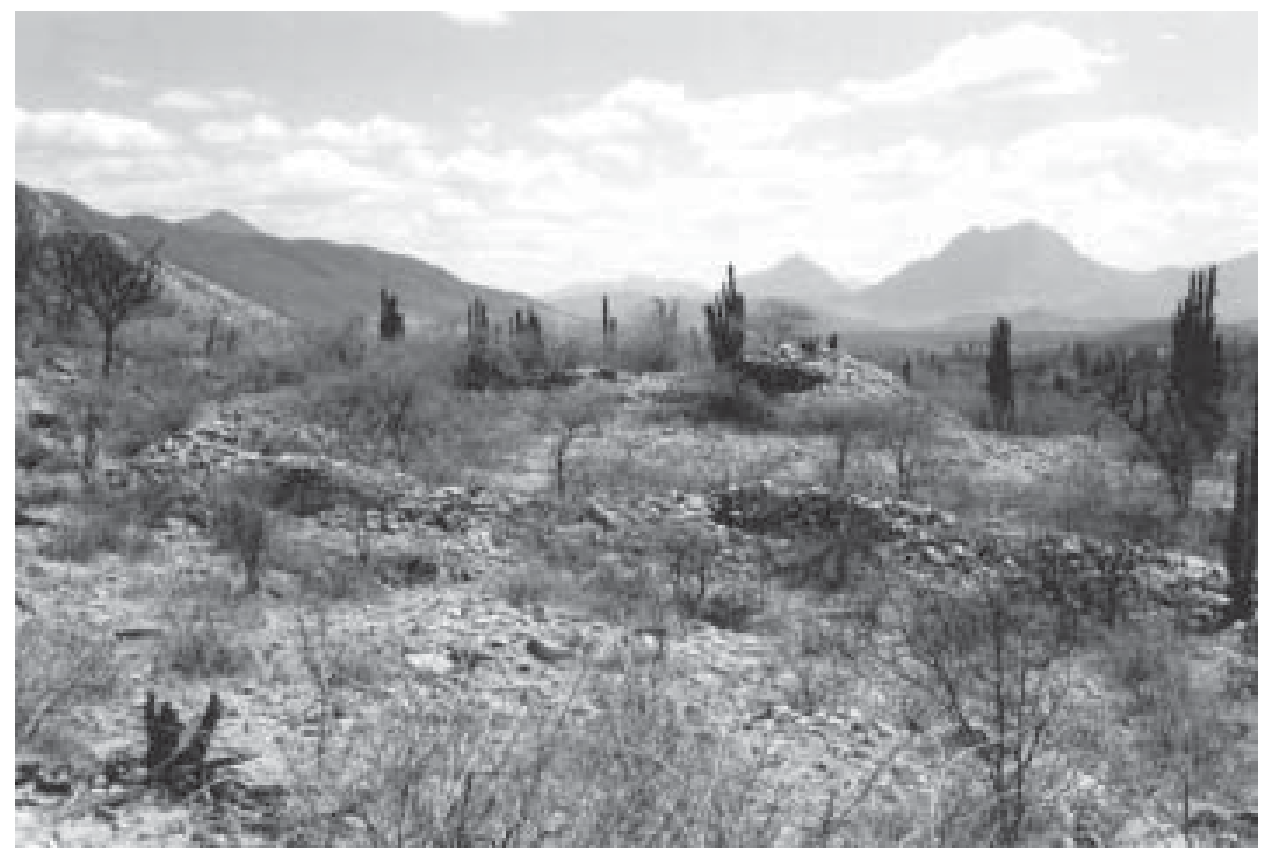

Fig. 29 - Estructuras de La Pirca en la margen derecha del río Piura.

En el Bajo Piura el centro administrativo de Narigualá crece a partir de 900 d.C., pero no logra dimensiones impactantes. La falta de agua en el lecho del río Piura durante la estación seca en los Andes limita seriamente la producción de sus tributarios. Es una desventaja que no puede compensar la utilización permanente de las chacras hundidas, en cuyos alrededores se ubican pequeños sitios con construcciones de adobes y quincha. Esto es el caso en Coscomba.

\section{1. 2. En el valle del Chira}

En la parte alta del valle del Chira los cimientos de numerosas estructuras con muros de tabique son visibles en los alrededores de la toma del canal de la margen derecha, cerca de Poechos, pero la moderna represa ha sumergido los sitios más notables. En la parte baja del valle se desarrolla el gran centro administrativo y ceremonial de Monte Lima, con estructuras de adobes, algunos cónicos, que quedan por investigar y atestiguaran sin duda del esplendor del sitio durante la época Sicán.

\section{1. 3. En los cerros Amotape}

En los cerros Amotape los sitios del Intermedio Tardío se ubican a lo largo de las grandes quebradas y en las pendientes, destaca y debe ser excavado el importante sitio administrativo y ceremonial de Guineal, para poder fechar sus estructuras más antiguas. A lo largo del camino entre Poechos y Tumbes hemos ubicado las huellas de los tambos. 


\section{1. 4. En el valle del Tumbes}

En el valle del Tumbes a lo largo de los canales proliferan pequeños sitios con las mismas estructuras que en los valles del Piura y Chira. En la parte baja del valle, en la margen derecha, queda por fechar el inicio del desarrollo de Corrales, el sitio de los sicán que seguirá ocupado por los chimú e inca.

\section{2. El incremento de poder de la teocracia Sicán Medio}

El sector administrativo y ceremonial es el que se relaciona, a nivel material, con la gestión de los recursos naturales y culturales, el control de la producción, de la recolección y redistribución del tributo, y a nivel ideológico, con la gestión de las fuerzas vitales, la celebración del culto a los ancestros que asegura la reproducción social, los ritos del calendario ceremonial y, cuando las circunstancias lo requieren los ritos de pasaje del ciclo de la vida y la muerte, entre los cuales los ritos funerarios y en casos de extrema necesidad de expiación y restauración del orden ancestral.

El crecimiento de este sector, del cual son indicios la proliferación, diversificación y la cada vez más obvia complejidad de los asentamientos, atestigua un incremento del poder de la teocracia Sicán Medio consecuencia directa e indirecta de los cambios inducidos por la producción de cobre arsenical, esta innovación tecnológica siendo la base del desarrollo territorial.

A partir de las investigaciones de Shimada en cuanto a la producción de cobre arsenical, de nuestra convicción de que herramientas como las puntas y rejas fueron herramientas utilizadas a partir de 900 d.C. y de los resultados de nuestras observaciones e interpretaciones de las huellas de las infraestructuras de producción y comunicación así como de los sitios administrativos y ceremoniales, llegamos a la conclusión siguiente:

- Si las características de una Edad del Bronce en el Viejo Mundo son, como lo define Lechtman, "[...] cambios importantes en el desarrollo de ciudades, el intercambio a larga distancia de bienes exóticos, el crecimiento de grandes estados políticos" que "coincidieron con el desarrollo del bronce y hasta cierto punto fueron facilitados por la producción de ese material”, podemos sostener que en el Nuevo Mundo una Edad del Bronce se gesta en los Andes Centrales a fines del Horizonte Medio, se manifiesta en todo su apogeo a inicios del Período Intermedio Tardío y perdura durante el Horizonte Tardío, hasta la llegada de los españoles que introducen y difunden el fierro en los Andes.

Nos quedaría tratar de percibir cuáles fueron los impactos de esta Edad del Bronce, no solamente en los Andes Centrales sino en todo el continente americano. Pero antes debemos detenernos algo más sobre sus inicios.

\section{EL INICIO DE LA EDAD DEL BRONCE EN LOS ANDES CENTRALES}

\section{1. ¿El bronce alto andino y el Horizonte Medio?}

Según Lechtman, hasta el presente, en los Andes Centrales se conocen cuatro o cinco aleaciones de cobre con otros metales que pueden llamarse bronces. Todas 
hubieran sido producidas por primera vez en el Horizonte Medio y durante este período el lago Titicaca constituiría el límite sur de la producción de bronce arsenical. Ahora:

"¿Donde se originaron los nuevos sistemas de fundir y alear? Puesto que las aleaciones de bronce aparecen hacia 600 d.C., tanto en la cuenca del Titicaca como en el Valle de Cusco en los Andes centrales, somos testigos de un acontecimiento tecnológico diseminado que coincide con el fenómeno del Horizonte Medio. Es posible que el horizonte tecnológico asociado con la producción de las aleaciones de bronce tuviera sus orígenes en los Andes sur-centrales, encontrando su expresión en la cultura material de Tiwanaku y Huari. La vinculación de la costa norte del Perú a la producción de bronce arsenical pudo ser posterior a la llegada a la zona de un complejo tecnológico cuyos cimientos estaban ya puestos." (Lechtman, 1998: 24).

"Durante el Horizonte Medio en toda la zona de los Andes centrales, es decir, en el territorio actualmente correspondiente a Perú y Ecuador, solamente se produjo bronce arsenical. El Lago Titicaca constituyó el límite sureño para la producción de este bronce." (Lechtman, 1998: 6).

Las piezas de Pikillacta, aproximadamente 50 artículos, de los cuales se examinaron en el laboratorio 31, el $62 \%$ :

“[...] datan del Horizonte Medio, época 1B-3 que corresponde a 600-1000 d.C." (Lechtman, 1998: 11).

Son pequeños objetos, tupus y agujas de cobre arsenical casi idéntico al de la costa norte (Lechtman, 1998: 12). La datación no es muy precisa, y no hay hasta ahora evidencias de la producción de estos objetos en Pikillacta mismo, por lo tanto podrían provenir de la costa norte.

En cuanto al bronce Tiwanaku de hecho es diferente del de la costa norte:

"Mientras que virtualmente todos los artefactos de Pikillacta fueron hechos con bronce arsenical, en Tiwanacu se usó una variedad mucho más amplia de aleaciones [...]. De los 20 artefactos de Tiwanaku analizados, 11 (55 \%) estaban hechos con aleaciones ternarias de cobre-arsénico-níquel en las que tanto el arsénico como el níquel están presentes en alta concentración en el cobre; 7 (35 \%) están hechos con bronce estañífero (la aleación de cobre y estaño); solamente 1 (5\%) está hecho con bronce arsenical y 1 (5 \%) con cobre impuro." (Lechtman, 1998: 12).

“[...] datan del Horizonte Medio (600-1000 d.C.), aunque en la hoya del Titicaca se produjeron hasta los primeros años del Período Intermedio Tardío, es decir aproximadamente 1000-1100 d.C. (Kolata, 1993; Janusek, 1994).” (Lechtman, 1998: 12).

Tenemos que admitir que los fechados de las producciones de Tiwanaku no son precisos y que tampoco se conocen evidencias del proceso local de producción de bronce. Hasta el momento, por lo tanto, no quedan tan evidentes las relaciones Horizonte Medio-Producción de Bronce, ni la anterioridad de la producción de bronce altoandina frente a la de la costa norte. 


\section{2. El bronce Sicán y el Período Intermedio Tardío}

En cuanto al bronce Sicán, los estudios de Shimada y sus colaboradores en la Huaca del Pueblo de Batán Grande y sus alrededores, dejan muy en claro la continuidad de la tradición metalúrgica del valle de La Leche donde se pasa de una producción de cobre Moche V, por 700 d.C., a una producción de cobre arsenical Sicán Medio de 900 a 1100 d.C.

El final del Horizonte Medio, entre 700 y 900 d.C., es un período hasta ahora muy poco estudiado, pero se podría pensar que en el valle de La Leche, donde abundan la malaquita y la scorodita, así como la leña de algarrobo y donde no falta la mano de obra y la organización para la producción, los metalurgistas sicán temprano fueron descubriendo los secretos de la aleación cobre-arsénico y experimentando las ventajas del bronce. Y que, a partir de 900 d.C. los sicán medio lograron una producción masiva de bronce arsenical, base de una economía pujante hasta la destrucción del sitio de Sicán a inicios del segundo milenio de nuestra era, que durante un siglo permite el desarrollo de la teocracia Sicán Medio y el incremento de su poder.

\section{3. La caída de la teocracia Sicán Medio}

\section{3. 1. Factores climáticos, socioeconómicos y políticos}

Shimada y sus colaboradores (1995: 170-177) encuentran indicios de un final abrupto y violento del centro administrativo y ceremonial Sicán, a raíz de un gran incendio, intencional y simultáneo, de las principales construcciones de adobes. Los fechados de las estructuras quemadas se agrupan entre los 1000 y 1050 d.C. Como hay evidencias de que cuando las estructuras se incendiaron estaban todavía en buen estado de conservación, el fuego tuvo lugar antes de una gran inundación que afectó las ruinas de Sicán y que ha sido fechada independientemente hacia 1100 d.C. en varios sitios de la costa norte:

"En resumen, la destrucción intencional de los templos que no nos muestran evidencias posteriores de su reconstrucción, apuntan hacia un esfuerzo concertado y muy violento para eliminar el liderazgo político y religioso existente en Sicán. Es así que Poma nunca pudo volver a tener la preeminencia que disfrutó durante el período Sicán Medio.

Aún no estamos seguros de cómo los procesos y factores de largo y corto plazo contribuyeron a esta situación. Las condiciones naturales adversas pueden haber contribuido a su caída. Una severa sequía de treinta años de duración, luego de condiciones pluviales estables, recientemente documentada, comenzando hacia el año 1020 d.C. (ver Shimada et al., 1991; Thompson et al., 1985; 1988; también Ortloff \& Kolata, 1993), habría reducido significativamente la cantidad de agua que llegaba a la costa desde la sierra adyacente. Esta fue la segunda sequía más severa y más larga de los Andes, que se haya documentado para los últimos 1500 años, en los registros de hielo del Quelccaya." (Shimada, 1995: 174).

Sabemos sin embargo lo difícil que es interpretar, fechar y correlar los registros de lluvias extraordinarias y sequías anormales que conservan los hielos, depósitos de 
diatomitas, macizos de corales, cordones litorales, sedimentos, estructuras arquitectónicas, testimonios arqueológicos o fuentes escritas (Hocquenghem \& Ortlieb, 1992a; 1992b; Macharé \& Ortlieb, 1993; Hocquenghem, 1998: Anexo 2; Ortlieb, 2000).

Lo cierto es que en los valles de los ríos Piura, Chira y Tumbes, la inestabilidad climática afecta la producción y que las largas sequías son más temibles que los sorpresivos eventos El Niño. Lo cierto también es que las poblaciones que se desarrollan rápidamente en base a la extensión de los sistemas de irrigación son, hoy como lo eran ayer, muy vulnerables. Una sequía que impediría la utilización del canal del Alto Piura durante más de un decenio podría, a pesar de las reservas almacenadas, causar hambrunas. Un desastre natural que alteraría en forma drástica y prolongada la producción de los valles de la costa norte y extremo norte, podría conducir a una catástrofe social. Y si en este caso la élite Sicán Medio no aseguraba la reproducción de sus tributarios, si se mostraba incapaz, a nivel material e ideológico, de cumplir con sus tareas administrativas y ceremoniales, podía ser destituida y su centro, Sicán, destruido.

Entendemos que la función de los miembros de las teocracias centro andinas era la de mantener el orden que permite asegurar la reproducción social. Las elites, al nivel material, asumían la tarea de regular, administrar y redistribuir los recursos naturales y culturales y, al nivel ideológico, de celebrar los ritos del calendario ceremonial que mantenían el contacto entre los hombres, sus antepasados y sus ancestros míticos. Cumpliendo con sus obligaciones aseguraban la circulación y acrecentar del caudal de las fuerzas vitales. En caso contrario eran culpables de los desórdenes, naturales o sociales, manifestaciones de la ira ancestral, y como tales posibles victimas de temibles "pachacuti", reinstauraciones del orden, que implicaban la destrucción de los centros de poder y de las teocracias ineficientes o deficientes (Hocquenghem, 1983; 1987; 1995b; 1997, 1998: 197-215).

Es más, a inicios del segundo milenio de nuestra era, no solo habría sido la producción y el caudal tributario que hubieran sido afectados por condiciones climáticas adversas sino, en forma independiente si bien contemporánea, el volumen de los intercambios y el monto de los beneficios de la economía centro andina, pudieran haber disminuido. De hecho durante un siglo los secretos de la producción de cobre arsenical deberían haberse difundidos en los Andes Centrales y, si es así, la teocracia Sicán Medio debería haber perdido el monopolio de la producción y distribución de este metal, uno de los fundamentos de su poder.

Podemos entonces pensar que el incendio de las huacas de Sicán atestigua de una de las reestructuraciones que se pueden observar y atribuir a varios factores o diversas configuraciones de factores, algunos naturales y muchos otros sociales, que los arqueólogos no logran, en el estado actual de sus conocimientos, identificar con certeza y vislumbrar en toda su complejidad. Demuestra ante todo que, por más poderosas que sean las teocracias de la costa norte, se mantenían en un frágil estado de equilibrio que solía romperse dando lugar al nivel material a una nueva configuración socioeconómica y política, si bien a nivel ideológico se mantenían el orden ancestral y el culto a los antepasados, la religión, base de la civilización centro andina. 


\section{3. 2. El Purgatorio y la dinastía Sicán Tardío}

Sicán fue destruido, pero esta no fue la suerte de otros centros ceremoniales y administrativos Sicán Medio:

"Es importante destacar que el contemporáneo sitio de Chotuna —en el valle bajo del Lambayeque - no presenta evidencias de un fin abrupto ni violento, como se ha visto en Sicán. Sólo existen evidencias de una gran inundación alrededor de 1100 d.C., seguido de una nueva construcción [...]". (Shimada, 1995: 175)

Una nueva teocracia, Sicán Tardío, toma la posta y, a partir de 1100 d.C., su centro administrativo y ceremonial, El Purgatorio, se desarrolla en la unión de los valles de La Leche y Lambayeque, cerca de Túcume, alrededor del cerro La Raya, hasta 1375 d.C.:

"[...] vemos una serie de grandes asentamientos urbanos — p.e., Saltur y Cintoemergiendo a lo largo de las faldas de los cerros, en gran parte de la región de Lambayeque [...]". (Shimada, 1995: 177).

Pero en ningún centro administrativo y ceremonial de la costa o de la sierra, en los Andes Centrales, se acumularan en tan poco tiempo riquezas comparables con las que atesoraron en sus tumbas las élites de la teocracia Sicán Medio, en un siglo y en base al monopolio de la producción y distribución del cobre arsenical y la redistribución de su contraparte norteña los Spondylus.

\section{A MODO DE CONCLUSIÓN}

\section{1. Un tema por investigar}

En cuanto a las consecuencias de la elaboración de instrumentos de bronce, a partir de 900 d.C., en la vertiente amazónica de los Andes Centrales, podríamos considerar un cambio que nos parece muy importante y que queda por investigar, el paso de una agricultura migratoria a una agricultura permanente en andenerías en la selva alta de los departamentos de Amazonas y San Martín y queda por ver más al sur hasta las yungas bolivianas. La expansión de las teocracias centro andinas, hacia el oriente y el norte a partir del Período Intermedio Tardío podría deberse a una innovación tecnológica, la producción de bronce, que se difundiría en los Andes Centrales generando cambios importantes desde finales del primer milenio de nuestra era. Deberíamos entonces estudiar con más detenimiento el caso de la penetración Sicán Medio al este de la abra de Porculla.

Y si así fuera, durante el Horizonte Tardío los incas solo habrían instalado andenerías en los alrededores de los centros administrativos del incanato al extremo norte de los Andes peruanos, en las serranías de Ayabaca y Loja hasta las de Quito, así como lo hemos tratado de documentar en otros trabajos (Hocquenghem, 1989; 1990; 1998: 175-215).

El cambio de una agricultura migratoria a una agricultura permanente significa deforestación. Unos centenares de miles de hectáreas de selva alta pueden haber sido 
deforestadas en toda la vertiente oriental de los Andes durante el Período Intermedio Tardío, pero la construcción de andenes hubiera limitado la erosión de las tierras. Conservadas las tierras en las andenerías el bosque hubiera podido recuperarse durante la colonia. De hecho la vertiente amazónica fue abandonada a una población indígena. Está reducida y, por lo tanto, en la imposibilidad, por falta de mano de obra, de mantener las infraestructuras de producción prehispánicas, hubiera vuelto a una agricultura migratoria. Es de notar que las consecuencias del retroceso del bosque a inicios del Período Intermedio Tardío, frente a una intensificación de la agricultura con instrumentos manuales de bronce, no se podrían comparar con las que observamos actualmente, frente a una explotación de los recursos forestales y extensión de una agricultura permanente sin remodelar las pendientes, con las maquinarias motorizadas, tractores y retroexcavadoras: las escalas de los impactos ambientales son incomparables.

\section{2. Algunas tareas pendientes}

Obviamente quedan muchos otros temas por investigar en cuanto a la evolución y las consecuencias de la producción de bronce, algunos ya fueron propuestos hace casi tres decenios por Lechtman (1978), otros surgen actualmente a partir de los resultados de las investigaciones realizadas desde entonces. Pero antes de abordarlos varias tareas pendientes se perfilan, entre otras:

- Seguir revisando las colecciones, identificar y analizar la composición química cuantitativa de los objetos de metal en particular las herramientas. De hecho, hasta hace pocos años y a pesar de los trabajos de los investigadores de la metalurgia andina muchos arqueólogos seguían sin distinguir claramente los artefactos de cobre y los de cobre arsenical u otros bronces.

- Reconsiderar las informaciones y teorías sobre las zonas de producción de metales, para tratar de entender mejor los inicios de la producción de bronce y su difusión en los Andes Centrales. Esto ayudaría a precisar lo que fue la naturaleza y la evolución de las relaciones durante el Horizonte Medio, entre Moche y Huari, Sicán Temprano y Pachacamac, que percibimos más del orden de los intercambios que de las conquistas.

- Esclarecer, a partir de 1100 d.C., las diferencias y conexiones entre los circuitos de intercambios de cobre arsenical norteño y los bronces estañíferos ternarios (cobre, arsénico y níquel) de la región del Lago Titicaca.

- Investigar el impacto de la utilización de las herramientas de cobre arsenical u otros bronces en toda la vertiente oriental de los Andes Centrales durante el Período Intermedio Tardío.

- Fomentar el estudio comparativo de la composición química cuantitativa de los objetos de metal provenientes de la vertiente amazónica de los Andes Centrales.

- Enfocar las bases económicas del surgimiento y la expansión del incanato, de las cuales poco se sabe. Indagar sobre las relaciones entre una intensificación de la agricultura en la selva alta, facilitada por los instrumentos de bronce y los inicios del desarrollo inca. Considerar las motivaciones de la conquista inca de los coya bien podría ser el control de la producción y redistribución de bronce estañífero. 
- Revisar las informaciones y concepciones de la evolución de las tecnologías prehispánicas y sus relaciones con el desarrollo territorial, económico y sociopolítico de las teocracias de los Andes Centrales.

- Pasando a otra escala espacial, es necesario estrechar las relaciones entre los investigadores de los Andes Centrales, Septentrionales y de Mesoamérica, para enfocar una Edad del Bronce a nivel continental.

- Y pasando a otra escala temporal, se debe tratar de compatibilizar las periodizaciones, prehispánicas, coloniales y republicanas, para enmarcar la visión de una Edad del Bronce amerindia en la perspectiva de la larga duración de una historia ambiental americana.

- Finalmente se deberán comparar los impactos de los inicios de una Edad del Bronce en los contextos del Antiguo y Nuevo Mundo.

\section{3. Hacia una historia ambiental}

En pocas palabras, una historia ambiental apuntaría a rendir cuentas de la evolución de las interrelaciones e interacciones de las sociedades con sus entornos naturales y culturales, por medio de sus organizaciones y tecnologías, así como de sus consecuencias a lo largo del tiempo (Castro Herrera, 1993; Hocquenghem, 1998: 26-27).

Esclareciendo los procesos que conducen a las situaciones actuales, esta historia debería tomarse en cuenta al momento de proyectar posibles evoluciones territoriales, socioeconómicas y políticas, o establecer pautas para enfrentar los problemas y aprovechar las oportunidades ambientales. Debería permitir abordar, desde la perspectiva de la larga duración del pasado, un tema que va ocupando un lugar importante en las discusiones en torno al porvenir del planeta. Un tema que para ser tratado a cabalidad requiere estimular las investigaciones interdisciplinarias y facilitar las comparaciones a escalas espaciales y temporales variables. Lo que implica establecer un diálogo entre las ciencias humanas y naturales a sabiendas que tiene un carácter histórico. Un diálogo que, en tiempos de globalización y descentralización, debería centrarse en torno al tema de las transformaciones, a diversas escalas desde lo local hasta lo global, que se inscriben en los paisajes y sus implicaciones, entendiendo y estudiando un paisaje en tanto que síntesis de las técnicas de producción y de las organizaciones de sociales que lo crearon, sobre determinada por el paisaje heredado de las sociedades anteriores, así como lo proponen Pierre Gourou (1984) o Marcel Mazoyer \& Laurence Roudart (1997). 


\section{Referencias citadas}

ALAMO, V. \& VALDIVIESO, V., 1987 - Lista sistemática de moluscos marinos del Perú. Boletín del Instituto del Mar del Perú, Volumen Extraordinario, 205 p.; Callao.

ALCINA FRANCH, J., ALONSO SAGASETA, A., BOUCHARD, J.-F. \& GUINEA BUENO, M., 1987 - Navegación precolombina: el caso del litoral pacífico ecuatorial: evidencias e hipótesis. Revista Española de Antropología Americana, XVII: 35-73; Madrid: Universidad Complutense de Madrid.

BAESSLER, A., 1906 - Altperuanische Metallgeräte; Berlin.

BÉAREZ, P., 1996 - Comparaison des ichtyofaunes marines actuelle et holocène et reconstitution de l'activité halieutique dans les civilisations précolombiennes de la côte du Manabí Sud (Équateur). Thèse présentée pour l'obtention du diplôme de Doctorat du Muséum National d'Histoire Naturelle. Spécialité: Ichtyologie Générale et Appliquée, Paris, 200 p.

BELTRÁN MEDINA, J., 1991 - Los concheros del Puerto de Salanga; México: ENAH.

BELTRÁN MEDINA, J., 1994-Comentarios arqueológicos sobre el antiguo Puerto de Salanga (playa el Tesoro). Vol. II colección Mar del Sur; México, Colima: Proyecto Historia general de Colima. Gobierno del Estado de Colima, Universidad de Colima, Consejo Nacional para la Cultura y las Artes.

BELTRÁN MEDINA, J., 1997- Proyecto Punta Mita. Informe final 1994, primera temporada; México: INAH.

BENNETT, W., 1939 - Archaeology of the North Coast of Peru. An account of exploration and excavation in Viru and Lambayeque valleys, 153 p.; New York: American Museum of natural history. Anthropological papers of the American Museum of natural history, $37(1)$.

BOMAN, E., 1908 - Antiquités de la Région Andine et du Désert d'Atacama; Paris.

BOURLIAUD, J., HERVÉ, D., MORLON, P. \& RÉAU, R., 1988 - Chakitaklla. Estrategias de barbecho e intensificación de la agricultura andina, 102 p.; Lima: ORSTOM-PISA.

BRAY, W., 1985 - Ancient American Metallurgy. In: The art of Precolombian Gold (Elizabeth Benson, Ed.): 76-84; New York: The Metropolitan Museum of Arts. The Jan Mitchell Collection.

BUSSY, M., 1996-1997 - Le spondylus au Pérou et en Équateur à l'époque préhispanique. Mémoire de maîtrise d'Archéologie Précolombienne. Université de Paris I PanthéonSorbonne, $104 \mathrm{p}$.

CALEY, E., 1973 - Chemical composition of Ancient Copper Objets of South America. In: Application of Sciences in examination of works of Art: 53-61; Boston: Editor W.J. Young.

CALEY, E. \& EASBY Jr, D., 1959 - The Smelting of Silfide Ore of Copper in preconquest Peru. American Antiquity, vol 25, $\mathbf{n}^{\circ}$ 1: 59-65; SaltLake City.

CALEY, E. \& SHANK, L., 1971 - Composition of ancient Peruvian copper. Ohio Journal of Science, $\mathbf{n}^{\circ}$ 71: 181-187; Ohio.

CASTRO HERRERA, G., 1993 - Hacia una Historia Ambiental de América Latina: Elementos para un marco de referencia; México: Departamento de Estudios Internacionales. Universidad de Las Américas, A. C. Mexico City's Bilingual University, Formerly Mexico City College. Cuaderno de Trabajo.

COOKE, R. \& SÁNCHEZ HERRERA, L. A., 1997 - Coetaneidad de metalurgia, artesanías de concha y cerámica pintada en cerro Juan Díaz, gran Coclé, Panamá. Boletín del Museo del Oro, 42: 56-83; Bogotá.

CORDY-COLLINS, A., 1990 - Fonga sigde, shell purveyor of the Chimu Kings. In: The northern dynasties: Kingship and statacraft in Chimor (M. Moseley \& A. Cordy-Collins, Eds.): 393-417; Washington DC: Dumbarton Oaks Research Library and Collection. 
EASBY Jr., D., CALEY, E. \& KHOSROW, M., 1967 - Axe-Money: facts and Speculation. Revista Mexicana de Estudios Antropólogicos, 21: 107-136; México.

EPSTEIN, St. M. \& SHIMADA, I., 1984 - Sicán Metallurgy. A reconstruction of copper alloy at Cerro de los Cementerios, Peru. Beitrage zur Allgemeinen und Vergleichenden Archäologie, 5 (1983); Bonn: KAVA, Deutschen Archäologischen Instituts.

ESTRADA, E., 1957 - Los Huancavilcas: últimas civilizaciones prehistóricas de la costa del Guayas, 82 p.; Guayaquil.

ESTRADA, E., 1961 - Excavaciones en la Tumba del Cacique Guayas. El Universo, 30 de octubre; Guayaquil.

ESTRADA, E., 1962 - Arqueología de Manabí central, 205 p.; Guayaquil.

ÉTESSE, G., 1991 - La sierra de Piura: ¿al margen de la evolución agraria andina? Bulletin de L'Institut Français d'Études Andines, 20(2): 599-620. Boletín temático Piura et sa région (Anne Marie Hocquenghem Ed.).

FERNÁNDEZ VILLEGAS, O., 1991 - Conflictos por el control de las tierras en Narigualá, valle del Bajo Piura. Manuscrito en prensa.

FESTER, G., 1962 - Copper and copper alloys in Ancient Argentina. Chymia, vol. 8: 21-23.

GOUROU, P., 1984 - Riz et Civilization, 299 p.; Paris: Fayard.

HOCQUENGHEM, A. M., 1983 - The beauty of the deer-serpent-jaguar. Camak1: 4-7; Berlín.

HOCQUENGHEM, A. M., 1987 - Iconografía Mochica, 280 p.; Lima: Pontificia Universidad Católica del Perú.

HOCQUENGHEM, A. M., s.f.[1989] - Los Guayacundos de Caxas y la Sierra Piurana, siglos 15 y 16, 200 p.; Lima: CIPCA-Institut Français d'Études Andines.

HOCQUENGHEM, A. M., 1990a - Cambios en el sistema de producción de la sierra piurana, siglos XV y XVI. Bulletin de l'Institut Français d'Études Andines, 19(1): 87-101.

HOCQUENGHEM, A. M., 1993 - Rutas de entrada del mullu en el extremo norte del Perú. Bulletin de l'Institut Français d'Études Andines, 22(3): 701-719.

HOCQUENGHEM, A. M., 1994 - Los españoles en los caminos del extremo norte del Perú en 1532. Bulletin de l'Institut Français d'Études Andines, 23(1): 1-67.

HOCQUENGHEM, A. M., 1995a - Intercambios entre los Andes centrales y norteños en el extremo norte del Perú. In: Primer encuentro de investigadores de la costa ecuatoriana en Europa: arqueología, etnohistoria, antropología sociocultural (Aurelio Álvarez, Silvia Álvarez, Carmen Fauría \& Jorge Marcos, Eds.): 259-298; Quito: Abya-Yala.

HOCQUENGHEM, A. M., 1995b - Les sociétés d'irrigation de la côte nord. In: Histoire Générale d'Amérique Latine, Las Sociedades Originarias, Vol. I, Chap. XV: 387-411; Paris: UNESCO.

HOCQUENGHEM, A. M., 1997 - Como una imagen del otro lado del espejo: una memoria para el futuro, una visión del orden del mundo andino. In: Pensar América, Cosmovisión mesoamericana y andinas: 215-247; Córdoba: Ayuntamiento de Montilla. Comp. A Garrido Aranda. Obra social y cultural CAJASUR.

HOCQUENGHEM, A. M., 1998 - Para vencer la muerte. Piura y Tumbes, raíces en el bosque seco y en la selva alta - horizontes en el Pacífico y en la Amazonia, 445 p.; Lima: CNRSIFEA-INCAH.

HOCQUENGHEM, A. M., 1999-Una historia del bosque seco. In: Bosques secos y desertificación. Memorias del Seminario Internacional: 231-254; Lima: Proyecto Algarrobo INRENA.

HOCQUENGHEM, A. M., 2001 - Una historia del Bosque Seco. Debate Agrario: Análisis y Alternativas, 33: 30-60; Lima.

HOCQUENGHEM, A. M. \& PEÑA RUIZ, M., 1994 - La talla del material malacológico en Tumbes. Bulletin de l'Institut Français d'Études Andines, 23(2): 209-229.

HOCQUENGHEM, A. M. \& ORTLIEB, L., 1992a - Eventos El Niño y lluvias anormales en la costa del Perú: siglos XVI-XIX. Bulletin de l'Institut Français d'Études Andines, 21(1): 197-278. 
HOCQUENGHEM, A. M. \& ORTLIEB, L., 1992b - Historical record of El Niño events in Peru (XVI-XVIIIth centuries): the Quinn et al. (1987) chronology revisited. In: Paleo-ENSO records international symposium: extended abstracts (Luc Ortlieb \& José Macharé, Eds.): 143-149; Lima: ORSTOM/CONCYTEC.

HOCQUENGHEM, A. M., URBINA, C., PALACIOS, R., 1995-Estudio del Sitio Arqueológico de Coscomba.Parque Ecológico Municipal “KartBeer”; Piura: Municipalidad Provincial de Piura.

HOLM, O., 1966-1967 - Money axes from Ecuador. Folks, 67 (8-9): 135-143; Copenhague.

HOLM, O., 1975 - Monedas primitivas del Ecuador prehistórico. La pieza, 3; Guayaquil: Casa de la Cultura Ecuatoriana.

HOLM, O., 1978 - Hachas monedas del Ecuador. In: Actas y Trabajos del 3 Congreso Peruano "El Hombre y la Cultura Andina”, T. I (Ramiro Matos M., Ed.): 347-361; Lima.

HOLM, O., 1980 - Monedas Primitivas del Ecuador. El indio ecuatoriano. Pasado Ancestral y Problemas de Aculturación. Cuadernos Prehispánicos, 8(8): 53-67; Valladolid.

HOLM, O., 1981-Cultura Milagro-Quevedo; Guayaquil: Museo de Antropología y Pinacoteca del Banco Central del Ecuador.

HOLM, O., 1982 - Cultura Manteña-Huancavelica; Guayaquil: Museo Antropologíco. Banco Central de Ecuador. Folleto de divulgación popular.

HOSLER, D., 1986a - The cultural organization of technology: Copper alloys in ancient West Mexico. In: Precolumbian American Metallurgy, Special Publication of the New World Metallurgy Symposium, Forty-Fifth International Congress of Americanists, Bogotá: 67-86; Bogotá: Banco de la República Colombia.

HOSLER, D., 1986b - The Origins, Technology and Social Construction of Ancient West Mexican Metallurgy. Ph.D. Dissertation, Department of Anthropology, University of California Santa Barbara.

HOSLER, D., 1988a - The Metallurgy of Ancient West Mexico. In: The Beginning of the use of Metals and Alloys (R. Madden, Ed.): 238-343; Cambridge: MIT press.

HOSLER, D., 1988b - West Mexican Metallurgy: A Technological Chronology. Journal of Field Archaeology, 15: 191-217.

HOSLER, D., 1990-The Development of Ancient Mesoamerican Metallurgy. Archaeometallurgy, Coord. V. C. Pigott. The Journal of the Minerals, Metals \& Material Society, JOM, 42 (5): 44-46.

HOSLER, D., 1993 - La metalurgia Antigua del México del Oeste: una cronología tecnológica. In: Arqueología del Occidente de México: nuevas aportaciones (E. Williams \& R. Novella, Eds.): 237-296; México: Colegio de Michoacán (Morelia).

HOSLER, D., 1994 - The Sounds and Colors of power: The Sacred Metallugical Technology of Ancient West Mexico; Cambridge: MIT press.

HOSLER, D., 1997a - Los orígenes andinos de la metalurgia del occidente de México. Boletín Museo del Oro, 42: 2-25; Bogotá: Banco de la República.

HOSLER, D., 1997b - La tecnología de la metalurgia sagrada del Occidente de México. Arqueología Mexicana, V, 27: 34-41; México.

HOSLER, D., 1998b - Ancient West Mexican Metallurgy: South American Origins and West Mexican Transformations. American Anthropologist, 90: 832-855.

HOSLER, D., LECHTMAN, H. \& HOLM, O., 1990 - Axe-monies and Their Relatives. Studies in Pre-Columbian Arts \& Archaeology, 30; Washington D.C.: Dumbarton Oaks.

HOSLER, D. \& MACFARLANE, A., 1996 - Cooper Sources, Metals production and Metal Trade in Late Postclassic Mesoamerica. Science, 273: 1819-1824.

HOSLER, D. \& STRESSER-PEAN, G., 1992 - The Huastec Region; A second Locus for the production of bronce Alloys in Ancient Mesoamerica. Science, 257: 1215-1220.

KROEBER, A., 1944 - Peruvian Archaeology in 1942; New York: Viking Fund publication of Anthropology n ${ }^{\circ} 4$. 
LECHTMAN, H., 1973 - The gilding of metals in pre-Columbian Peru. In: The application of science in examination of works of art (W. J. Young, Ed.): 38-52; Boston: Museum of Fine Art.

LECHTMAN, H., 1976 - A metallurgical site survey in the Peruvians Andes. Journal of Field Archaeology, 3: 1-42; Boston.

LECHTMAN, H., 1978 -Temas de metalurgia Andina. In: Tecnología Andina (R. Ravines, Comp.): 489-520; Lima: IEP-Instituto de Investigación Tecnológica Industrial y de Normas Técnicas.

LECHTMAN, H., 1979 - Issues in Andean metallurgy. In: Pre-Columbian metallurgy of South America (E. P. Benson, Ed.): 1-40; Washington D.C.: Dumbarton Oaks.

LECHTMAN, H., 1980 - The Central Andes: metallurgy without iron. In: The coming of the Age of Iron (T. A. Wertime \& J. D. Muhly, Eds.): 267-334; New Haven: Yale University.

LECHTMAN, H., 1981 - Copper-arsenic bronzes from the north coast of Peru. The Research Potential of Anthropoligical Museums Collections. Annals of the New York Academy of Sciences, 376: 77-122; New York.

LECHTMAN, H., 1984a - Pre-Columbian surface metallurgy. Scientific American, 250 (6): 56-63.

LECHTMAN, H., 1984b - Andean value system and the development of prehistoric metallurgy. Technology and Culture, 25: 1-36.

LECHTMAN, H., 1988 - Traditions and styles in the Central Andes metalworking. In: The beginning of the use of metals and alloys (R. Madden, Ed.):344-378; Cambridge: MIT press.

LECHTMAN, H., 1991 - The production of copper arsenic alloys in the Central Andes: Highland ores and coastal smelter? Journal of field Archaeology, 18: 43-76.

LECHTMAN, H., 1996 - Arsenic Bronze: Dirty Copper or Chosen Alloy? A View from the Americas. Journal of Field Archaeology, 23: 477-514.

LECHTMAN, H., 1997-El Bronce arsenical y el Horizonte Medio. In:Arqueología, Antropología e Historia en los Andes: Homenaje a María Rostworowski (R. Varón G. \& J. Flores E., Eds.): 153-186; Lima: Instituto de Estudios Peruanos (IEP).

LECHTMAN, H., 1998 - El bronce y el Horizonte Medio. Boletín Museo del Oro, 41: 3-25; Bogotá: Banco de la República.

LUEGER, 1961 - Lexikon der Technik 3; Stuttgart: Werlstoffe und Werkstoffprüfung.

MACHARÉ, J. \& ORTLIEB, L. (Comps.), 1993 - Registro del Fenómeno el Niño y de Eventos ENSO en América del Sur. Bulletin de l'Institut Français d'Études Andines, 22(1): 406 p.

MARCOS, J., 1977-1978 - Cruising to Acapulco and Back with the Thorny Oyster Set: Model for a Lineal Exchange System. Journal of the Steward Anthropological Society, 9(1-2): 99-132.

MARCOS, J., 1981 - Informe sobre el área ceremonial del complejo Manteño-Huancavilca de la Loma de los Cangrejitos, Valle de Chanduy, Ecuador. El Arquitecto, 1(5): 54-63; Guayaquil.

MARCOS, J., 1985 - El "Mullo" (Spondylus princeps) Alimento de los Dioses Andinos. In: Actas del Seminario sobre la situación de la investigación de las Culturas Indígenas de los Andes septentrionales; Madrid: Ediciones Cultura Hispánica.

MARCOS, J., 1986a - Intercambio a larga distancia en América: El caso del Spondylus. In: Arqueología de la costa ecuatoriana: Nuevos enfoques, 1 (J. Marcos, Ed.): 197-206; Guayaquil: ESPOL.

MARCOS, J., 1986b - De Ida y Vuelta a Acapulco con los Mercaderes de Mullu. In: Arqueología de la costa ecuatoriana: Nuevos enfoques, 1 (J. Marcos, Ed.): 161-196; Quito: Biblioteca Ecuatoriana de Arqueología, ESPOL.

MARCOS, J., 1995 - El Mullo y el Pututo: La articulación de la ideología y el tráfico a larga distancia en la formación del estado Huancavilca. In: Primer encuentro de investigadores de la costa ecuatoriana en Europa: arqueología, etnohistoria, antropología sociocultural (Aurelio Álvarez, Silvia Álvarez, Carmen Fauría, Jorge Marcos, Eds.): 97-142; Quito: Abya-Yala. 
MARCOS, J. \& NORTON, P., 1981 - Interpretación sobre la arqueología de la Isla de la Plata; Guayaquil.

MAYER,E., 1992 - Armas y Herramientas de Metal Prehispánicas en Ecuador.AVA-Materialien, 47; Mainz am Rhein: Verlag Philipp von Zabern.

MAZOYER, M. \& ROUDART, L., 1997 - Histoire des agricultures du Monde. Du néolithique à la crise contemporaine, 356 p.; Paris: Seuil.

MERKEL, J., 1984 - Analysis of Copper Smelting Specimens from the site of Huaca del Pueblo Batán Grande, Peru. Report sumitted to MASCA, The University Museum, University of Pennsylvania.

MERKEL, J., SHIMADA, I., SWANN, C.P. \& DOONAN, R., 1994 - Investigation of the prehistoric copper production at Batán Grande, Peru: interpretation of the analytical data for ore sample. In: Archaeometry of Pre-Columbian sites and artifacts (D.A. Scout \& P. Meyers, Eds.): 199-227; Marina del Rey. CA: The Getty Conservation institute.

MOGOLLÓN AVILA, V., 1999 - Spondylus princeps, Símbolo de Paz. Wiñay Yachay, 3, 1: 115-120; Lima.

MORLON, P., 1996 - Comprender la agricultura campesina en los Andes Centrales. PerúBolivia, 498 p.; Lima: Instituto Francés de Estudios Andinos (IFEA) - Centro de Estudios Regionales Andinos "Bartolomé de las Casas" (CBC).

MURRA, J., 1975 - El Tráfico del Mullu en la costa del Pacífico. In: Formaciones Económicas y Políticas del Mundo Andino: 225-267; Lima: IEP.

NORDENSKIÖLD, E., 1921 - The copper and bronze ages in South America. In: Comparative Ethnographical Studies, Vol. 4; Gothenburg.

NORTON, P., 1985 - El señorío de Salangone y la Liga de mercaderes. In: Simposio del $48^{\circ}$ Congreso Internacional de Americanistas: 131-143; Bogotá: Universidad de Los Andes, 1-7 de Julio 1985. Republicado en 1988 por Jenny Estrada. La Balsa en la historia de la navegación ecuatoriana: 255-274; Guayaquil: Instituto de historia marítima.

NORTON, P., 1986-El señorío de Salangone y la liga de mercaderes. El cartel Spondylus-Balsa. In: Miscelánea Antropológica Ecuatoriana 6: 131-144; Guayaquil.

NORTON, P., 1992 - Las culturas cerámicas prehispánicas del sur de Manabí. In: 5000 años de ocupación. Parque Machalilla (P. Norton, Ed.): 9-40; Quito: Centro Cultural Artes \& Ediciones Abya-Yala.

OEHM, V., 1984 - Investigaciones sobre minería y metalurgia en el Perú prehispánico. Una visión crítica actualizada; Bonn: BAS 12, Bonner Amerikanistische Studien.

ORTLIEB, L., 2000 - The Documented Historical Record of El Niño Events in Peru: An Update of the Quinn Record (Sixteenth Through Nineteenth Centuries). In: El Niño and the southern Oscillation. Multiscale Variability and Global and Regional Impacts (Henry Diaz \& Vera Markgraf, Eds.): 207-295; Cambridge: Cambridge University Press.

ORTLOFF, C. \& KOLATA, A., 1993 - Climate and collapse: agro-ecological perspectivas on the decline of the Tiwanaku state. Journal of archaeological Science, 20: 195-221.

PEDERSEN, A., 1976 - El Ajuar Funerario de la Tumba de la Huaca Menor de Batán Grande, Lambayeque, Perú. In: Actas del 41 Congreso Internacional de Americanistas 2: 60-73; México: Ciudad de México.

PENDERGAST, D., 1962 - Metal Artifacts in prehispanic Mesoamerica. American Antiquity, vol. 27: 520-545; Salt Lake City.

PINO ZEMBRANO, V., 2001 - Herramientas y Sistemas Agrícolas en el Qosqo, 304 p.; Cusco: Asociación Iniciativa Comunal de los Andes, INCA.

RIEFF ANAWALT, P., 1997 - Traders of the Ecuadorian Littoral. Archaeology, NovemberDecember: 48-52.

SAMANO, J. \& XIMENEZ, F., 1968[1527] - La relación. In: El Perú a través de los siglos: 514; Lima: Ediciones Técnicos Asociados. Biblioteca Peruana, Tomo 1. 
SCHLÜPMANN, J., 1993-1994 - La structure agraire et le développement d'une société régionale au nord du Pérou. Piura, 1588-1854. Thèse de doctorat nouveau régime, UER Géographie, Histoire, Sciences de la Société, Paris: Université de Paris VII - Denis Diderot, 2 t., 688 p.

SHIMADA, I., 1981 - Temples of Time: The Ancient Burial and Religious Center of Batán Grande, Peru. Archaeology, 34 (5): 37-45.

SHIMADA, I., 1985a-Perception, Procurement, and Management of Resources: Archaeological Perspective. In: Andean Ecology and Civilization (Izumi Shimada \& Craig Morris, Eds.): 357-399; Tokio: Shozo Masuda, University of Tokyo Press.

SHIMADA, I., 1985b - La Cultura Sicán: Caracterización Arqueologíca. In: Presencia Histórica de Lambayeque (E. Mendoza, Comp.): 76-133; Lima: DESA S. A.

SHIMADA, I., 1987- Aspectos tecnológicos y productivos de la metalurgia Sicán, costa norte del Perú. Gaceta Arqueológica Andina, Año IV, 13: 15-21; Lima.

SHIMADA, I., 1988 - A metallurgical survey in the Vicús region of the far north coast of Peru. Paper presented at the 7th North-East Conference on Andean Archaeology and Ethnohistory, Amherst, Nov. 6-7, 1988.

SHIMADA, I., 1990 - Cultural Continuities and Discontinuities on the Northern North Coast of Peru, Middle-Late Horizons. In: The Northern Dynasties: Kingship and Statecraft in Chimor(Michael E. Moseley \& Alana Cordy-Collins, Eds.): 297-392; Washington, D.C.: Dumbarton Oaks.

SHIMADA, I., 1992 - The regional status of the coast during the Late Intermediate Period: archaeological evidence, ethnohistorical record and art outline. In: I Regni Preincaici e Il Mondo Inca (L. Laurencich-Minelli, Ed.): 49-64,97-110; Milan: Corpus Precolombiano Series, JACA Book.

SHIMADA, I., 1994 - Pampa Grande and the Mochica Culture, 323 p.; Austin: University of Texas Press.

SHIMADA, I., 1995 - Cultura Sicán. Dios, riqueza y poder en la costa norte del Perú, 219 p.; Lima: Fundación del Banco Continental para el Fomento de la Educación y la Cultura, EDUBANCO.

SHIMADA, I., EPSTEIN, S. \& CRAIG, A., 1982 - Batán Grande: a prehistoric metallurgical center in Peru. Science, 216: 952-959.

SHIMADA, I., EPSTEIN, S. \& CRAIG, A., 1983 - The metallurgical process in ancient north Peru. Archaeology, 36 (5): 38-45.

SHIMADA, I. \& MERKEL, J., 1991 - Copper-Alloy Metallurgy in Ancient Peru. Scientific American, Vol 265, $\mathbf{n}^{\circ}$ 1: 80-86.

SHIMADA, I. \& MERKEL, J., 1993 - A Sicán Tomb in Perú. Minerva, 4 (1): 18-25; London.

SHIMADA, I. \& MONTENEGRO, J., 1993 - El Poder y la Naturaleza de la Élite Sicán: Una mirada a la Tumba de Huaca Loro, Batán Grande. Boletín de Lima, 90: 67-96; Lima.

SHIMADA, I., SCHAAF, C., THOMPSON, L. \& MOSELEY-THOMPSON, E., 1991 Implicaciones culturales de una gran sequía del siglo VI d.C. en los Andes peruanos. Boletín de Lima, XIII (77): 33-56; Lima.

SKOGLUND, C. \& MULLINER, D. K., 1996 - The Genus Spondylus (Bivalvia: Spondylidae) of the Panamic Province. The Festivus, XXVIII, 9: 92-107. A publication of the San Diego Shell Club. San Diego.

STOTHERT, K., 1997 - Fundición tradicional campesina en la costa del Ecuador. Boletín del Museo del Oro, $\mathbf{n}^{\circ}$ 43: 89-117; Bogotá.

TAYLOR, G., 1987 - Ritos y tradiciones de Huarochirí. Manuscrito quechua de comienzos del siglo XVII. Estudio biográfico sobre Francisco de Ávila por A. Acosta, 618 p.; Lima: Institut Français d'Études Andines/Instituto de Estudios Peruanos.

THOMPSON, L., DAVIS, M.E., MOSELEY-THOMPSON, E. \& LIU, K. B., 1988 - Pre-Incan agricultural activity recorded in dust layer in two tropical ice cores. Nature, 336: 763-765. 
THOMPSON, L., MOSELEY-THOMPSON, E., BOLZAN, J. F. \&KOCI, B. R., 1985-A 1500year record of tropical precipitation in ice cores from the Quelccaya ice cap, Peru. Science, 229: 971-973.

VERNEAU, R. \& RIVET, P., 1912 - Ethnographie Ancienne de l'Équateur (Mission du Service Géographique de l'Armée pour la Mesure d'un Arc Méridien en Amérique du Sud VI 1899-1906); Paris.

VETTER, L. M., 1993 - Análisis de las puntas de aleación de cobre de la tumba de un señor de la élite sicán, Batán Grande, Lambayeque, Perú. Memoria de Bachiller, Especialidad de Arqueología, Pontificia Universidad Católica del Perú. Lima.

VETTER, L. M., 1996-El uso del cobre arsenical en las culturas prehispánicas del norte del Perú. Boletín Museo del Oro, 41: 63-81; Bogotá: Banco de la República.

VETTER, L. M., CARCEDO, P., CUTIDA, S. \& MONTOYA, E., 1997 - Estudio descriptivo, metalográfico y químico de las puntas de aleación de cobre de la tumba de un Señor de la élite Sicán, Lambayeque-Perú, empleando técnicas de microscopia óptica y análisis por activación neutrónica. Revista Española de Antropología Americana, 27: 23-28; Madrid: Universidad Complutense, Servicio de publicaciones.

WASSÉN, S. H., 1972 - A problematic Metal Objet from Northern Peru. Arstry: 29-33; Göteborg: Göteborg Etnografiska Museum.

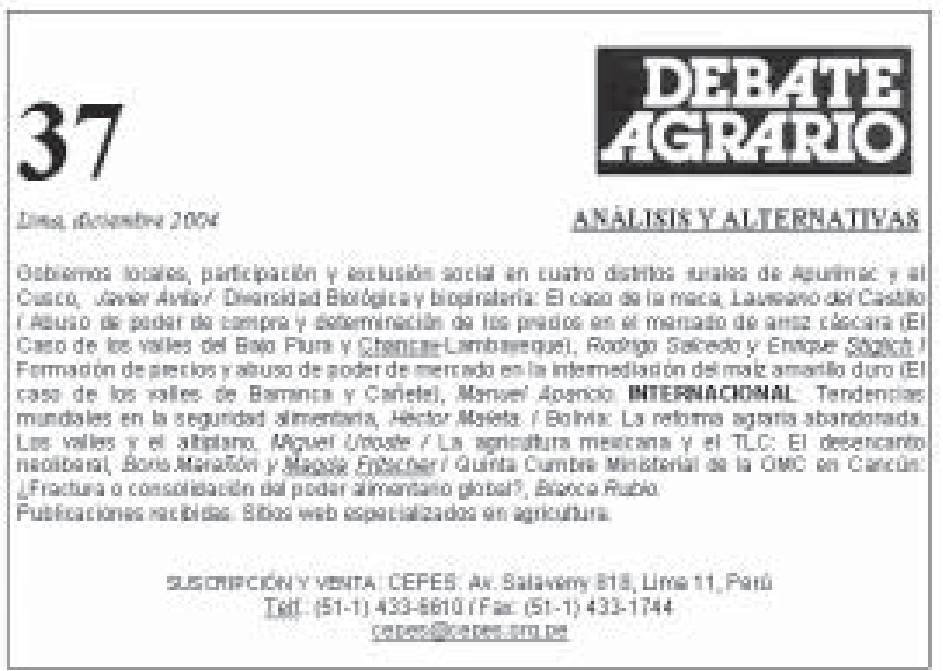

